Aus der Klinik für Neurologie

(Prof. Dr. med. M. Bähr)

der Medizinischen Fakultät der Universität Göttingen

\title{
Auswirkung der TLR4-Inhibition bei verschiedenen Applikationswegen im Modell des ischämischen Schlaganfalls
}

\author{
INAUGURAL-DISSERTATION \\ zur Erlangung des Doktorgrades \\ der Medizinischen Fakultät der \\ Georg-August Universität Göttingen
}

vorgelegt von

Konstantina Theodorou

aus

Lovec, Bulgarien

Göttingen 2020 
Dekan:

Referent:

Ko-Referent:

Drittreferent:

Promotor-Vertretung:
Prof. Dr.med. W. Brück

Prof. Dr.med. G. Trendelenburg

Prof. Dr.rer.nat. Thomas Bayer

Prof. Dr.rer.nat. Holger Reichardt

Prof. Dr.med.dent. Rainer Mausberg

Datum der mündlichen Prüfung: 16.11 .2020 
Hiermit erkläre ich, die Dissertation mit dem Titel „Auswirkung der TLR4-Inhibition bei verschiedenen Applikationswegen im Modell des ischämischen Schlaganfalls" eigenständig angefertigt und keine anderen als die von mir angegebenen Quellen und Hilfsmittel verwendet zu haben.

Göttingen, den 
Die Daten, auf denen die vorliegende Arbeit basiert, wurden teilweise publiziert:

Andresen L*, Theodorou K* Grünewald S*, Czech-Zechmeister B, Könnecke B, Lühder F, Trendelenburg G (2016): Evaluation of the Therapeutic Potential of Anti-TLR4-Antibody MTS510 in Experimental Stroke and Significance of Different Routes of Application. PloS One 11, e0148428

*Diese Autoren teilen die Erstautorenschaft 


\section{Inhaltsverzeichnis}

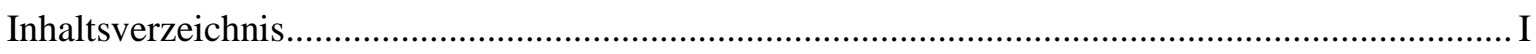

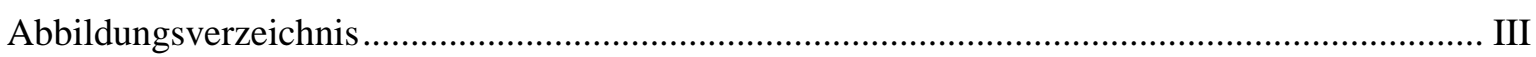

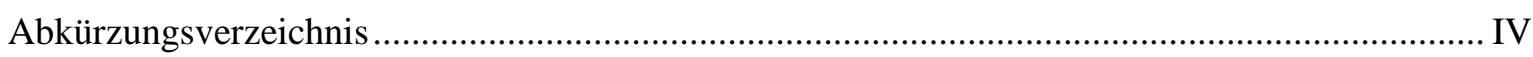

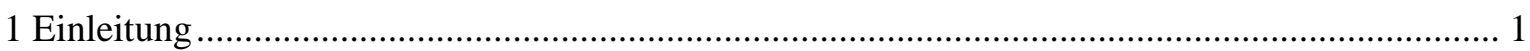

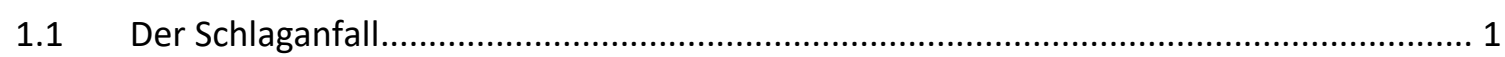

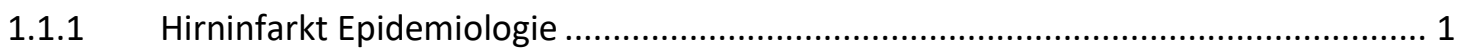

1.1.2 Ätiologie, Klinik und Akutversorgung in Deutschland ............................................. 1

1.1.3 Pathophysiologie des Schlaganfalls...................................................................... 3

1.1.3.1 Akute Phase des Schlaganfalls: ....................................................................... 4

1.1.3.2 Subakute Phase des Schlaganfalls:................................................................. 5

1.1.3.3 Chronische Phase des Schlaganfalls:................................................................. 6

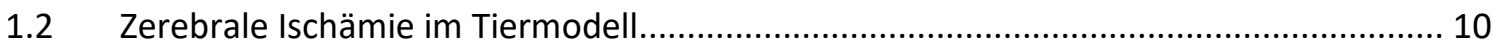

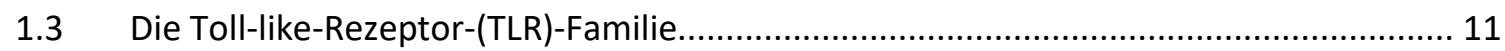

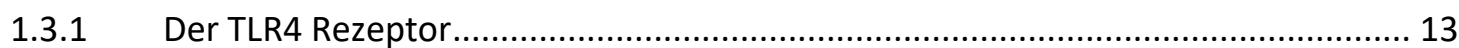

1.3.2 Stand der Forschung: TLR4 Inaktivierung als Therapieansatz im ischämischen

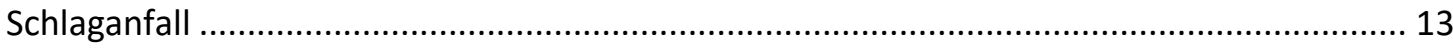

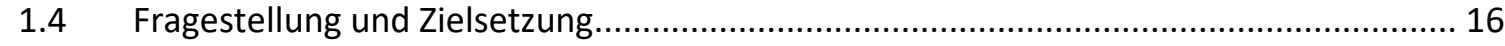

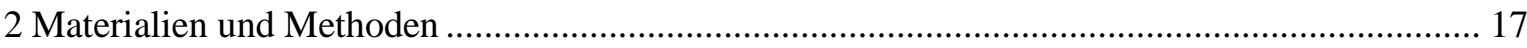

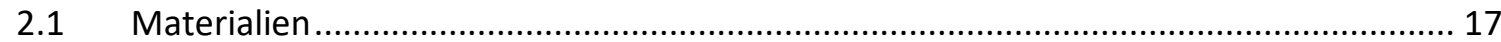

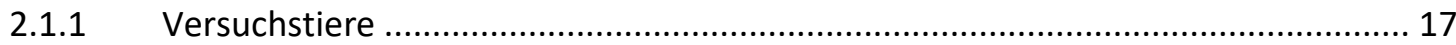

2.1.2 Okklusion der Arteria cerebri media (MCAO-Modell) ........................................... 17

2.1.3 Therapeutische Antikörpertherapie........................................................................ 17

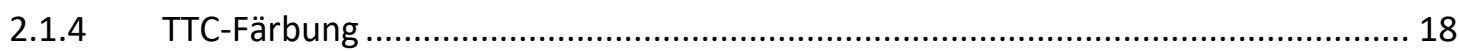

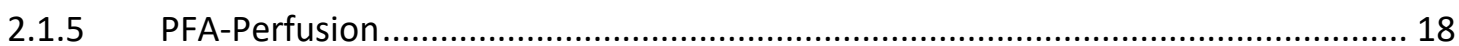

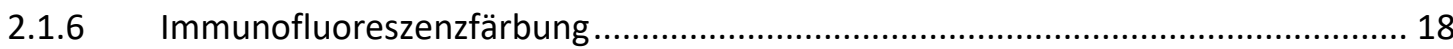

2.1.7 Antikörper für die Immunofluoreszenz ................................................................ 19

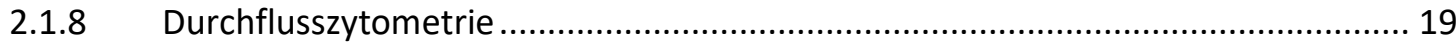

2.1.9 Antikörper für die Durchflusszytometrie ........................................................ 20

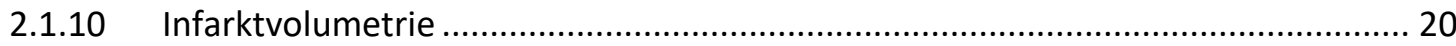

2.1.11 Weitere Chemikalien \& Geräte: ........................................................................... 20

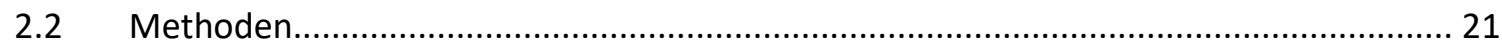

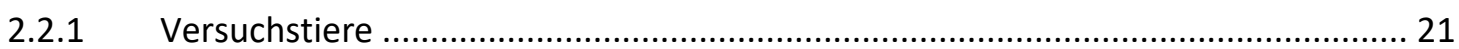

2.2.2 Middle-cerebral-artery-occlusion-Modell (MCAO-Modell) ..................................... 21 
2.2.3 Therapeutische Applikation des TLR4/MD2-Antikörpers ..................................... 23

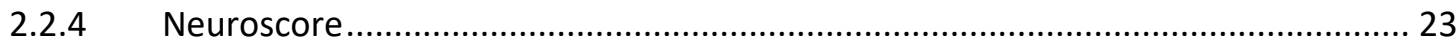

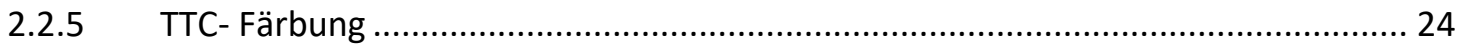

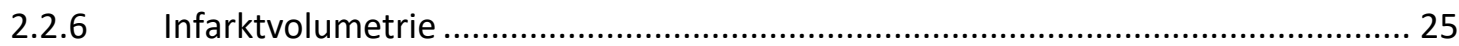

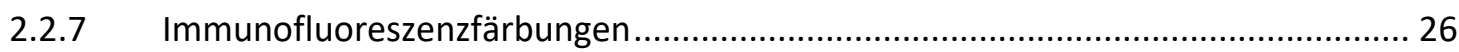

2.2.8 Bestimmung der Neuronen- und Monozytenzahl ................................................ 28

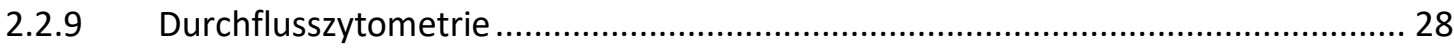

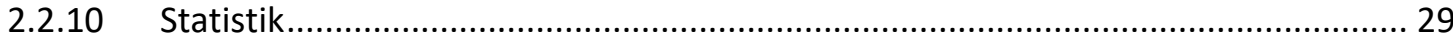

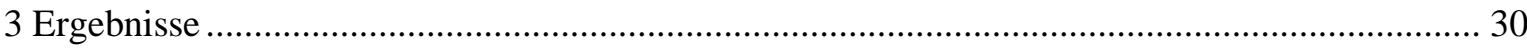

3.1 Intraperitoneale TLR4-Antikörper Applikation im MCAO-Modell .................................... 30

3.1.1 Körpergewicht und Körpertemperatur ................................................................ 31

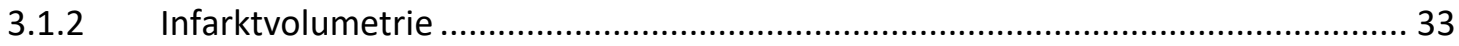

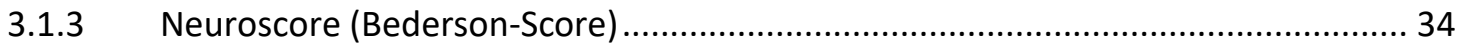

3.1.4 Bestimmung der Neuronen- und Monozytenzahlen ............................................ 35

3.2 Intravenöse TLR4-Antikörper Applikation im MCAO-Modell........................................... 39

3.2.1 Körpergewicht und Körpertemperatur ............................................................. 39

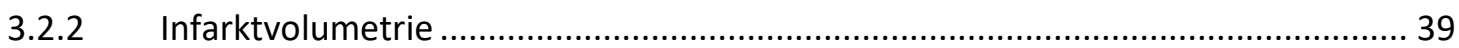

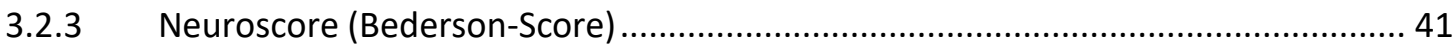

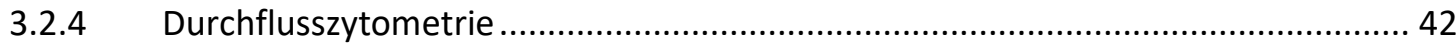

4.1 Therapeutische Schlaganfallforschung und das Potential einer TLR4 Blockierung im

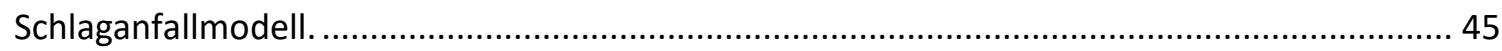

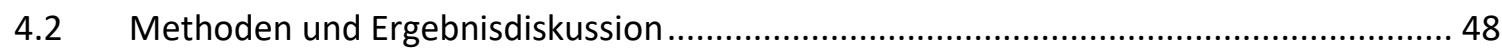

4.2.1 Induktion eines ischämischen Schlaganfalls und Auswertung der Infarktgröße ..... 48

4.2.2 Beurteilung des neurologischen Defizites........................................................... 51

4.2.3 Veränderungen auf zellulärer Ebene ……….................................................... 52

4.2.3.1 Aktivierte Makrophagen und Mikroglia ............................................................. 52

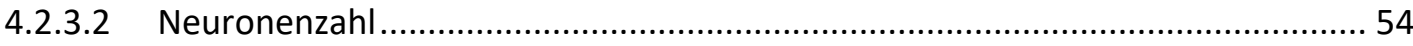

4.2.3.3 Die Anzahl der Lymphozyten, ein kontroverses Ergebnis .................................. 54

4.3 Die klinische Translation der experimentellen Therapieansätze an Menschen schlägt

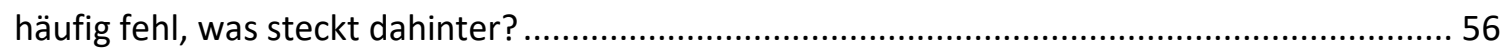

4.4 Blockierung des TLR4 und seine klinische Anwendung beim ischämischen Schlaganfall?

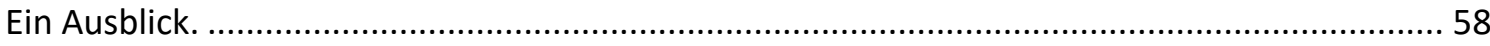

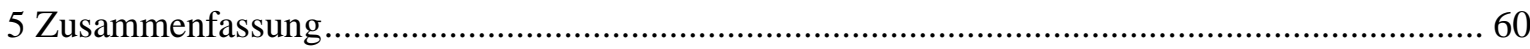

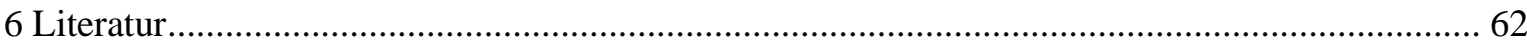




\section{Abbildungsverzeichnis}

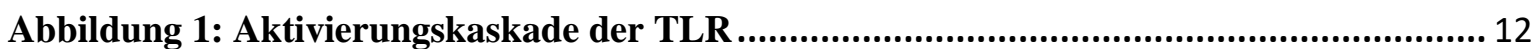

Abbildung 2: Schema und Operationssitus des MCAO-Modells ............................................. 22

Abbildung 3: Umwandlung von 2,3,5-Triphenyltetrazoliumchlorid in 1,3,5-

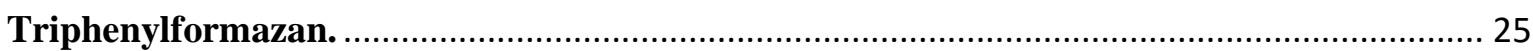

Abbildung 4: Infarktvolumetrie mit TTC-gefärbten Schnitten............................................. 26

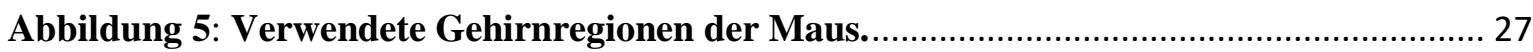

Abbildung 6: Auszählung der Neuronen- und Monozytenzahl an immunfluoreszenz-

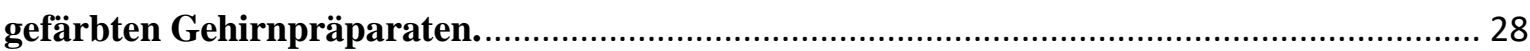

Abbildung 7: Gewichts- und Temperaturkontrollen der i.p. behandelten Mäuse. ................ 32

Abbildung 8: Direktes, indirektes Infarktvolumen und Hirnödem nach 45 min MCAO und 48 Stunden Reperfusion bei intraperitonealer Applikation.

Abbildung 9: Bederson-Score 24 und 48 Stunden postoperativ nach 45 min MCAO mit 48 h Reperfusion.

Abbildung 10: Immunfluoreszenzfärbungen von Neuronen und monozytären Zellen im Vergleich zwischen ipsilateralem und kontralateralem Infarktgebiet. 36

Abbildung 11: Anzahl von Neuronen und Iba1-positiven Zellen 48 Stunden nach MCAO mit 45 Minuten Okklusionszeit nach i. p. Applikation 37

Abbildung 12: Gewichts- und Temperaturkontrollen der i.v. behandelten Mäuse. 39

Abbildung 13: Direktes und indirektes Infarktvolumen und Hirnödem nach 45 Minuten MCAO und 48 Stunden Reperfusion bei intravenöser Applikation des TLR4-Antikörpers.. 40 Abbildung 14: Bederson-Score 24 und 48 Stunden postoperativ nach 45 min MCAO und 48 h Reperfusion bei i.v. Applikation des TLR4-Antikörpers. 41

Abbildung 15: Zellzahl der inflammatorischen Zellen pro Hemisphäre nach i.v. Applikation des TLR4-Antikörpers nach 45 Minuten MCAO und 48 Stunden Reperfusion. 43

Abbildung 16: Analyse der zellulären Antwort des adaptiven Immunsystems nach 45 min MCAO und 48 h Reperfusion bei i.v. TLR4-Antikörper Applikation. 


\section{Abkürzungsverzeichnis}

A.

ATP

BSA

CSPG

CT

DAMP

DAPI

DGN

DGNR

FACS

HE

HSP

$\mathrm{ICH}$

$\operatorname{Ig}$

IGF-1

IL

IRAK

IKK

Ipsi

ISO

Kontra
Arteria

Adenosintriphosphat

Bovines Serum Albumin

chondroitin sulphate proteoglycans

Computertomographie

danger associated molecular patterns

4',6-Diamidin-2-phenylindol

Deutsche Gesellschaft für Neurologie

Deutsche Gesellschaft für Neuroregeneration

fluorescence-activated cell scanning

Hämatoxylin-Eosin

heat shock protein

Intracerebralehämorrhagie

Immunglobulin

insulin growth faktor 1

Interleukin

IL-1 Rezeptor assoziierten Kinase

IkB-Kinase

ipsilateral

Isotyp

kontralateral 
LPS

MAPK

MCAO

MMP

mRS

MRT

MyD88

NFKB

NMDA

PAMP

PBS

PFA

ROS

rtPA

SVZ

TAK242

TBS

TGF- $\beta$

TIR

TLR

TNF- $\alpha$

TRAF

TRIF
Lipopolysaccharide

mitogenaktivierende Proteinkinase

middle cerebral artery occlusion

Matrix-Metalloproteinasen

Modified Rankin Scale

Magnetresonanztomographie

Myeloiddifferenzierungsfaktor 88 Adaptorprotein

nuclear factor kappa-light-chain-enhancer of activated B cells

N-Methyl-D-Aspartat

Pathogen associated molekular patterns

phosphate-buffered saline

Paraformaldehyd

reactive oxygen species

rekombinanter gewebespezifischer Plasminogenaktivator

Subventrikuläre Zone

Resatorvid

TRIS-Buffered Saline

Transforming Growth Factor- $\beta$

Toll/IL-1

Toll-like-Rezeptor

Tumornekrosefaktor- $\alpha$

tumor necrosis factor receptor associated factor

TIR domäne-containing adaptor inducing interferon 
TRIS

TTC

VEGF

WHO

ZNS
Tris(hydroxymethyl)

2,3,5-Triphenyltetrazoliumchlorid

vascular endothelial growth faktor

world health organization

Zentralnervensystem 


\section{Einleitung}

\subsection{Der Schlaganfall}

\subsubsection{Hirninfarkt Epidemiologie}

Der Hirninfarkt, auch Schlaganfall genannt, ist nach Krebs und Herz/ Kreislauferkrankungen auf Platz drei der häufigsten Todesursachen und die Hauptursache für erworbene Behinderungen bei Erwachsenen (Heuschmann et al. 2010) in den heutigen Industrienationen. Mit ca. 262000 Neuerkrankungen, ca. 63000 Todesfällen und chronischen Behinderungen bei über $42 \%$ der Überlebenden pro Jahr alleine in Deutschland (Heuschmann et al. 2010) stellt der Schlaganfall eine der am langwierigsten zu behandelnden Erkrankungen dar. Mit ca. 44000 Euro Behandlungskosten pro Patient (Kolominsky-Rabas et al. 2006) ist er einer der größten sozioökonomischen Belastungen für unsere Gesellschaft und das Gesundheitssystem. Der demographische Wandel und die steigende Lebenserwartung in Deutschland und weltweit werden zu einer zunehmenden Inzidenz des Schlaganfalls führen (Foerch et al. 2008). Weitere Forschungen nach neuen Therapieansätzen sowohl für die Prophylaxe als auch für die Akuttherapie des Hirninfarkts sind somit von wesentlicher Bedeutung.

\subsection{2 Ätiologie, Klinik und Akutversorgung in Deutschland}

Mit der zunehmenden Industrialisierung unserer Welt kam es unvermeidlich auch zu einer Veränderung unseres Lebensstils, was zu einer Erhöhung der Lebenserwartung führte, die wiederum eine steigende Anzahl von Schlaganfälle mit sich brachte. Ungefähr die Hälfte aller Schlaganfälle ereignen sich bei Personen über 73 Jahren (Heuschmann et al. 2010). Wichtige Risikofaktoren für die Entstehung eines Schlaganfalls sind Komorbiditäten wie die Arteriosklerose oder die arterielle Hypertonie sowie Lebensstilfaktoren wie der Nikotinabusus und die Immobilisation (Benjamin et al. 2018). 87\% aller Schlaganfälle sind ischämischer Genese, $10 \%$ der Schlaganfälle entstehen aufgrund von Hirnblutungen und 3\% durch Subarachnoidalblutungen (Benjamin et al. 2018). Klinisch kann ein Schlaganfall, je nach Ausmaß, zu keinen Symptomen (silent) oder bis zu plötzlich auftretenden, ausgeprägten und zunehmenden neurologischen Ausfällen und zum Tode führen (Coupland et al. 2017). Grund für die Entstehung eines ischämischen Schlaganfalls und der darauffolgenden Symptomatik ist eine Unterversorgung des Gehirns mit Blut und der daraus resultierende akute Sauerstoffmangel des Hirngewebes. Kardioembolien sind mit 25,6\%, die häufigste Ursache eines ischämischen Schlaganfalls vor allem bei Personen über 70 
Jahren.(Grau et al. 2001). Die Arteriosklerose macht mit 20,9\% der ischämischen Hirninsulte den größten Anteil der Patienten zwischen 45 und 70 Jahren aus. Schlaganfälle verursacht durch Mikroangiopathien sind vor allem bei Patienten mit Nebendiagnosen wie erhöhtem Blutdruck, Diabetes mellitus oder Hypercholesterinämie zu treffen (Grau et al. 2001). An einer aktuellen, einheitlichen Definition der Erkrankung wird von Seiten der American Heart und American Stroke Association gearbeitet (Coupland et al. 2017).

Der Grundstein der aktuellen Akutversorgung der zerebralen Ischämie ist die rasche Wiederherstellung der Blutzirkulation im unterversorgten Hirnareal mit dem Ziel eine weitere Ausbreitung des ischämischen Gebietes und den dadurch resultierenden neuronalen Untergang so weit wie möglich zu begrenzen. Sollte eine Hirnischämie in weniger als 4,5 Stunden diagnostiziert worden sein, ist die medikamentöse Thrombolyse das Mittel der ersten Wahl. Dafür ist rtPA (rekombinanter tissue-type Plasminogenaktivator) zugelassen. Eine obere Altersgrenze für diese Therapie gibt es nicht. Eine rtPA-Therapie ist sogar bei Patienten mit einem Geschehen von bis zu unter sechs Stunden individuell durchführbar (DGN 2012, DGN 2015). Ausgeschlossen werden Patienten mit nicht einstellbarem Blutdruck von über 180/110 mmHg sowie Patienten mit einem erhöhten Blutungsrisiko mit einem INR (international normalized ratio) Wert von über 1,7 und Einnahme von oralen Antikoagulatien in einem Zeitraum von weniger als 48 Stunden (DGN 2012, DGN 2015). Bei Patienten mit ausgeprägten neurologischen Defiziten und großen Gefäßverschlüsse vor allem im vorderen Kreislauf aber auch bei Patienten mit einer Nichtübereinstimmung zwischen Infarktgröße und neurologisches Defizit kommt in einem Zeitfenster von bis zu 24 Stunden die mechanische Rekanalisation mittels Thrombektomie zum Einsatz (Marks et al. 2018; Nogueira et al. 2018). Die kann bei Geschehen unter 4,5 Stunden auch in Kombination mit einer rtPA-Gabe erfolgen. Für die Thrombektomie sind die Stent-Retriever zu bevorzugen (DGN 2012, DGN 2015).

Neben der Akuttherapie des Hirninfarkts sind die Sekundärprophylaxe sowie die Neurorehabilitation unverzichtbar. Die Einleitung einer Therapie mit Acetylsalicylsäure (ASS) 100mg innerhalb der ersten 48 Stunden nach dem ischämischen Geschehen sowie die Einnahme von Statinen bei Hyperlipidämie sind dringend zu empfehlen (DGN 2015). Der beste Zeitpunkt zu Beginn einer rehabilitativen Therapie befindet sich im subakuten Stadium eines Schlaganfalls (spätestens nach 2-3 Wochen), da ab diesem Zeitraum die postläsionelle Plastizität beginnt und beim Menschen bis ca. 3-4 Monate lang anhält (DGNR 2015). 
Zusammengefasst ist die Therapie des akuten ischämischen Schlaganfalls multimodal und besteht aus der Kombination von Akutversorgung, Sekundärprophylaxe und rehabilitativen Maßnahmen. Trotz der soweit gut etablierten Therapien ist weiterhin mit schweren Folgen des Schlaganfalls für den Patienten und der Gesellschaft zu rechnen. Die Forschung nach neuen Therapiemöglichkeiten, die langfristig zu einer Optimierung der Prophylaxe aber auch zur Verbesserung des neurologischen Outcomes nach einem Schlaganfall führen könnten, ist sehr bedeutsam.

\subsubsection{Pathophysiologie des Schlaganfalls}

Im Zentrum einer Infarktregion, die klinisch als die Gehirnregion mit einer Durchblutung von weniger als $20 \%$ des Blutflusses definiert ist, kommt es innerhalb von Minuten bis Stunden, nach dem ischämischen Geschehen, zu einem akuten Untergang von Neuronen (Jackman und Iadecola 2015). Dafür ist hauptsächlich ein Energiemangel verantwortlich was zu einem intrazellulären Ungleichgewicht von Ionen und Destabilisierung des Membranpotentials der Zellen sowie mitochondrialer Dysfunktion und Aktivierung von Proteasen, Lipasen und Ribonucleasen führt, die wiederrum den Verlust der zellulären Integrität und den Zelluntergang verursachen. Um dieses Infarktzentrum befinden sich die so genannte Penumbra, die Hirnregion die zwar mit Sauerstoff und Energie unterversorgt ist, aber doch ausreichenden Blutfluss genießt, um das Überleben ihrer Zellen sichern zu können (Jackman und Iadecola 2015). Allerdingst sind genau diese potentiell zu rettenden Zellen nach der Wiederherstellung des Blutflusses mit pathophysiologischen Prozessen wie Exzitotoxizität und inflammatorischen Reaktionen konfrontiert, die das Überleben zu einer großen Herausforderung machen (Anrather und Iadecola 2016). Um in diese Vorgänge eingreifen und potentielle Therapien entwickeln zu können ist es entscheidend die Pathophysiologie des ischämischen Geschehens gründlich zu analysieren und zu verstehen. Diese Abläufe können in drei Phasen unterteilt werden: Die akute Phase (Minuten bis Stunden), die subakute Phase (Stunden bis Tage) und die chronische Phase (Tage bis Monate) nach dem Infarkt (Jin et al. 2013). 


\subsubsection{Akute Phase des Schlaganfalls:}

Die inflammatorische Signalkaskade wird unmittelbar nach der Okklusion eines Gefäßes ausgelöst (Iadecola und Anrather 2011).

Intravaskulär verursacht der verminderte Blutfluss und die dadurch veränderte Blutviskosität, Stress am Gefäßendothel und an den Thrombozyten. Dadurch wird aus Endothelzellen und Blutplättchen das Adhäsionsmolekul P-Selektin freigesetzt was an den P-Selektin Liganden-1 von zirkulierenden Leukozyten bindet und sie an der Endotheloberfläche anhaftet. Mit Hilfe von E-Selektin und V-Selektin kommt es dann zur Aktivierung und Diapedese der Leukozyten durch das Endothel in die betroffenen Hirnregionen (Anrather und Iadecola 2016). Das Thrombin anderseits ist in der Lage Monozyten und neutrophile Granulozyten ins ischämische Areal anzulocken und die Expression von weiteren Adhäsionsmolekülen für Immunzellen an der Endotheloberfläche zu induzieren (Rezaie 2014). Durch direkte Aktivierung des erworbenen Immunsystems mittels der Komplementfaktoren C3 und C5 kommt es zur Freisetzung von bioaktiven Produkten wie Opsonine und Anaphylatoxine sowie eines terminalen zytolytischen membranattakierenden Komplexes der zum Zerfall der Blut-Hirn Schranke und weiterer Invasion von Leukozyten ins ischämische Areal führt (Anrather und Iadecola 2016).

Während intravaskuläre Prozesse, die hauptsächlich für die Destruktion der Blut/Hirn Schranke und für die Einwanderung von Immunzellen verantwortlich sind, werden auch im umliegenden Gewebe unter dem Energiemangel pathobiochemische Reaktionen ausgelöst. Der akute Mangel an ATP (Adenosintriphosphat), den Hauptenergielieferanten der Zellen, führt zu Destabilisierung des Membranpotentials der Zellen, da ATP abhängige Ionenpumpen ausfallen. Der Ionengradient der Membran kann nicht weiter aufrechterhalten werden und es kommt zu einem massiven, passiven Einstrom von Ionen wie Natrium und Calcium und von Wasser ins Zellinnere. Durch das entstehende Hirnödem kommt es zu zellulärer Dysfunktion und Untergang der Neurone (Andresen et al. 2016). Der Calciumeinstrom in der Zelle hat als Folge die Freisetzung von großen Mengen an Aminosäuren, wie Glutamat, in den synaptischen Spalt, die wiederum N-methyl-Daspartate (NMDA)-Kanäle und $\alpha$-amino-3-hydroxy-5-methyl-4-isoxazolepropionic-acid (AMPA)-Rezeptoren aktivieren (Dirnagl et al. 1999), die noch mehr Calcium, Natrium und Chlor ins Zellinnere fördern und die weitere Ödembildung begünstigen. Dieses Phänomen wird auch Exzitotoxizität bezeichnet (Anrather und Iadecola 2016). Innerhalb von Minuten setzten die sterbenden Zellen Stressmetabolite, die so genannten danger/damage associa- 
ted molecular patterns (DAMPS) frei, die wiederum die ortsständigen Mikroglia und Astrozyten aktivieren und zur Sekretion von Interleukin $1 ß$ (IL-1ß) und Tumor Nekrose Faktor $\alpha(\mathrm{TNF}-\alpha)$ führen (Anrather und Iadecola 2016).

\subsubsection{Subakute Phase des Schlaganfalls:}

Stunden bis einige Tage nach dem ischämischen Schlaganfall kommt es durch die eingewanderte Leukozyten zur Freisetzung von proinflammatorischen Mediatoren sowie Zytokinen und Chemokinen, reaktiven Sauerstoffspezies (ROS), Matrix-Metalloproteinasen (MMPs) und anderen Proteasen, die die Inflammation im Gehirn aufrechterhalten und eine weitere Aktivierung von ortsständigen Immunzellen verursachen (Iadecola und Anrather 2011). Als Konsequenz davon folgt der weitere Zusammenfall der Bluthirnschranke, die Zunahme des Hirnödems mit Kompressionen und Herniationen im Gehirn. Von dieser Phase des Schlaganfalls sind Neuronen der Penumbra besonders schwer betroffen, allerdings sind diese Zellen durch den zeitlichen Rahmen des Eingreifens des Immunsystems potentiell noch zu retten. Somit ist die subakute Phase, die Phase mit den meisten potentiellen therapeutischen Zielen für die Forschung.

Innerhalb von wenigen Stunden wandern neutrophile Granulozyten ins Hirnparenchym ein und setzten proinflammatorische Mediatoren wie inducible nitric oxide synthase (iNOS), MMPs und ROS frei (Jin et al. 2013; Anrather und Iadecola 2016). Diese haben eine neurotoxische Wirkung auf die Zellen der Blut/Hirn Schranke und führen zu weiterer Destabilisierung.

Monocyten und Makrophagen spielen eine doppelte Rolle im ischämischen Geschehen. In der frühen subakuten Phase induzieren sie die Expression von proinflammatorischen Zytokinen wie IL-1ß, TNF- $\alpha$ und Chemokinen und wirken somit destruktiv (Jin et al. 2013), in der späten subakuten Phase exprimieren sie antiinflammatorische Faktoren wie Interleukin 10 (IL-10) und transforming growth faktor-ß (TGF-ß), die neuroprotektive Funktionen aufweisen (Jin et al. 2013).

Lymphozyten haben auch eine wichtige Rolle in der Pathogenese des Schlaganfalls. Vor allem $\gamma \delta$-T Zellen tragen in der Expression von proinflammatorischem IL-17 (Anrather und Iadecola 2016) und INF- $\gamma$ bei (Jin et al. 2013). Anderseits werden durch regulatorische T-Zellen (Treg Zellen) neuroprotektive Faktoren wie Interleukin 10 sezerniert, die die postischämische Immunreakton herunterfahren (Anrather und Iadecola 2016). 
Weiterhin werden die ortsständigen Immunzellen an diesem Zeitpunkt durch die Stressmediatoren rekrutiert und aktiviert. Mikroglia sind die am stärksten repräsentierten Zellen im ZNS. So wie bei Makrophagen haben sie sowohl neurotoxische als auch neuroprotektive Qualitäten. Einerseits führt deren frühe Aktivierung zu Zellschädigung und Zelltod durch Freisetzung von proinflammatorischen Zytokinen (Jin et al. 2013) anderseits tragen sie durch die Expression von insulin growth Faktor-1 (IGF-1) und TGF-ß zu Neuroptotektion bei (Jin et al. 2013).

Die meisten Schlaganfallpatienten zeigen wenige Stunden nach einem Schlaganfall eine systemische Immunreaktion mit darauffolgender Immunsuppression und erhöhten Infektionsraten, die wiederum eine ausschlaggebende Rolle für das Überleben spielt. Dies geschieht primär durch folgende Mechanismen: Infolge des Schlaganfalls wird die Blut/Hirn Schranke nicht nur für einwandernde Immunzellen durchlässig sondern es kommt zu einer Freisetzung von Entzündungsmediatoren wie DAMPs und Zytokinen in den peripheren Kreislauf (Anrather und Iadecola 2016). Die primären und sekundären lymphatische Organen reagieren auf diese Entzündungsmediatoren mit dem so genannten systemic inflamatory response syndrome (SIRS) in Folge dessen es zu Expression und Freisetzung von weiteren inflammatorischen Mediatoren wie IL-6, und TNF- $\alpha$ durch die peripheren Immunzellen kommt (Anrather und Iadecola 2016). Es kommt zu einem extremen Verbrauch an Immunzellen und später zu einer Lymphopenie und einer Immunsuppression die sympatho-adrenerg getriggert ist (Dirnagl et al. 2007). Schlaganfall Patienten sind demnach anfälliger für nosokomiale Infektionen wie Pneumonien und urogenitale Infektionen (Anrather und Iadecola 2016).

\subsubsection{Chronische Phase des Schlaganfalls:}

Während der chronischen Phase führt die postischämische inflammatorische Reaktion eher zu Reparaturen im Hirnparenchym und zur Wiederherstellung der Funktionalität des Gewebes. Wichtige Mechanismen die in dieser Phase involviert sind, sind die Neovaskularisation, die Phagozytose, die reaktive Gliose und die Neurogenese.

Phagozytose: 24 Stunden nach der Ischämie, kommt es zu einer ausgeprägten Aktivierung von residenten Mikroglia vor allem in der Penumbra. In Stunden bis wenige Tagen verwandeln sich diese Mikroglia in Phagozyten, sie ändern ihre Struktur werden amöboid und entwickeln Pseudopodien, was sie befähigt apoptotische Neuronenreste zu resorbieren und abzubauen (Shilling M. et al. 2005; Amantea et al. 2009). Auch eingewanderte Makropha- 
gen aus der Blutbahn sind in der Lage, nach einer Ischämie im ZNS Phagozytose zu betreiben, allerdings konnte deren Aktivität bislang nicht früher als am vierten postischämischen Tag nachgewiesen werden (Schilling et al. 2005).

Neovaskularisation: In Rahmen eines ischämischen Schlaganfalls wird unter hypoxischen Bedingungen der Transkriptionsfaktor Hypoxia-inducible Faktor 1 (HIF-1) hochreguliert. Der führt zu einer erhöhten Transkription des vaskular endothelial growth faktor $A$ (VEGF-A) und seiner Rezeptoren VEGF Receptor-1 (VEGFR-1) und VEGR Receptor-2 (VEGF-2) die wiederum eine essentielle Rolle in der Angiogenese nach einer Ischämie spielen (Geiseler und Morland 2018). Die Konzentration von VEGF-A ist vor allem in Astrozyten und Neuronen in der Penumbra erhöht, steigt 2-4 Stunden postischämisch und bleibt bis zum 28. Tag erhöht mit Punktum maximum jeweils nach 6 Stunden und nach 7 Tagen (Geiseler und Morland 2018). Die Angiogenese im Gehirn wird über die VEGFRezeptoren 1 und 2, die eine antagonistische Funktion haben, streng reguliert. VEGFR 1 und 2 befinden sich an Endothelzellen und binden VEGF-A. Während VEGFR-2 die Entstehung von neuen Gefäßen fördert, lenkt der VEGFR-1 die Zellen in die richtige Richtung und schützt gleichzeitig vor einer übermäßigen Angiogenese, indem das Gefäßwachstum hemmt (Geiseler und Morland 2018). Dem VEGF-A werden in der akuten postischämischen Phase neurodestruktive Prozesse, die durch Destabilisierung der Blut-HirnSchranke und Vergrößerung des Hirnödems entstehen, zugesprochen. Anderseits scheint seine Rolle in der chronischen Phase durch Neoangiogenese und Neurogenese unerlässlich zu sein.

Die Angiogenese nach einem ischämischen Schlaganfall ist ebenso TNF- $\alpha$ abhängig. Der TNF- $\alpha$ interagiert mit dem tumor necrosis faktor receptor 1 (TNFR1), sowie vaskulären Endothelzellen und über die Expression der Integrine $\alpha 5 \beta 1$ und $\alpha 5 \beta 3$ führt er zur Angiogenese. Der exakte Mechanismus ist allerdings noch nicht bekannt. (Huang et al. 2016)

Reaktive Gliose: Die ischämische Schädigung im Hirngewebe führt ab dem ersten postischämischen Tag zu einer Aktivierung von Prozessen in den Gliazellen des Gehirns, bekannt auch als reaktive Gliose und ist charakterisiert durch eine erhöhte Expression von Markern wie glial fibrillary acidic protein (GFAP) für Astrozyten, diverse extrazelulläre Matrix-Moleküle (ECM), wie z.B. chondroitin sulphate proteoglycans (CSPG) und Mikroglia (Huang et al. 2014). Die reaktive Gliose hat sowohl positive als auch negative 
Auswirkungen in der Entwicklung der postischämischen Phase (Trendelenburg und Dirnagl 2005). Sie ist in der Ausbildung der sogenannten Glianarbe beteiligt, die eine wichtige Rolle für die postischämischen Reparaturmechanismen spielt, aber anderseits die Neurogenese und das axonale Wachstum verhindert (Rolls et al. 2009). Die meisten reaktiven Astrozyten sind im Bereich der Penumbra anzutreffen. Dort hypertrophieren diese Zellen, "verkapseln" die betroffene Region und bilden eine Barriere zwischen verletztem und gesundem Gewebe (Huang et al. 2014). Somit wird die weitere Ausbreitung von neurodegenerativen Substanzen wie exzitatorischen Aminosäuren, Ionen und ROS im Gewebe verhindert. Außerdem sind Astrozyten in der Lage über einen Glutathion abhängigen Mechanismus, Neurone direkt von toxischen Nitritradikalen zu schützen (Rolls et al. 2009). Durch die Produktion und Freisetzung von CSPG tragen Astrozyten bei der Protektion des gesunden Gewebes bei, indem sie die Ausbreitung von Schadstoffen aus der Infarktregion blockieren und somit sekundären neuronalen Zelltod verhindern (Rolls et al. 2009). Zusätzlich leisten sie, durch die Versorgung der Zellen mit Glukose, insulin growth Faktor (IGF), brain-derived neurotrophic factor (BDNF) und neurotrophin 3 trophische und metabolische Unterstützung für die Neuronen auf der ischämischen Seite (Rolls et al. 2009). Anderseits sind die CSPG eine Familie von Makromolekülen die in der Ausbildung der Glianarbe beteiligt sind und von Astrozyten sezeniert werden für ihre wachstumshemmende Funktion bekannt. Sie stören das axonale Wachstum und verhindern somit erheblich die Neurogenese (Huang et al. 2014).

Neurogenese: Früher wurde behauptet, dass die Neurogenese ausschließlich in der embryonal und perinatal Periode stattfinden kann (Tobin et al. 2014). Mittlerweile haben Forschungen gezeigt, dass die Neurogenese auch im erwachsenen Gehirn existiert und in gewisse Hirnregionen wie in der Subventrikulären Zone (SVZ) im Striatum oder den Gyrus dentatus im Hippocampus stattfinden kann (Tobin et al. 2014). Experimente bei Nagetieren zeigten, dass die Ischämie zu einer Aktivierung und Proliferation von neuronalem Stamm- oder Progenitorzellen (NPC) in der SVZ führt. Es werden somit Neuroblasten geformt die die Fähigkeit haben, in der ischämischen Region einzuwandern, sich dort in reife Neurone zu entwickeln und sich ins synaptische Netz zu integrieren (Tobin et al. 2014; Lindvall und Kokaia 2015). Bei Menschen, gibt es Hinweise über die Existenz eines ähnlichen Mechanismus der Neurogenese nach einem ischämischen Schlaganfall, der allerdingt noch nicht ausführlich erforscht und sein Ablauf bislang nicht beschrieben werden konnte (Lindvall und Kokaia 2015) . Es wurde mittels ${ }^{14} \mathrm{C}$-Markierung nachgewiesen, dass im 
Hippocampus des adulten Menschen, ca. 700 neue Neuronen pro Tag entstehen, das entspricht ca. 1,75\% der gesamten Neuronenzahl jährlich. Eine Anzahl, die sehr wahrscheinlich in der Wiederherstellung der Funktionalität nach dem Schlaganfall beitragen könnte (Spalding et al. 2013). 


\subsection{Zerebrale Ischämie im Tiermodell}

Es existieren verschiedene Tiermodelle der zerebralen Ischämie die die pathophysiologischen Konditionen eines Schlaganfalls imitieren und zu Forschungszwecke experimentell angewendet werden. Diese Modelle haben als Ziel, motorische, sensorische und kognitive Veränderungen nachzustellen ähnlich wie solche, die bei Schlaganfallpatienten beobachtet werden, um das Krankheitsbild besser zu erforschen und mögliche Therapieansätze zu entwickeln (Leifer und Kowall 1993).

Das bekannteste und am meisten angewendete Modell mit dem diese Konditionen erreicht werden können, ist das so genannte middle cerebral artery occlusion (MCAO)-Modell, was 1986 durch Koizumi (Rami et al. 2008) entwickelt und im Verlauf durch Longa modifiziert wurde (Ansari et al. 2011). Da die arterielle Blutversorgung von Nagetieren wie Mäuse und Ratten, der des Menschen sehr ähnlich ist, werden vorzugsweise diese Tiere für die experimentelle Schlaganfallforschung verwendet (Rami et al. 2008). Beim MCAOModell wird die Arteria cerebri media okkludiert. Es gibt Modelle der permanenten und der transienten zerebralen Ischämie. Im Rahmen des in dieser Arbeit verwendeten Modells wird über die A. carotis interna ein silikonüberzogenes Filament bis zur Basis der A. cerebri media eingeführt um die Blutversorgung im Mediagebiet zu unterbrechen. Im Verlauf wird das Filament entfernt um die Reperfusion, wie nach einem Schlaganfall beim Menschen, zu imitieren (Ansari et al. 2011). Die Größe und Ausprägung des Schlaganfalls können zum Teil über die Okklusionszeit reguliert werden. Eine Okklusionszeit von unter 30 Minuten führt eher zu milden Infarkten, die sich vor allem mit neuronalen Untergang im Striatum begrenzt manifestieren (Andresen et al. 2016) . Längere Okklusionszeiten können wiederum die ganze Hemisphäre betreffen und zu einer erhöhten Todesrate bei den Tieren nach der Okklusion führen (Andresen et al. 2016).

Mit Hilfe des MCAO Modells kann die Pathophysiologie des Schlaganfalls weiter erforscht und etabliert werden. Diese Methode bietet zusätzlich die Möglichkeit interventionell auf verschiedenste Ebenen und Reaktionskaskaden, die sich im Rahmen der Ischämie im Gewebe entwickeln, einzugreifen um potentielle Therapieansätze zu entwickeln. Einer dieser potentiellen Angriffspunkte könnte die Reduktion der Inflammation in der akuten postischämischen Phase über die Blockierung der TLR-4 Rezeptoren sein. 


\subsection{Die Toll-like-Rezeptor-(TLR)-Familie}

Die Toll-like Rezeptoren (TLR) verdanken ihren Namen der Nobelpreisträgerin Christiane Nüsslein-Volhard, die sie aus großer Begeisterung über ihre Entdeckung heraus als „Toll“ bezeichnete (O’Neill et al. 2013). Die TLR sind ein Teil des angeborenen Immunsystems und sind Transmembranproteine die durch diverse Immunzellen im Körper exprimiert werden und die primäre Immunantwort im Rahmen von entzündlichen Prozessen in Gang setzen (Medzhitov und Janeway 1997). Soweit sind 14 verschiedene Typen dieser Rezeptoren bekannt, die je nach Funktion und Aktivierungsweg aufgeteilt werden (Jin et al. 2013). Im Gehirn werden sie von ortständigen B-Zellen, Makrophagen, dendritischen Zellen, Astrozyten, Oligodendrozyten, Endothelzellen und Neuronen exprimiert (Jin et al. 2013) (Iadecola und Anrather 2011). Die TLR sind ähnlich aufgebaut, sie verfügen über eine große N-terminale Ektodomäne bestehend aus Leucin-rich repeats (LRRs), eine Transmembranhelix und eine C-terminale, im Zytoplasma liegende, Toll/IL-1 (Interleukin) Rezeptor Domäne (Pohar et al. 2014). Die TLR erkennen, im Rahmen einer Infektion, Pathogen assoziierte molekulare Signale (PAMP) und werden hierdurch aktiviert (Andresen et al. 2016). Solche PAMPs sind beispielsweise Peptidoglycane am TLR 2 oder Lipopolysaccharide (LPS), die vorwiegend den TLR 4 Rezeptor aktivieren (Jin et al. 2013). Die TLR werden aber auch durch endogene Stress Signale oder auch danger associated molecular patterns (DAMPs) genannt, ohne eine infektiöse Entzündungsreaktion aktiviert (O’Neill et al. 2013). Solche DAMPs werden durch verletzte oder sterbende Zellen während einer sterilen Inflammation oder einer Ischämie freigesetzt. Bekannte endogene Aktivatoren der TLR sind Surfactant Faktor, Heat Shock Protein (HSP), Fibrinogen und highmobility-Group-Protein B1 (HMGPB1) (Marsh et al. 2009).

Die TLR-Aktivierung geschieht über zwei verschiedene Signaltransduktionswege, einen Myeloiddifferenzierungsfaktor 88 Adaptorprotein (MyD88)-abhängigen und einem MyD88-unabhängigen Weg, entweder direkt (z.B. TLR 2, 5, 11) oder indirekt über das Toll/IL-1 Adapterprotein (TIRAP) wie bei TLR 1, 4 oder 6 (Marsh et al. 2009; Jin et al. 2013). Alle TLR, bis auf den TLR 3, sind MyD88 abhängig. Das MyD88 ermöglicht der IL-1 Rezeptor assoziierten Kinase (IRAK 1, 2 und 4) einen Prozess der Auto- und transPhosphorylierung zu beginnen. Sobald die Phosphorylierung abgeschlossen ist, spaltet sich die IRAK vom MyD88 ab und verbindet sich mit dem Tumornekrosefaktor (TNF)- Rezeptor assoziierten Faktor 6 (TRAF6), der wiederum aktiviert die aktivierte Kinase 1 (TAK1), die den IкB Kinase (IKK) Komplex, sowie die Mitogen-aktivierende Protein Kinase Kina- 
se Kinase (MAPKKKs) aktiviert (Marsh et al. 2009). Dies führt letztendlich zur Aktivierung des Transkriptionsfaktors nuclear factor kappa-light-chain-enhancer of activated $B$ cells $(\mathrm{NF \kappa B})$ und des Aktivator-Proteins-1 (AP-1). Als Effekt werden nun verschiedene inflammatorische Mediatoren induziert, wie TNF- $\alpha$, IL-1ß oder Metalloproteinasen (MMPs) (Jin et al. 2013). Der TLR3 Rezeptor ist wiederum vom MyD88 Adapterprotein unabhängig. Er liegt vor allem intrazellulär im Zytoplasma kann aber auch an der Plasmamembran vorkommen (Pohar et al. 2014). Der TLR 3 wird über den TIR domänecontaining adaptor inducing interferon (TRIF) aktiviert und führt ebenso über eine Signalkaskade zur Aktivierung von MAPK, IKK und Interferon-Rezeptoren (IRF) und zur Freisetzung von proinflammatorischen Zytokinen (Jin et al. 2013; Pohar et al. 2014).

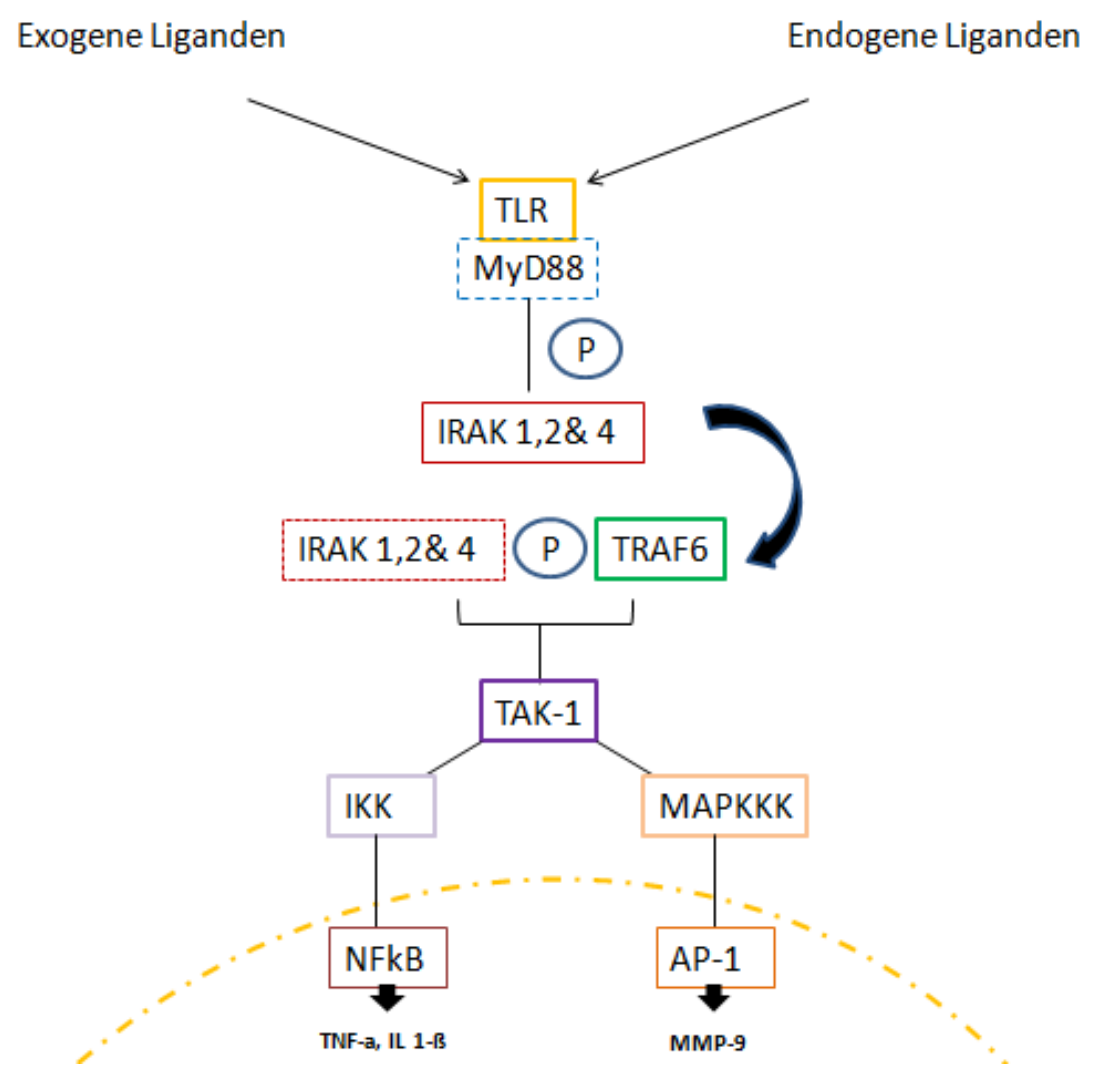

Abbildung 1: Aktivierungskaskade der TLR

TLR = Toll like Receptors, MyD88 = Myeloid differentiation primary response gene 88, IRAK= IL-1 receptor-associated kinase, TRAF6 = TNF-receptor-associated-factor 6 , TAK1 $=$ activated kinase-1, $\mathbf{I K K}=$ I $\kappa$ B kinase, $\mathbf{M A P K K K}=$ Mitogen-activated protein kinase $k i$ nase kinase, $\mathbf{N F} \mathbf{K B}=$ Nuclear factor 'kappa-light-chain-enhancer' of activated B-cells, $\mathbf{A P - 1}=$ Activator protein 1.

Vereinfachte Darstellung der Aktivierungskaskade für die in dieser Arbeit relevanten Aspekte. 


\subsubsection{Der TLR4 Rezeptor}

Der TLR4 Rezeptor ist ein Transmembranprotein mit einer intrazellulären, einer trans- und einer extrazellulären Domäne (Pohar et al. 2014). Er kann sowohl durch exogene Liganden (LPS von Gram-negativen Bakterien) als auch durch endogene Liganden (HSP 60 \& 70, HMBG1) aktiviert werden (Daubeuf et al. 2007). Im ZNS ist der TLR4 vor allem an Mikroglia und Neuronen exprimiert (Sansing et al. 2011).

Der TLR4 Rezeptor ist der einzige TLR, der sowohl MyD88 abhängig als auch MyD88 unabhängig aktiviert werden kann (Jin et al. 2013). Für die Erkennung der Liganden und seine Aktivierung benötigt der Rezeptor einen Co-Faktor, das myeloid differentiation protein 2 (MD-2) und bildet damit einen Komplex, den TLR4/MD-2 Komplex, der die Transduktionskaskade in Gang setzt (Daubeuf et al. 2007). Der MyD88 Signalweg wird im vorherigen Kapitel ausführlich beschrieben. Der zweite Signalweg führt wie beim TLR3 Rezeptor über die Toll/IL1 Rezeptor-Domäne (TRIF) zur Aktivierung des tumor necrosis factor receptor associated factor 3 (TRAF3). TRAF3 aktiviert wiederum den TANK

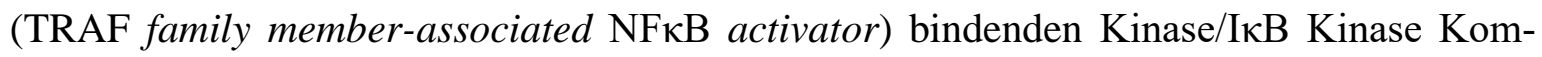
plex (TBK1/IKK) der dann den IFN regulierenden Faktor 3 (INF3) phosphoryliert. Es kommt zu einer Translokation des phosphorylierten IFN3 in den Nukleus und zur Induktion von Interferon- $\alpha$ und Interferon- $\beta$ (Gesuete et al. 2014). Die TRIF Domäne ist aber auch in der Lage über das Rezeptor interacting Protein-1 (RIP1) die TRAF6 Kaskade zu aktivieren und die NFאB übermittelte Genexpression zu induzieren (Gesuete et al. 2014).

Im ischämischen Schlaganfall scheint der TLR4 eine protagonistische Rolle zu spielen. Es gibt mehrere Hinweise darüber, dass die Aktivierung des Rezeptors über DAMP die durch beschädigte Neuronen im ZNS freigesetzt werden, zu einer ausgeprägten inflammatorischen Reaktion und Freisetzung von proinflammatorischen Zytokinen und Chemokinen führt und zu apoptotischen Zellvorgängen beiträgt (Sansing et al. 2011; Ziegler et al. 2011; Gesuete et al. 2014). Allerdings werden dem TLR4 auch neuroprotektive Wirkungen im Rahmen eines Schlaganfalls zugeschrieben (Hanisch et al. 2008).

\subsubsection{Stand der Forschung: TLR4 Inaktivierung als Therapieansatz im ischämischen Schlaganfall}

Diverse Forschungsgruppen die im Bereich der Schlaganfallforschung tätig sind konnten mittels Tiermodelversuchen mit TLR4 Knockout Tieren nachweisen, dass sich die TLR4 Inaktivierung positiv auf die Infarktgröße, den neurologischen Status und die postischämi- 
sche Inflammation nach einem Schlaganfall auswirkt und somit die Aktivierung des TLR4 Rezeptors im Rahmen eines Schlaganfalls eine negative Auswirkung hat (Cao et al. 2007; Caso et al. 2007; Caso et al. 2008; Hyakkoku et al. 2010; Sansing et al. 2011; Ahmad et al. 2013; Pushkov et al. 2016).

Andere Forschungsgruppen versuchten ebenso im Mausmodel den TLR4 Rezeptor pharmakologisch zu blockieren oder seine Expression zu unterdrücken um mögliche Effekte nach einem Schlaganfall zu evaluieren. Bisher wurden der TLR4/NOX4-Rezeptor Antagonist TAK242 (Resatorvid) erfolgreich sowohl im Modell der zerebralen Blutung als auch im Modell der zerebralen Ischämie entweder intrazerebrovaskulär oder intraperitoneal angewendet und eine protektive Wirkung gezeigt (Suzuki et al. 2012; Hua et al. 2015).

Auch die Präkonditionierung des ZNS mit Isofluran vor der Induktion einer zerebralen Ischämie an Mäusen stellte sich über eine Senkung der Expression des TLR4-Rezeptors als neuroprotektiv dar (Sun et al. 2015).

Aktuelle Studien mit Applikation von verschiedenen potenziellen Therapeutika wie z.B. Daphentin (Liu et al. 2016; Liu et al. 2017) oder die Kombination von Ligusticum chuanxiong und Radix Paeoniae ( $\mathrm{Gu}$ et al. 2018) zeigten kleinere Infarkte und antiapoptotische Effekte über eine Suppression der TLR4/NFkB Signalkaskade.

Außerdem bewies eine aktuelle Studie an Ratten, dass DNA-Aptamere die an den TLR4 Rezeptor binden und sie blockieren können, protektiv im Rahmen einer akuten Ischämie sind (Fernández et al. 2018).

Schlaganfallpatienten mit erhöhter Expression von TLR4 im Blut hatten ebenso eine erhöhte Konzentration von Cyclooxygenase 2 sowie ausgeprägtere Symptomatik und eine schlechtere Prognose (Brea et al. 2011; Ferronato et al. 2011).

$\mathrm{Zu}$ Beginn dieser Arbeit gab es noch keine Nachweise über die Auswirkung einer antikörpervermittelten Blockierung des TLR4 Rezeptors. Der Anti-TLR4/MD2-Rezeptor Antikörper MTS510 sollte daher nun im Rahmen eines ischämischen Schlaganfalls getestet werden. Ein vorheriger Versuch in unserer Arbeitsgruppe, der von der Doktorandin Sarah Grünewald durchgeführt wurde, zeigte dass die intraarterielle Applikation des MTS510 Antikörpers vor Induktion einer zerebralen Ischämie mittels 45 Minuten MCAO und 48 Stunden Reperfusion sowohl ein kleineres Infarktvolumen, als auch ein besseres neurologisches Ergebnis verspricht. In Folge dessen wurde die vorliegende Arbeit mit der Appli- 
kation des MTS510 Antikörpers insbesondere für die Induktion eines ischämischen Schlaganfalls unter weiteren Injektionswegen konzipiert, da dies für die klinische Anwendung besonders interessant und relevant ist. Es wurde die intraperitoneale und die intravenöse Injektion und deren Wirkung untersucht. Das MCAO Modell blieb das gleiche wie beim intraarteriellen Versuch. 


\subsection{Fragestellung und Zielsetzung}

Obwohl es deutliche Anhaltspunkte für einen neuroprotektiven Effekt der TLR4 Blockierung nach ischämischem Schlaganfall im Tiermodell gibt und mehrere Studien einen besseren klinischen Ausgang bei TLR4 Knockout Tieren nachgewiesen haben, wurde zu Beginn dieser Arbeit das therapeutische Potential der TLR4 Inaktivierung mittels eines Antikörpers, der postischämisch appliziert wurde, noch nicht untersucht.

Ziel dieser Arbeit ist es, dies durchzuführen und die therapeutischen Fähigkeiten einer TLR4 Inaktivierung mittels Applikation eines für den TLR4/MD2-Komplex spezifischen Antikörper, den MTS 510 Antikörper, zu evaluieren:

- An Mäusen wird ein ischämischer Schlaganfall mit Hilfe eines MCAO-Modells (45 min Okklusion, 48 h Reperfusion) herbeigeführt und der TLR4/MD2 Antikörper (MTS 510) wird auf zwei verschiedenen Applikationswegen, intraperitoneal und intravenös mit therapeutischem Einsatz injiziert und der Effekt mit einer Placebogruppe (PBS) und einer Antikörper-Isotyp Gruppe verglichen. Die möglichen Wirkungen werden sowohl verhaltensbiologisch in Form eines Neuroscores als auch in der histologischen Aufbereitung der Gehirne mit anschließender Infarktvolumetrie gemessen.

- Mikroskopische Effekte einer TLR4/MD2-Komplex Inaktivierung werden an immunfluoreszenzmarkierten Neuronen und Mikroglia von Hirnschnitten nach MCAO erforscht, indem das Ausmaß des Neuronenuntergangs erfasst wird. Außerdem werden aktivierte und migrierte Mikroglia gezählt als Hinweis auf die Aktivität des inflammatorischen Geschehens.

- Zusätzlich wird mittels Durchflusszytometrie die Reaktion des Immunsystems auf die TLR4/MD2-Komplex Inaktivierung auf zellulärer Ebene untersucht, indem die Anzahl der Makrophagen, aktivierte Mikroglia, Granulozyten, T- und B-Zellen bestimmt und zwischen den Gruppen verglichen wird. 


\section{Materialien und Methoden}

\subsection{Materialien}

\subsubsection{Versuchstiere}

Mäuse des Stammes C57B1/6N 8-10 Wochen alt, männlich (Charles River, Köln)

\subsubsection{Okklusion der Arteria cerebri media (MCAO-Modell)}

\section{Operationszubehör:}

\begin{tabular}{|l|}
\hline Buprenorphin (Temgesic) (RB Pharmaceuticals Ltd., Slough, England) \\
\hline Gefäßklammer (F.S.T, Heidelberg) \\
\hline Geflochtener Faden Mersilene, 5-0 USP (Ethicon, Norderstedt) \\
\hline Geflochtener Faden Perma-Hand Seide, 3-0 USP (Ethicon, Norderstedt) \\
\hline $\begin{array}{l}\text { Homeothermic Blanket System (Harvard Apparatus, Holliston, Massachusetts, Verei- } \\
\text { nigte Staaten) }\end{array}$ \\
\hline Isofluran (Abbott, Hannover) \\
\hline Isofluran-Verdampfer (Dräger, Lübeck) \\
\hline Nadelhalter (F.S.T, Heidelberg) \\
\hline Nylon Monofilament 6-0 USP 11 mm Länge mit einem Silikonüberzug von 9-10 mm \\
und einem Durchmesser von 0,21 mm (Doccol Corp., Sharon, Vereinigte Staaten) \\
\hline Operationsmikroskop Stemi 2000C (Leica Zeiss Oberkochen) \\
\hline Pinzette (F.S.T, Heidelberg) \\
\hline Recovery Chamber (Peco Services, Cumbria, England) \\
\hline Schere (F.S.T, Heidelberg) \\
\hline
\end{tabular}

\subsubsection{Therapeutische Antikörpertherapie}

TLR4/MD2 Antikörper (MTS 510) CN: 16-9924, (eBioscience Inc., San Diego, CA)

Isotyp- Antikörper, Ratte IgG2a K (eBioscience, Inc., San Diego, CA) 


\subsubsection{TTC-Färbung}

2,3,5- Triphenyltetrazoliumchlorid (TTC) (Merck, Darmstadt)

Metall Brainmatrix für Gehirnsektionen (Ted Pella Inc, Vereinigte Staaten/ Kanada)

(Carl Roth, Karlsruhe)

Präparationspinzette (F.S.T, Heidelberg)

Präparationsschere (F.S.T., Heidelberg)

\subsubsection{PFA-Perfusion}

Paraformaldehyde 4\% (PFA)

Perfusionspumpe ISM596D (Ismatec, Wertheim)

Phosphatgepufferte Salzlösung (Phosphate-Buffered Saline, PBS)

Saccharose (Roth, Karlsruhe)

\subsubsection{Immunofluoreszenzfärbung}

4', 6-Diamidin-2-phenylindol (DAPI), 1:1000 (Merck Millipore, Darmstadt)

AxioCamMRm Mikroskop, (Carl Zeiss, Wetzlar)

CryoMatrix Einbettmedium (Thermo Scientific, UK)

Deckgläschen, ThermoFisher (Waltham, Massachusetts, Vereinigte Staaten)

Kryotom CM3050S (Leica, Wetzlar)

Objektträger Superforst Plus Menzel-Gläser (ThermoFischer, Waltham, Massachusetts, Vereinigte Staaten)

TBS-Puffer (Tris-buffered-saline): Hydroxymethyl-aminomethan (Tris) (Roth, Karlsruhe), Natriumchlorid ( $\mathrm{NaCl}$ ) (Roth, Karlsruhe); Zusammensetzung: $50 \mathrm{mM}$ Tris, 150 $\mathrm{mM} \mathrm{NaCl}$.

TBS++-Puffer: 1x TBS, Normales Eselsserum (Merck, Darmstadt), Triton-X-100 (Octoxinol 9) (Carl Roth, Karlsruhe); Zusammensetzung: $50 \mathrm{ml} \mathrm{TBS,} \mathrm{1,5} \mathrm{ml} \mathrm{Esels} \mathrm{Serum,}$ $1,25 \mathrm{ml} 10 \%$ Triton-X 100

Zen- Software Version 1.0.0.0, Carl Zeiss, Wetzlar 


\subsubsection{Antikörper für die Immunofluoreszenz}

Primärantikörper:

Anti-Iba 1 (Maus), monoklonal, 1:500 (Wako Chemicals GmbH, Neuss)

Anti-NeuN (Kaninchen), polyklonal, 1:500 (Merck, Millipore, Vereinigte Staaten)

$\underline{\text { Sekundärantikörper: }}$

Anti-Kaninchen IgG konjugiert mit AlexaFluor 488 (Esel), 1:250 (Jackson ImmunoResearch Europe Ltd., Suffol, Großbritannien)

Anti-Maus IgG konjugiert mit Cy3 (Esel), 1:250 (Jackson ImmunoResearch Europe Ltd., Suffol, Großbritannien)

\subsubsection{Durchflusszytometrie}

BD FACSDiva Version 6.1 Software (BD Bioscience, Heidelberg)

FACS Aria Software (BD Bioscience, Heidelberg)

FACS-Puffer: 10\% Bovines Serum Albumin (BSA) (Merck, Millipore, Darmstadt), Phosphatgepufferte Salzlösung (Phosphate-Buffered Saline, PBS); Zusammensetzung: $10 \mu \mathrm{l}$ BSA $10 \%, 100 \mathrm{ml}$ PBS

Gehirn-Resuspensionspuffer: 10\% Bovines Serum Albumin (BSA) (Merck, Millipore, Darmstadt), DNase (Carl Roth, Karlsruhe), Glukose (Carl Roth, Karlsruhe), Phosphatgepufferte Salzlösung (PBS); Zusammensetzung: $1 \mathrm{ml}$ BSA 10\%, $1 \mathrm{~g}$ Glukose, $1 \mathrm{ml}$ DNase $(10 \mathrm{mg} / \mathrm{ml}), 100 \mathrm{ml}$ PBS

Percoll Zentrifugationsmedium (BD-Bioscience, San Jose, CA, USA)

Phosphatgepufferte Salzlösung (PBS), eigene Herstellung: Natriumchlorid ( $\mathrm{NaCl}$ ) ( Roth, Karlsruhe), Kaliumchlorid ( $\mathrm{KCl})$ ( Roth, Karlsruhe), Dinatriumhydrogenphosphat $\left(\mathrm{Na}_{2} \mathrm{HPO}_{4}\right)$ ( Roth, Karlsruhe), Kaliumdihydrogenphosphat (Roth,Kalrsruhe); Zusammensetzung: $8 \mathrm{~g} \mathrm{NaCl}, 0,2 \mathrm{~g} \mathrm{KCl}, 1,44 \mathrm{gNa}_{2} \mathrm{HPO}_{4}, 0,24 \mathrm{~g} \mathrm{KH}_{2} \mathrm{PO}_{4}$ 


\subsubsection{Antikörper für die Durchflusszytometrie}

Anti-APC/Cy7, 1:300, Biolegend (San Diego, CA)

Anti-CD11b-APC, 1:300, Klon 111/70 (Biolegend, San Diego, CA)

Anti-CD3-biotin, 1:200, Klon 15-2C11 (BD Bioscience,Heidelberg)

Anti-CD45 B220-PE 1:300, Klon RA3-6b2 (BD Pharmingen, San Diego, CA)

Anti-CD45.2-FITC, 1:100, Klon 104 (Biolegend, San Diego, CA)

\subsubsection{Infarktvolumetrie}

Graph PadPrism Software Version 5 (La Jolla, Vereinigte Staaten)

ImageJ- Software (NIH, Vereinigte Staaten)

\subsubsection{Weitere Chemikalien \& Geräte:}

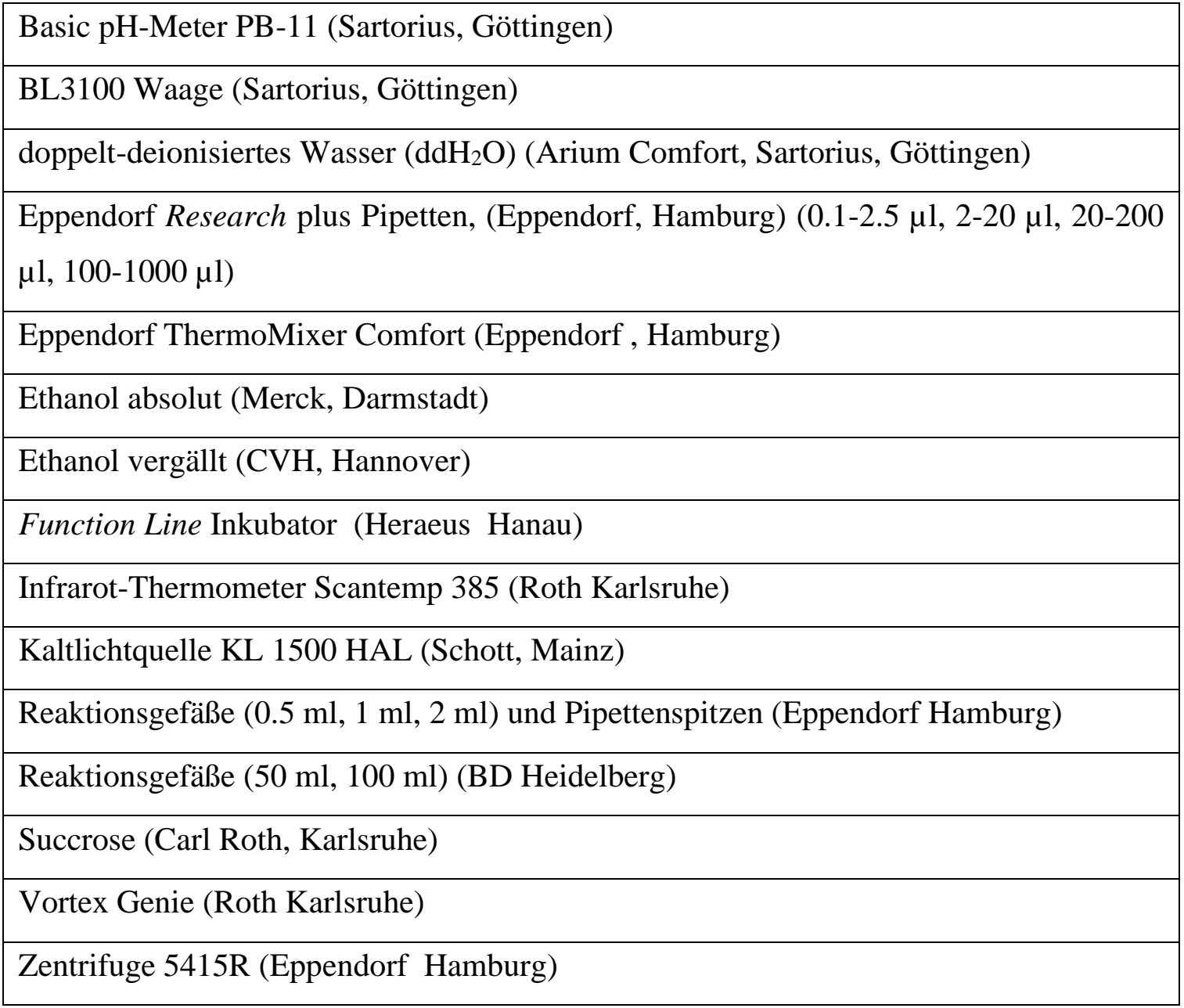




\subsection{Methoden}

\subsubsection{Versuchstiere}

8-10 Wochen alte, männliche C57B1/6N-Wild-Typ-Mäuse wurden unter 12:12-stündigem Tag/Nacht-Rhythmus gehalten und hatten Zugang zu Wasser und Futter ad libitum. Alle Tierversuche sowie die operativen Verfahren, die an den Tieren angewendet wurden, haben nach den Leitlinien für die Nutzung von Tieren in der neurowissenschaftlichen Forschung der Gesellschaft für Neurowissenschaften sowie den Leitlinien der Zentralen Tierexperimentellen Einrichtung des Universitätsklinikums Göttingen stattgefunden. Alle Experimente wurden von der lokalen Tierschutzkomission überprüft, wie auch vom Niedersächsischen Landesamt für Verbraucherschutz und Lebensmittelsicherheit (LaVes) unter der Tierversuchsnummer 33.9-42502-04-12/849 genehmigt. Um die Tiere vor starken Leiden zu schützen, wurden strikte Abbruchskriterien für den Versuch formuliert. Narkosebedingte Komplikationen, Gefäßdissektionen und -rupturen oder intrazerebrale Blutungen, wie auch Paralysen, eine dunkle Verfärbung des Unterbauches und des Skrotums, Rektumprolaps und ein moribunder Zustand führten zu einem Abbruch der Versuche und der Tötung der Mäuse. Tiere, die Zeichen der Aggression als Ausdruck von starken Schmerzen zeigten, sowie Tiere, die über 20\% vom Ausgangsgewicht innerhalb von 24 Stunden abgenommen hatten wurden letal anästhesiert und aus dem Versuch ausgeschlossen. Ebenso Tiere, die innerhalb von 6 Stunden postoperativ verestorben sind.

\subsubsection{Middle-cerebral-artery-occlusion-Modell (MCAO-Modell)}

Initial wurden alle Versuchstiere mit 100\% Sauerstoff- und 5\% Isofluran- Zufuhr über eine Nasenmaske in Narkose gelegt. Die Narkose wurde mit $1 \%$ Isofluran, unter Spontanatmung, für die Dauer der Operation (ca. 15 Minuten) aufrechterhalten. Zur Analgesie wurde $0,1 \mathrm{mg} / \mathrm{kg}$ Buprenorphin subkutan injiziert. Während der Operation wurden die Tiere auf einer Wärmeplatte mit einer konstanten Temperatur von $37^{\circ} \mathrm{C}$ gelagert, um Unterkühlungen zu vermeiden. Das Operationsgebiet wurde mit 97\% Ethanol desinfiziert. Es erfolgte ein ca. $1 \mathrm{~cm}$ langer Schnitt in der linken medioclavicular Linie. Die Glandula parotis wurde frei präpariert und vorsichtig stumpf aus dem Operationsgebiet geschoben. Die Arteria carotis communis, A. carotis externa und A. carotis interna wurden ebenso frei präpariert. Die A. carotis communis und A. carotis externa wurden ligiert. Die A. carotis interna wurde mit Hilfe einer speziellen Mikrogefäßklemme abgeklemmt. Als nächstes erfolgte ein ca. $1 \mathrm{~mm}$ lange Inzision entlang der A. carotis communis und ein silikonbeschichteter 
Nylon-Faden wurde durch die A. carotis interna nach cranial in die A. cerebri media eingeführt, um die Blutzirkulation zu unterbinden und mit einem Knoten befestigt. Die Glandula parotis wurde repositioniert und der Hautschnitt mittels Einzelknopfnähten verschlossen. Die Versuchstiere wurden in einer Recovery Chamber bei $30^{\circ} \mathrm{C}$ zum Aufwachen gelegt. Die Okklusionszeit betrug 45 Minuten. Nach Ablauf der Okklusionszeit wurden die Tiere mittels 100\% Sauerstoff und 5\% Isofluran erneut narkotisiert. Die Operationsnaht wurde desinfiziert und eröffnet. Der Nylon-Faden wurde aus der A. carotis interna entfernt sodass die Durchblutung im Bereich der A. cerebri media über Kollateralversorgung wiederhergestellt werden konnte. Die A. carotis interna wurde dann ligiert. Der Hautschnitt wurde mittels Einzelknopfnähten adaptiert. Die Versuchstiere wurden erneut bis zum vollständigen Aufwachen in die Recovery Chamber gelegt.

Die Tiere wurden ca. 2 Stunden postoperativ, nach Ausschluss von möglichen Abbruchsindikatoren, in deren Käfigen platziert. In jedem Käfig wurden maximal 2 Tiere gehalten. Um aggressives Verhalten und Verletzungen zu vermeiden, mussten alle Tiere die zu zweit einen neuen Käfig bewohnten, präoperativ aus dem gleichen Käfig stammen. Die Tiere hatten postoperativ freien Zugang zu Wasser und breiigem sowie auch normalem

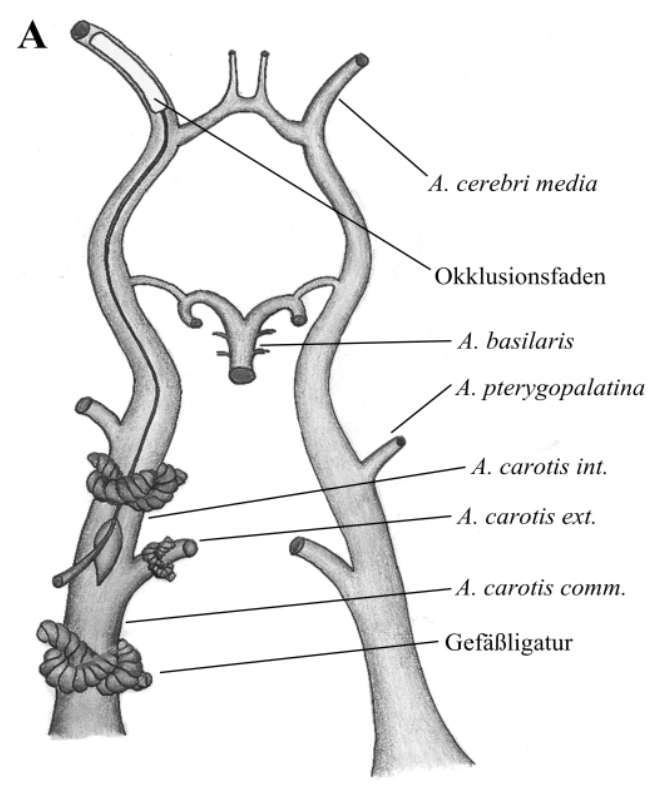

\section{Abbildung 2: Schema und Operationssitus des MCAO-Modells}

Schema der zerebralen Gefäßanatomie an der Maus und der Durchführung des MCAO-Modells. Die A. carotis comm. wurde ligiert, wie auch die A. carotis ext. Der Okklusionsfaden wurde über die perforierte A. carotis comm. bis zur A. cerebri media vorgeführt. Es ist darauf zu achten den Faden nicht in die A. pterygopalatina einzuführen. Die Verwendung von der Abbildung erfolgte mit freundlicher Genehmigung von Sarah Grünewald und Abass Eidizadeh. 
Futter.

\subsubsection{Therapeutische Applikation des TLR4/MD2-Antikörpers}

Die Behandlung der Tiere erfolgte direkt nach der Reperfusion und 24 Stunden postoperativ. Zwei Gruppen wurden mit $1 \mu \mathrm{g}$ TLR4/MD2-Antikörper (MTS 510), in $100 \mu \mathrm{PBS}$ gelöst, behandelt. Eine Gruppe davon intraperitoneal (i.p.) und die andere intravenös (i.v.). Bei der nächsten Gruppe wurde $1 \mu \mathrm{g}$ IgG2a K, ein Isotyp des Antiköpers aus der Ratte, ebenso in $100 \mu$ PBS gelöst, als Kontrollgruppe injiziert. Den Isotyp bekam nur die i.p. behandelte Gruppe und nicht die i.v. behandelte Gruppe. Die letzten zwei Gruppen wurden mit $100 \mu$ l PBS (Placebo), entweder intraperitoneal oder intravenös behandelt.

Die intraperitoneale Applikation erfolgte zuerst rechtsseitig und 24 Stunden später linksseitig am Bauch indem eine Hautfalte mit zwei Fingern angehoben wurde und die Nadel in einem Winkel von $45^{\circ}$ an der Basis der Hautfalte angesetzt und bis ins Peritoneum vorgeschoben wurden.

Die intravenöse Injektion erfolgte unter Kurznarkose ins retrobulbäre Venengeflecht, bei Fixierung des Tieres mittels Nackengriff. Zuerst am rechten und nach 24 Stunden am linken Auge.

Die Applikation erfolgte randomisiert und verblindet. Der durchführenden Person war nicht bekannt welche Stoffmischung jeweils appliziert wurde.

Die Analgesie der Tiere erfolgte mit Buprenorphin 0,1 mg/kg Körpergewicht intraperitoneal, sowohl präoperativ als auch 24 h postoperativ. Lidocain Salbe wurde auf der Hautnaht unmittelbar postoperativ als auch $12 \mathrm{~h}$ und $24 \mathrm{~h}$ postoperativ aufgetragen.

\subsubsection{Neuroscore}

Präoperativ sowie $24 \mathrm{~h}$ und $48 \mathrm{~h}$ postoperativ wurde an allen Versuchstieren ein Neuroscore erhoben. Die sensomotorischen Defizite wurden nach dem Schema wie von (Bederson et al. 1986) beschrieben und von (Hara et al. 1996) modifiziert, in 5 Grade eingeteilt (Tabelle 1): Grad $0=$ kein Defizit, Grad 1 = Unfähigkeit die kontralaterale Pfote zu heben, Grad $2=$ Kreisende Drehung zur kontralateralen Seite, Grad 3 = keine spontane Aktivität und Grad 4 = Tod. Die Erhebung des Neuroscores wurde stets von der gleichen Person durchgeführt. Die Person war zu jedem Zeitpunkt bezüglich der Art der Behandlung der Tiere verblindet. 
Tabelle 1: Neuroscore

\begin{tabular}{ll}
\hline PUNKTZAHL & DEFIZIT \\
\hline 0 & Kein Defizit \\
\hline 1 & Unfähigkeit die kontralaterale Pfote zu bewegen \\
\hline 2 & Kreisende Drehung in die kontralaterale Seite \\
\hline 3 & keine spontane Aktivität \\
\hline 4 & Tod \\
\hline
\end{tabular}

\subsubsection{TTC- Färbung}

Die TTC (2,3,5-Triphenyltetrazoliumchlorid)-Färbung ist eine bekannte und häufig angewendete histochemische Methode, die zur Unterscheidung zwischen metabolisch aktivem oder schon metabolisch inaktivem Gewebe, angewendet wird.

Großen Gebrauch findet diese Methode in der Pathologie und basiert auf der Fähigkeit der verschiedenen Dehydrogenasen (z.B. Succinatdehydrogenase) und deren Kofaktoren mit Tetrazolium zu reagieren und ein rotes Farbpigmente unter Reduktion zu bilden (Abbildung). Im MCAO-Modell kann die TTC-Färbung für die Bestimmung der Infarktgröße in einem Zeitraum von circa 30 Minuten postmortal angewendet werden. Hirnareale die sich nicht färben lassen, also weiß bleiben, sind entweder schon nekrotisch oder leiden unter einer maßgeblichen mitochondrialen Dysfunktion, die zum Zelltod führt (Türeyen et al. 2004). Das vitale Gewebe färbt sich immer rot als Zeichen der noch erhaltenen Aktivität der Dehydrogenasen (Pfeilschifter et al. 2011). Nach Ablaufen der Versuchszeit (48 Stunden) wurden die Versuchstiere mit $\mathrm{CO}_{2}$ letal anästhesiert und mit $50 \mathrm{ml}$ PBS transkardial, mittels einer Perfusionspumpe, perfundiert. Danach wurden die Gehirne entnommen. Das Hirngewebe wurde mit Hilfe einer Maus Brainmatrix in $2 \mathrm{~mm}$ breite Schnitte geschnitten. Die Schnitte wurden in 2\% TTC/PBS Lösung bei Raumtemperatur für 10 min im Dunkeln inkubiert. Im Anschluss wurden die Schnitte für 3 min in 4\% PFA Lösung für eine bessere Konservierung gelegt. Mit Hilfe eines Farbscanners wurden die gefärbten Schnitte digitalisiert. 

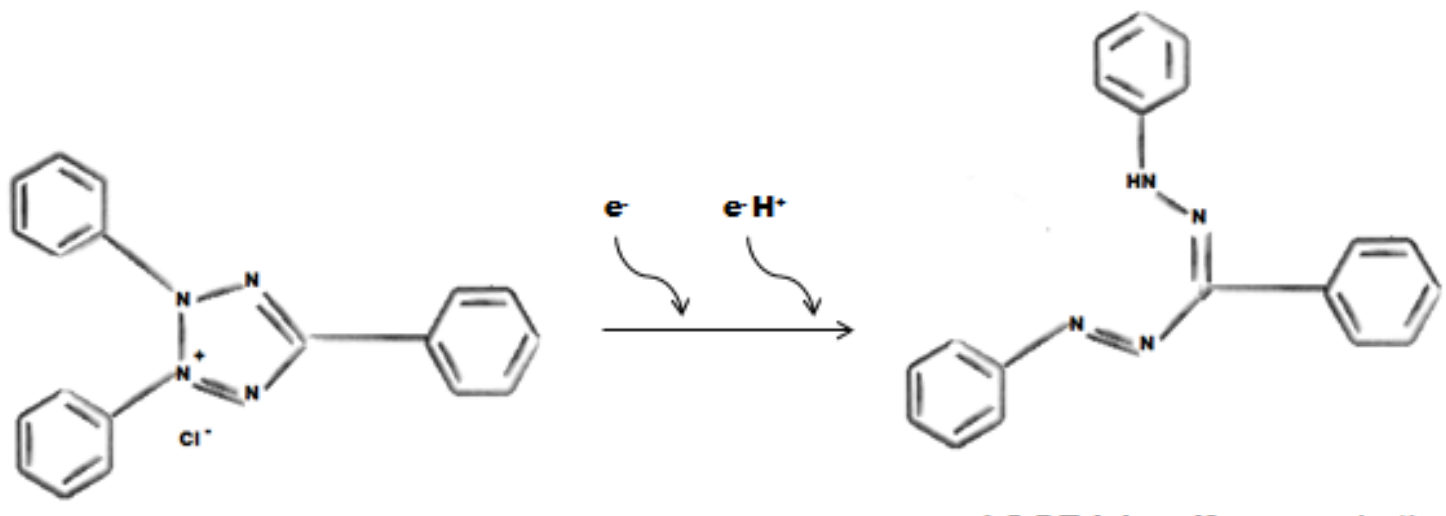

2,3,5 Triphenyltetrazoliumchlorid (farblos)

1,3,5 Triphenylformazan (rot)

\section{Abbildung 3: Umwandlung von 2,3,5-Triphenyltetrazoliumchlorid in 1,3,5- Triphenylformazan.}

Das TPH wird mittels Aufnahme von 2 Elektronen und 1 Proton zu TPF umgewandelt.

\subsubsection{Infarktvolumetrie}

Die Infarktvolumina wurden mittels der Software Image J (NIH, USA) ausgemessen.

Um die verschiedenen Volumina aus den TTC-Schnitten zu generieren, wurden jeweils die reinen Flächen des Schnittes ventral und dorsal ausgemessen und der Mittelwert davon in $\mathrm{mm}^{2}$ errechnet (Abbildung). Dieser Wert wurde dann mit der Dicke des Schnittes multipliziert (hier: $2 \mathrm{~mm}$ ), um auf das Volumen in $\mathrm{mm}^{3}$ zu kommen. Alle Volumina, die sich aus den Schnitten eines Gehirns ergaben wurden mit einander addiert. Somit konnte das Gesamtvolumen bestimmt werden. Um das direkte Infarktvolumen zu bestimmen, wurde von jedem Schnitt nur das Volumen auf der ipsilateralen Seite ausgerechnet, das einen Infarkt präsentierte (gelbe Umrandung).

Für die Bestimmung des indirekten Infarktvolumens wurde das gesamte Volumen der kontralateralen Seite (rot gestreifte Fläche) bestimmt. Das Volumen der ipsilateralen Seite, das vom Infarkt nicht betroffen war (grüne Fläche), wurde ebenso ausgerechnet. Das indirekte Infarktvolumen wurde als die Differenz zwischen dem Volumen der kontralateralen Seite minus des Volumens der nicht betroffenen ipsilateralen Seite definiert. 
Das Hirnödem wurde als Differenz zwischen direktem Infarktvolumen und indirektem Infarktvolumen bestimmt.
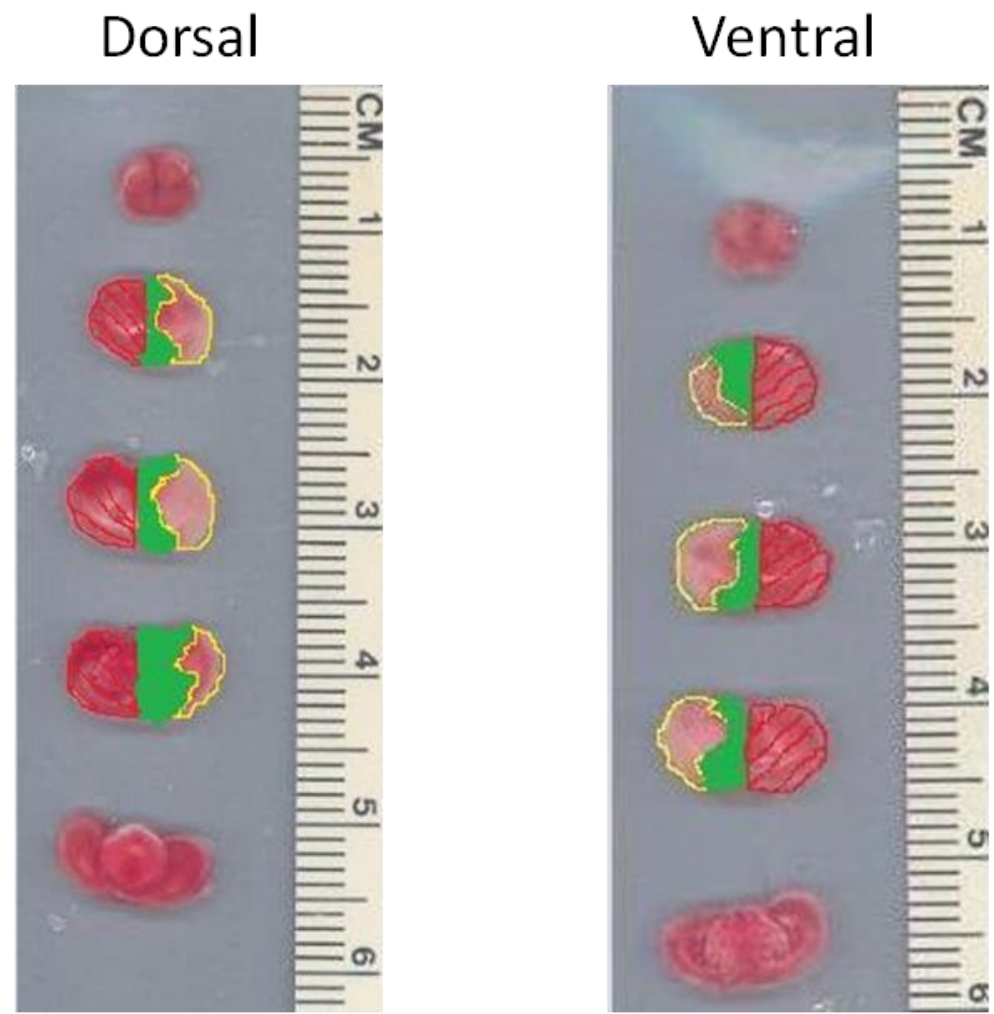

\section{Abbildung 4: Infarktvolumetrie mit TTC-gefärbten Schnitten.}

Gelbe Markierung: infarzierte Fläche. Grün: nicht-infarzierte ipsilaterale Fläche. Rot gestrichelt: Kontralaterale Fläche.

\subsubsection{Immunofluoreszenzfärbungen}

Vorbereitung des Gewebes:48 Stunden nach Okklusion der A. cerebri media, wurden die Versuchstiere in einer $\mathrm{CO}_{2}$ - Kammer letal anästhesiert und transkardial mittels $50 \mathrm{ml}$ PBSLösung und $50 \mathrm{ml}$ 4\% PFA- Lösung mittels einer Perfusionspumpe mit einer Flussgeschwindigkeit von $10 \mathrm{ml} / \mathrm{min}$ perfundiert. Um die Perfusion zu gewährleisten wurde die Leber vorher fenestriert. Die Gehirne wurden raus präpariert und für 24 Stunden, zur Fixierung, in 4\% PFA-Lösung gelagert. Daraufhin wurden die Gehirne in 30\% SuccroseLösung, zu Dehydratation, für 24 Stunden bei $4{ }^{\circ} \mathrm{C}$ gelagert. Die im Voraus mittels TTCFärbung gefärbten Gehirnschnitte wurden ebenso für 24 Stunden in einer 4\% PFA-Lösung und für weitere 24 Stunden in einer $30 \%$ Succrose-Lösung bei $4{ }^{\circ} \mathrm{C}$ gelagert. 
Als nächstes wurden die Schnitte in einem speziellen Medium zum Einfrieren (Cryomatrix) bei $-30{ }^{\circ} \mathrm{C}$ eingebettet und eine Serie von Schnitten mit $14 \mu \mathrm{m}$ Dicke mittels Kryotom (Leica CM3050S) angefertigt. Jeder Objektträger trug 5 Schnitte, jeder Schnitt stammte aus einer anderen Gehirnregion (frontaler Kortex, pyriformer Kortex, septales Zwischenhirn, caudales Zwischenhirn, rostrales Mittelhirn). Alle Objektträger trugen die gleichen 5 Gehirnregionen. Die Objektträger wurden bei $-80{ }^{\circ} \mathrm{C}$ gelagert.

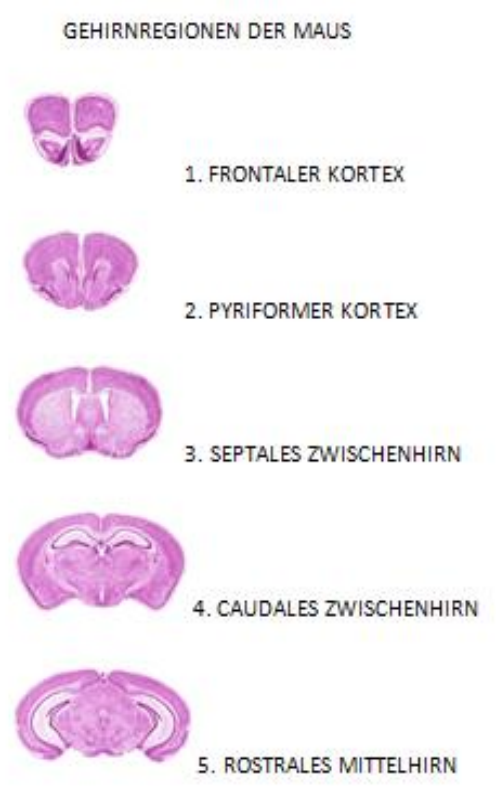

\section{Abbildung 5: Verwendete Gehirnregionen der Maus.}

Die Verwendung der Abbildung erfolgt mit freundlicher Genehmigung von Sidman et al. (1999).

Färbung von Neuronen und Monozyten: Die im Vorfeld vorbereiteten Schnitte wurden zweimal in TBS-Lösung je 5 min gespült. In einer feuchten Kammer wurden die Schnitte mit TBS++ für 60 min geblockt und mit den Primärantikörpern (Anti-NeuN und AntiIba1) für $48 \mathrm{~h}$ bei $4{ }^{\circ} \mathrm{C}$ inkubiert. Alle darauf folgenden Schritte erfolgten in einem verdunkelten Raum. Die Schnitte wurden erneut zweimal mit TBS je 5 Minuten und einmal mit TBS++ für 30 Minuten gespült. Die sekundären Antikörper wurden aufgetragen und für 120 Minuten bei Raumtemperatur inkubiert. Nach Ablauf der Inkubationszeit wurden die Objektträger mit TBS gespült und in DAPI für 5 Minuten inkubiert, erneut mit TBS gespült, mit Immunofluoreszens Mounting Medium beschichteten Deckeln abgedeckt und bei $4{ }^{\circ} \mathrm{C}$ gelagert. Die Schnitte wurden mit der AxioCamMRm aufgenommen und mit der Zen Software, Version 1.0.0.0 bearbeitet. 


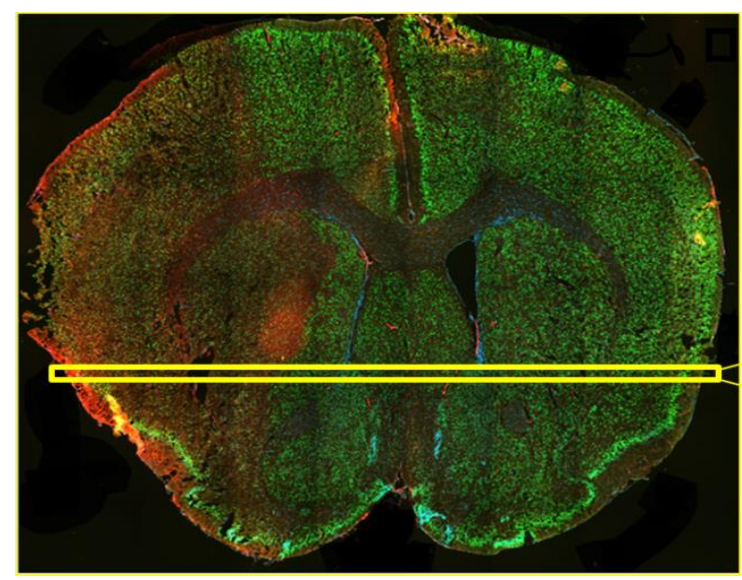

Abbildung 6: Auszählung der Neuronen- und Monozytenzahl an immunfluoreszenzgefärbten Gehirnpräparaten.

Grün: NeuN-positive Zellen. Rot: Iba1-positive Zellen. Blau: DAPI. Gelbmarkiertes Areal: $1 \mathrm{~mm}$ breite Box zur Auszählung unter den Ventrikelräumen. Gehirn Ebene 3: Septales Zwischenhirn, 10x Vergrößerung. Weiterhin abgebildet: Isolierter Abschnitt.

\subsubsection{Bestimmung der Neuronen- und Monozytenzahl}

Die Auszählung der Neuronen (NeuN-positiv) und der Monozyten (Iba1-positiv) erfolgte mit der Software ImageJ. Die Zellzahl wurde pro $\mathrm{mm}^{2}$ bestimmt. Dafür wurde die 3. Ebene am septalen Zwischenhirn im Versorgungsgebiet der A. cerebri media ausgewählt. Beide Hemisphären wurden durch die Fissura longitudinalis cerebri voneinander getrennt und einzeln betrachtet. Auf Höhe der Liquorräume wurde ein Areal von $1 \mathrm{~mm}$ Breite über der endsprechenden Länge des Schnittes ausgeschnitten und die Neuronen in dem Areal ausgezählt. Die Zahl der Zellen wurde dann auf $1 \mathrm{~mm}^{2}$ umgerechnet.

\subsubsection{Durchflusszytometrie}

Vorbereitung des Gewebes: Die Versuchstiere wurden 48 Stunden nach MCAO mittels $\mathrm{CO}_{2}$ letal anästhesiert und transkardial mit $50 \mathrm{ml} \mathrm{PBS}$ und $50 \mathrm{ml} \mathrm{NaCl}$ perfundiert. Die Gehirne wurden heraus präpariert und jede Gehirnhemisphäre wurde getrennt behandelt. Die Hemisphären wurden unmittelbar nach Entnahme in jeweils $20 \mathrm{ml}$ PBS zerkleinert und für eine Stunde auf Eis gelagert. Als nächstes wurde die Suspension zentrifugiert (1600 $\mathrm{rpm}, 10 \mathrm{~min}, 4^{\circ} \mathrm{C}$ ) und das Zellpellet in 30\% Percoll-Lösung gelöst. Mittels Zugabe von 4 $\mathrm{ml} \mathrm{45 \%} \mathrm{und} 2 \mathrm{ml} 70 \%$ Percoll-Lösung unter Zentrifugation (2300 rpm, $20 \mathrm{~min}, 4^{\circ} \mathrm{C}$ ) wurde ein Gradient aufgebaut. Die Leukozyten konnten aus den beiden Interphasen gewonnen werden. Die Zellen wurden dann in $50 \mathrm{ml}$ FACS-Puffer zentrifugiert (1600 rpm, 10 min, 4 ${ }^{\circ} \mathrm{C}$ ) und erst in $10 \mathrm{ml}$ dann in $1 \mathrm{ml}$ FACS-Puffer resuspendiert. Anschließend wurden die 
Zellen ein letztes Mal zentrifugiert (1600 rpm, $\left.10 \mathrm{~min}, 4{ }^{\circ} \mathrm{C}\right)$ und in FACS-Puffer aufgenommen.

Markierung und Auswertung: Die Anzahl der gewonnenen Zellen wurde mit Hilfe der Tryptanblau-Färbung und einer Neumann-Zählkammer bestimmt. Für die Durchflusszytometrie wurden die gewonnenen Zellen mittels Antikörpern markiert. Dafür wurden die Zellen mit FACS-Puffer dekantiert (1200 rpm, 8 min), gewaschen und mit jeweils $100 \mu \mathrm{l}$ der Lösung aus den ausgewählten primären Antikörpern für 15 Minuten bei $4{ }^{\circ} \mathrm{C}$ abgedunkelt inkubiert. Als nächstes wurden die Zellen erneut mit FACS-Puffer gewaschen (1200 rpm, $8 \mathrm{~min}$ ) und 15 Minuten bei $4{ }^{\circ} \mathrm{C}$ mit den sekundären Antikörpern inkubiert. Zu den Endprodukten wurden $200 \mu$ FACS-Puffer addiert. Die Zellen wurden mit dem FACS Aria Cells (BD Bioscience) und FACSDiva Version 6.1 Software pro Hemisphäre bestimmt. Die Zellzahl je Hemisphäre wurde dann auf 200.000 Zellen hochgerechnet und vergleichbare Werte zu erzielen. Es wurde die Anzahl der Zellen sowohl zwischen der ipsilateralen und der kontralateralen Seite jeder Gruppe, als auch die Zellezahl zwischen der ipsilateralen und der kontralateralen Seiten zwischen der beiden Gruppen verglichen. Es wurde die Anzahl der folgenden Zellarten bestimmt: CD 45+ für alle detektierete Immunzellen. CD 45.2+ für Mikroglia, CD11b+ für aktivierte Mikroglia und Makrophagen, CD 3+ für T-Zellen und CD 45/B220+ für B-Zellen.

\subsubsection{Statistik}

Die statistischen Analysen erfolgten stets mit dem einseitigen Mann-Whitney-U-Test. Alle Angaben erfolgten als Mittelwert \pm Standardabweichung. P-Werte die unter 0,05 lagen wurden als statistisch signifikant betrachtet. Die statistischen Analysen und graphische Darstellungen erfolgten mit Graph PadPrism und Microsoft Excel. Die Textverarbeitung erfolgte mit Microsoft Word und PowerPoint. 


\section{Ergebnisse}

Ziel dieser Arbeit war es, das therapeutische Potential einer intraperitonealen (i .p.) und einer intravenösen (i. v.) Blockierung des TLR4/MD2 Rezeptors mittels Anwendung des MTS510-Antikörpers zu evaluieren, wenn die Applikation erst nach Ablauf der Okklusionszeit (45 Minuten) und $24 \mathrm{~h}$ später erfolgt. Die Bewertung des Therapienutzens erfolgte durch Beobachtungen des neurologischen Defizits mittels der Erhebung eines Neuroscores und durch den histologischen Vergleich der Infarktvolumina und des entstandenen Hirnödems. Weiterhin wurde histologisch mittels Immunfluoreszenzfärbung eine Gegenüberstellung des neuronalen Überlebens durch Auszählung von Neuronen gezogen und das Ausmaß des inflammatorischen Geschehens durch Zählung aktivierter und migrierter monozytärer Zellen erstellt. Zudem erfolgte eine Durchflusszytometrie um die genaue Anzahl und Differenzierung der aktivierten und migrierten Monozyten und Lymphozyten zu bestimmen und den Einfluss einer TLR4 Blockierung zu eruieren.

\subsection{Intraperitoneale TLR4-Antikörper Applikation im MCAO- Modell}

Der erste Versuch dieser Arbeit befasste sich mit der Frage ob die Inaktivierung des TLR4 Rezeptors, mittels intraperitonealer Behandlung mit dem TLR4/MD2-Antikörper MTS510, eine neuroprotektive Wirkung nach einem ischämischen Schlaganfall im MCAO-Modell an Mäusen haben könnte. Die Aspekte direktes und indirektes Infarktvolumen, Ödembildung sowie die Ausprägung von neurologischen Defiziten nach einem Schlaganfall wurden untersucht und zwischen den mit Antikörper, Isotyp-Antikörper oder PBS behandelten Gruppen verglichen.

Die Applikation eines IgG-Isotyps des TLR4-Antikörpers erfolgte um eine potenzielle generelle Wirkung einer Antikörperinjektion gegenüber der Injektion mit einem spezifischen Antikörper auszuschließen.

PBS wurde als Placebo benutzt, da es sich um eine isotonische Salzlösung handelt die dem Blutplasma ähnelt. Die Lösung ist für Zellen unschädlich, deswegen wurde angenommen, dass es durch die Applikation von PBS als Placebo nicht zu einer Verfälschung der Ergebnisse kommt.

Die Versuchstiere wurden in drei Gruppen aufgeteilt. Die Placebogruppe (PBS) $(n=10)$, die Isotypgruppe (ISO) $(n=8)$ und die TLR4-Antikörpergruppe (TLR4-Ab) $(n=8)$. Die 
Mäuse wurden mit dem MCAO-Modell behandelt. Es erfolgte stets eine Okklusion von 45 min mit einer Reperfusionszeit von 48 h. Die Applikation erfolgte intraperitoneal immer direkt nach der Reperfusion sowie nach 24 h erneut.

\subsubsection{Körpergewicht und Körpertemperatur}

Vor der 45-minütigen MCAO, sowie alle $24 \mathrm{~h}$ wurden Körpergewicht (Abbildung A) und Temperatur (Abbildung B) der Tiere gemessen. Beobachtet wurden nach $24 \mathrm{~h}$ ein starker Gewichtsverlust, der sich aber in den folgenden Stunden normalisierte und eine moderate Hypothermie der Tiere in allen Gruppen. Es konnten keine signifikanten Unterschiede im Temperatur- und Gewichtsverlauf zwischen den Antikörper-behandelten, den mit dem Isotyp behandelten oder den Tieren der Kontrollgruppe festgestellt werden (Mann-Whitney-UTest: Körpergewicht TLR4-Ab vs. PBS: $p=0,2$; TLR4-Ab vs. ISO: $p=0,5$; ISO vs. PBS: $p=0,35$; Temperatur TLR4-Ab vs. PBS: $p=0,2$; TLR4-Ab vs. ISO: $p=0,35$; ISO vs. PBS: $p=0,35)$. 


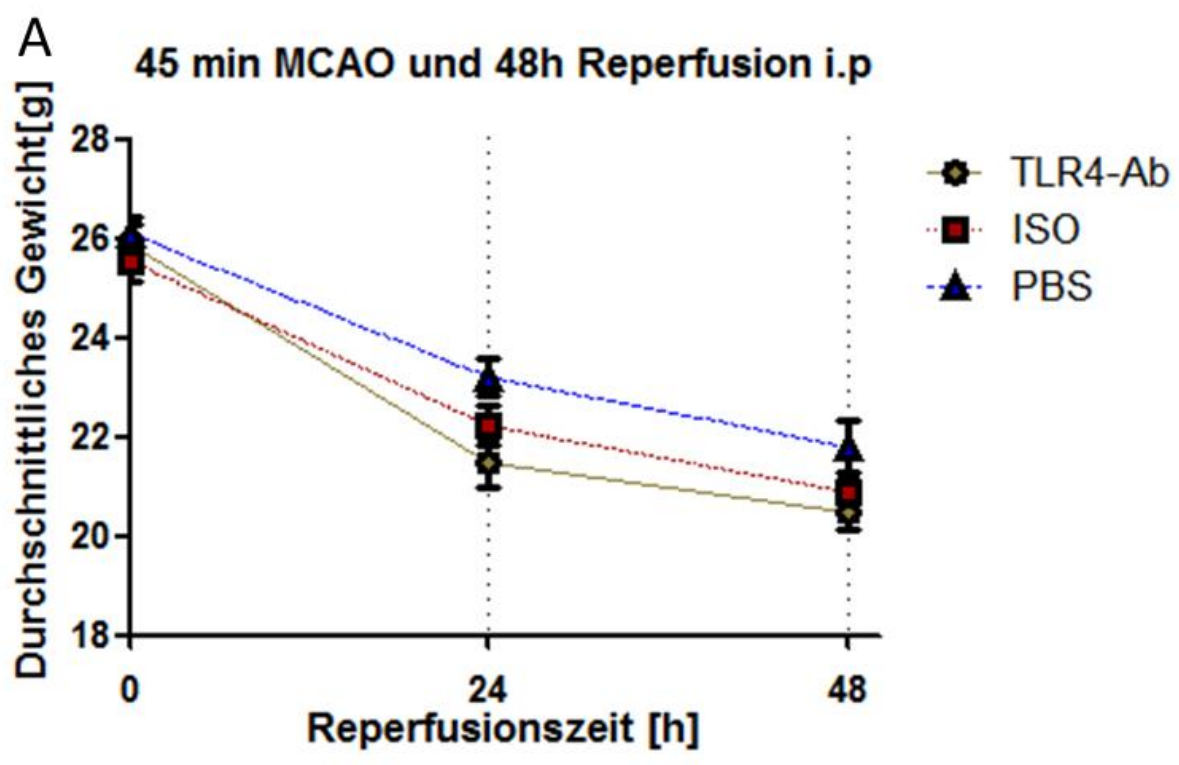

B

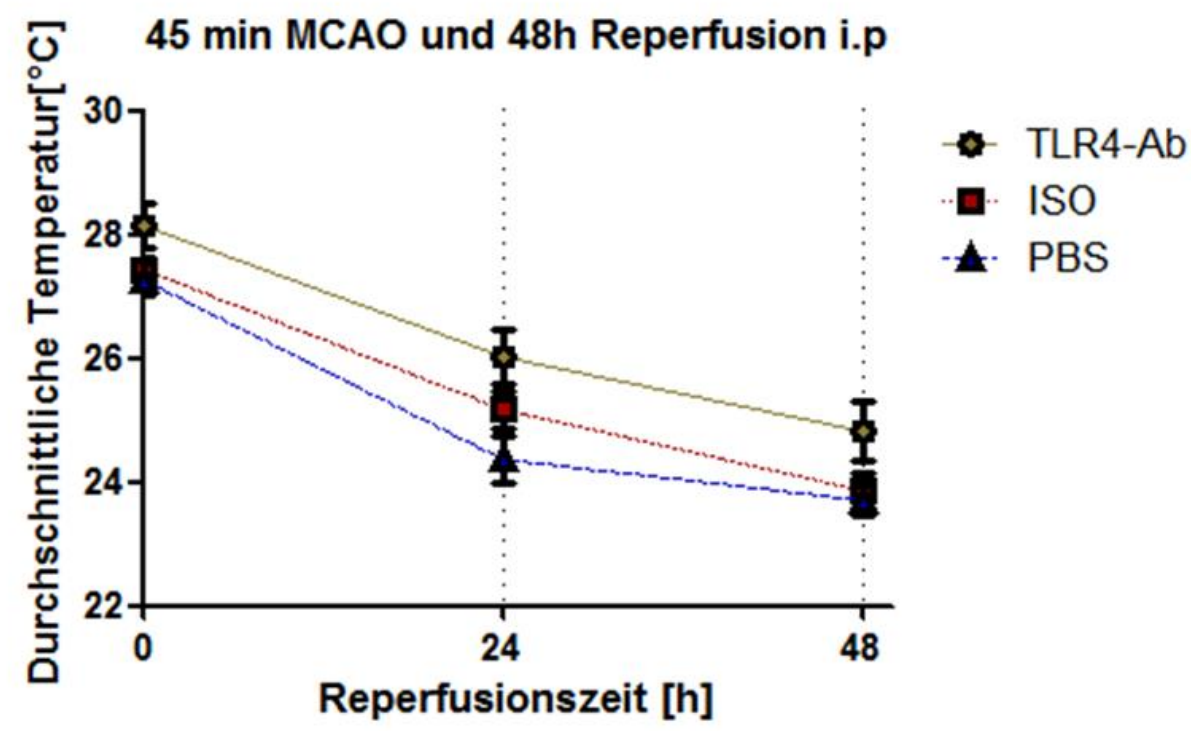

Abbildung 7: Gewichts- und Temperaturkontrollen der i.p. behandelten Mäuse.

(A) Entwicklung des mittleren Gewichts und (B) der mittleren Temperatur ( \pm Standardabweichung) der Mäuse im 45-min-Okklusions- und 48-h-Reperfusions-MCAO-Modell nach intraperitonealer Applikation über die Zeit $\left(n_{\mathrm{TLR} 4-\mathrm{Ab}}=8 ; n_{\mathrm{ISO}}=8 ; n_{\mathrm{PBS}}=10\right)$. 


\subsubsection{Infarktvolumetrie}

Für die Auswertung der Infarktvolumetrie wurde der einseitige Mann-Whitney-U-Test angewendet. Die histologische Analyse zeigte keine signifikanten Unterschiede in der Infarktausprägung zwischen den drei Gruppen, weder in der direkten und indirekten Infarkvolumetrie, noch in der Ausmessung des Hirnödems. Ergebnisse der direkten Infarktvolumetrie (Abbildung A): TLR4-Ab $(n=8)$ vs. PBS $(n=10): 143,1 \pm 15,16$ vs. $174 \pm 11,65$ $\mathrm{mm}^{3}, p=0.2574$, TLR4-Ab vs. Isotyp $(n=8): 143.1 \pm 15.16$ vs. $174.0 \pm 11.65 \mathrm{~mm}^{3}, p=$ 0,5033; Isotyp vs. PBS: $174.0 \pm 11.65$ vs. $156.7 \pm 15.33 \mathrm{~mm}^{3}, p=0,3212$. Ergebnisse der indirekten Infarktvolumetrie (Abbildung B): TLR4-Ab vs. PBS: $48 \pm 25.54$ vs. 82,31 \pm 23,25 mm $3 \mathrm{~mm}^{3}, p=0,28$; TLR4-Ab vs. Isotyp: $76.48 \pm 9.029$ vs. $92.39 \pm 10.23 \mathrm{~mm}^{3}, p=$ 0,7504; Isotyp vs. PBS: $92.39 \pm 10.23$ vs. $82.31 \pm 7.352 \mathrm{~mm}^{3}, p=0,5302$. Ergebnisse der Hirnödem-Ausmessung (Abbildung C): TLR4-Ab vs. PBS: 67,01 \pm 21,69 vs. 74,63 \pm $28,11 \mathrm{~mm}^{3}, p=0,3167$; TLR4-Ab vs. Isotyp: $67,01 \pm 21,69$ vs. $86,00 \pm 8,847 \mathrm{~mm}^{3}, p=$ 0,0803; Isotyp vs. PBS: $86,00 \pm 8,847 \mathrm{~mm}^{3}$ vs. $74,63 \pm 28,11 \mathrm{~mm}^{3}, p=0,2041$.

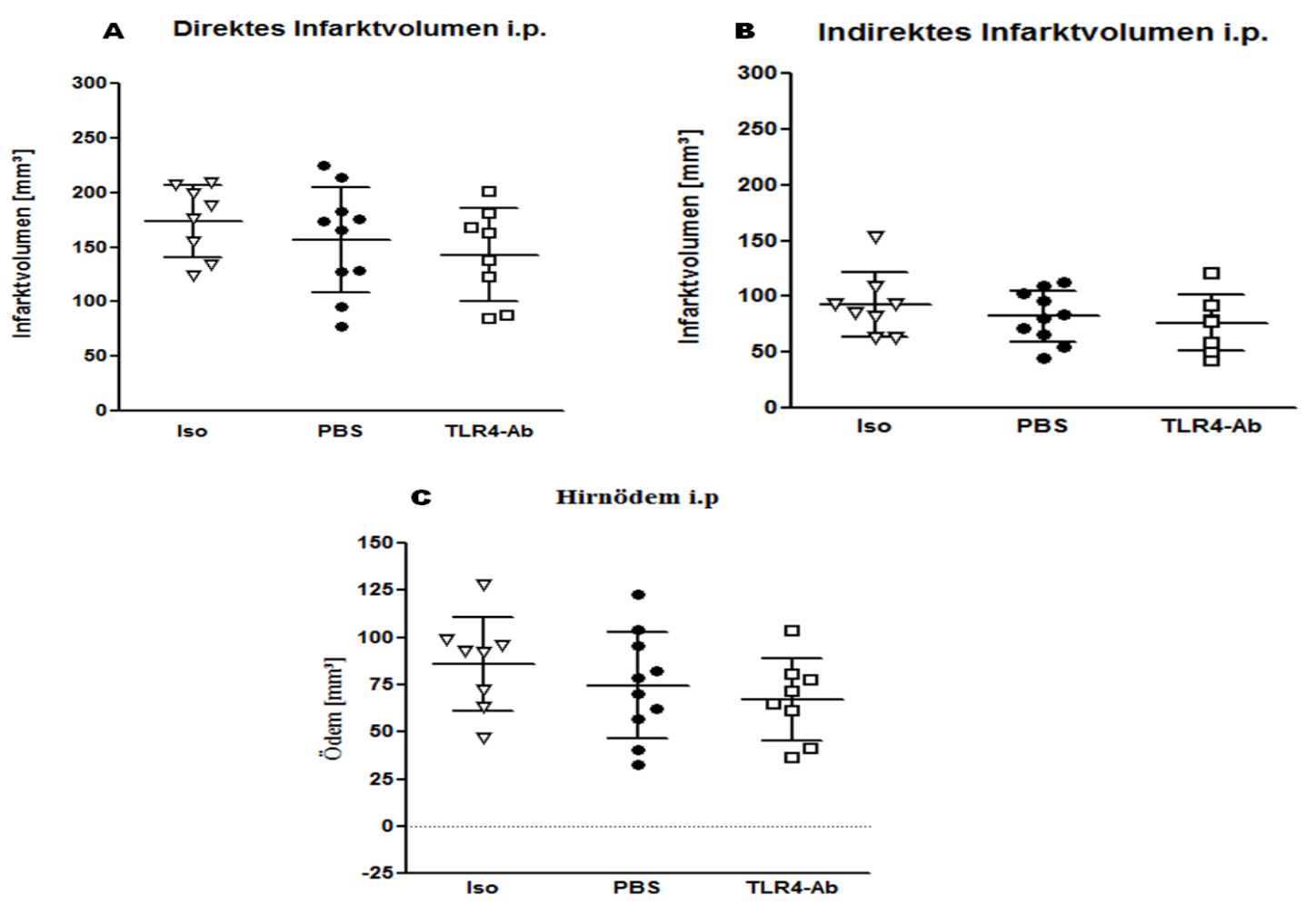

Abbildung 8: Direktes, indirektes Infarktvolumen und Hirnödem nach 45 min MCAO und 48 Stunden Reperfusion bei intraperitonealer Applikation.

Es wurden drei Gruppen gebildet: TLR4-Antikörper $(n=8)$, Isotyp-Antikörper $(n=8)$ und PBS $(n=10)$. Die Gehirne wurden mittels TTC-Färbung gefärbt. Für die Auswertung wurde der einseitige Mann Whitney U- Test benutzt. In der Abbildung sind Mittelwerte \pm Standardabweichung angezeigt. $* p \leq 0,05$. 


\subsubsection{Neuroscore (Bederson-Score)}

Präoperativ, nach 24 Stunden als auch nach 48 Stunden postoperativ, wurde der modifizierte Test nach Bederson zur Eruierung der Motorik der Tiere durchgeführt. Dabei wurden neurologische Defizite, die die Tiere postoperativ zeigten, dokumentiert. Der Test hatte das Ziel mögliche Unterschiede im postoperativen, neurologischen Status zwischen den verschiedenen Gruppen nachzuweisen. Dieser Test untersucht die Motorik der Tiere und besteht aus 5 Stufen von 0 Punkte für kein neurologisches Defizit bis maximal 4 Punkte, die den Tod des Tieres bedeuten. Alle Tiere, die im Versucht beteiligt waren, hatten präoperativ einen Neuroscore von 0 Punkte. 24 Stunden postoperativ zeigte der Test, auch wenn nicht signifikant, eine Tendenz dazu, dass mit dem Placebo behandelte Tiere, in Vergleich zu denen mit dem TLR4-Antikörper behandelten Tieren, einen besseren neurologischen Status hatten: Bederson-Score: TLR4-Ab $(n=8)$ vs. PBS $(n=10)$ nach 24 h: 2,000 $\pm 0,9258$ vs. $1,400 \pm 0,8433 ; p=0,0850$. Im Verlauf und nach 48 Stunden postoperativ zeigte sich eine rasante Verschlechterung der Motorik der Tiere aus der PBS Gruppe. Dagegen zeigten die Tiere aus der TLR4-Ab Gruppe nur eine leichte Verschlechterung des neurologischen Status. Der Bederson-Score TLR4-Ab vs. PBS nach 48 h: 2,375 \pm 0,7440 vs. 2,500 $\pm 0,7071 p=0,3602$. Im Vergleich zu der TLR4-Ab Gruppe zeigte sich bei der Gruppe, die den Isotyp (ISO) injiziert bekam weder nach $24 \mathrm{~h}$ noch $48 \mathrm{~h}$ postoperativ relevante neurologische Unterschiede. Im Vergleich zu der PBS-Gruppe zeigte sich allerdings $24 \mathrm{~h}$ postoperativ ein Unterschied im Neuroscore, der aber nach 48 Stunden verschwand. TLR4-Ab vs. ISO $(n=10)$ nach 24 h: $2,000 \pm 0,9258$ vs. $2,333 \pm 0,8233, p=0,2388$. TLR4-Ab vs. ISO nach 48 h: 2,375 $\pm 0,7440$ vs. $2,700 \pm 0,9487, p=0,2200$. ISO vs. PBS nach 24 h: $2,333 \pm 0,8233$ vs. $1,400 \pm 0,8433, p=0,0133$. ISO vs. PBS nach 48 h: $2,375 \pm$ 0,7440 vs. $2,500 \pm 0,7071, p=0,2998$. 


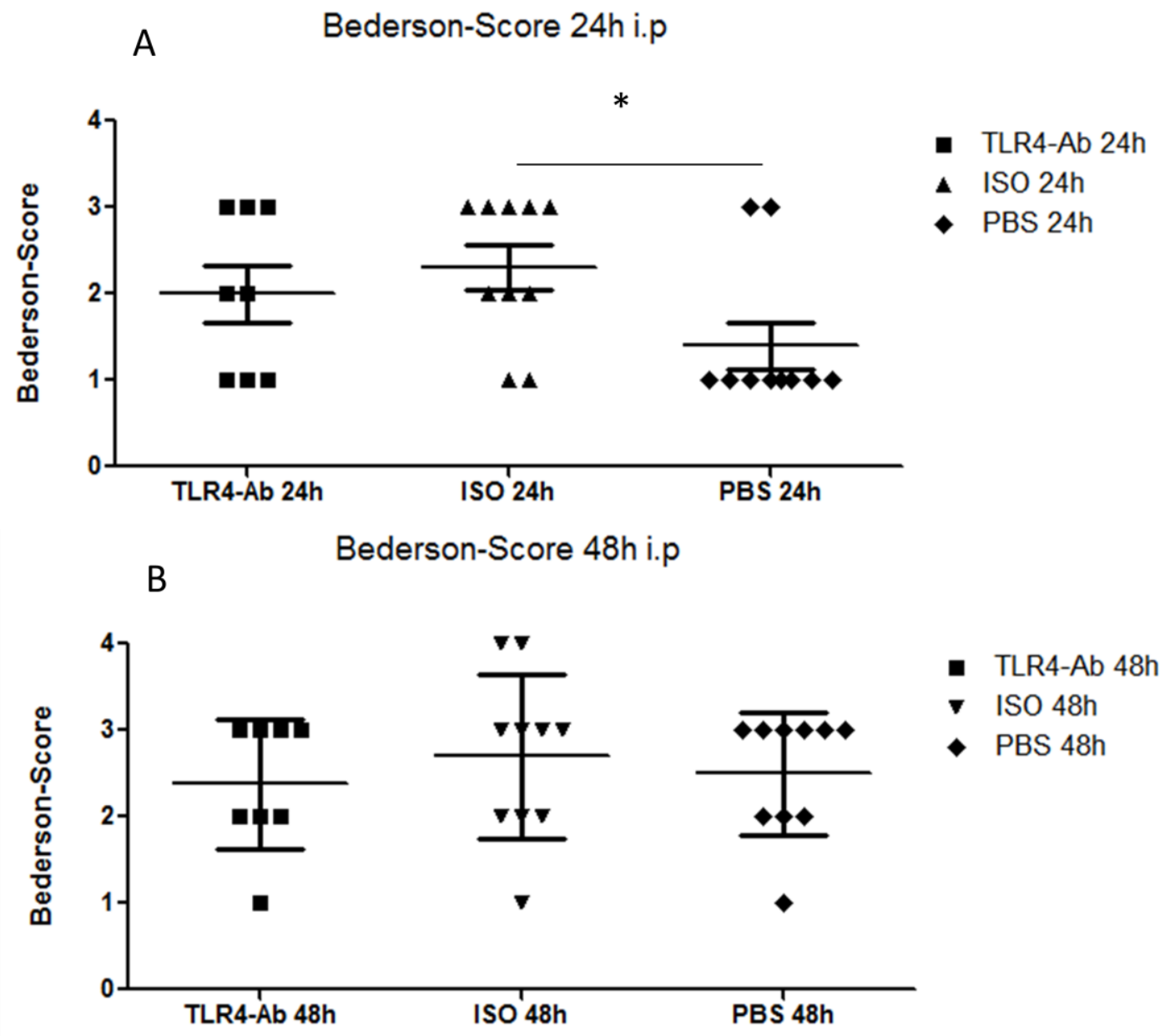

Abbildung 9: Bederson-Score 24 und 48 Stunden postoperativ nach 45 min MCAO mit 48 h

\section{Reperfusion.}

Es wurde der modifizierte Bederson-Test angewendet. Alle Tiere zeigten präoperativ einen Neuroscore von 0 (kein Defizit). Nach 24 und 48 Stunden zeigten die Tiere aus der mit dem Placebo behandelten Gruppe $(n=10)$ keinen signifikanten Unterschied zu den, mit dem Antikörper behandelten Tiere $(n=8), p=0,0850$. Die Gruppe, die den Isotyp $(n=10)$ erhielt zeigte eine signifikant schwerere Symptomatik ( $p=0,0133$ ) gegenüber der PBS-Gruppe nach $24 \mathrm{~h}$, welche aber nach 48 $\mathrm{h}$ wieder verschwunden war $(p=0,2998)$. Für die Auswertung wurde der einseitige MannWhitney U-Test angewendet. In der Abbildung sind Mittelwerte \pm Standardabweichungen angezeigt. $* p \leq 0,05$.

\subsubsection{Bestimmung der Neuronen- und Monozytenzahlen}

Nach Entnahme der Gehirne erfolgte die Anfärbung der NeuN- und Iba-1 positiven Zellen mittels Immunfluoreszenz. Iba-1 wird vor allem in Monozyten (Makrophagen und Mikroglia exprimiert. NeuN wird in Neuronen exprimiert und ist für sie charakteristisch. 
Die Auszählung der Neuronen erfolgte an definierten Arealen, die der Monozyten im gesamten Schnitt, für jeweils ipsi- und kontralaterale Seite. Die Zellzahlen wurden auf die Fläche von $1 \mathrm{~mm}^{2}$ bezogen. Bei der Auszählung der Neuronen- und Monozytenzahl konnte zwischen den beiden Gruppen kein signifikanter Unterschied in der Anzahl der überlebenden Neuronen oder der Anzahl der sich im Infarktgebiet befindenden Iba-1 positiven Zellen festgestellt werden. Ergebnisse der Neuronenzahlen ipsilateral: TLR4-Ab $(n=7)$ vs. PBS $(n=5): 69.2 \pm 6.6$ vs. $71.2 \pm 9.0 ; p=0,4$. Neuronenzahl kontralateral: TLR4-Ab vs. PBS: $110.2 \pm 6.5$ vs. $108.6 \pm 10.4 ; p=0,4$. Ergebnisse der Monozytenzahlen ipsilateral: TLR4-Ab vs. PBS: $15.79 \pm 1.9$ vs. $15.4 \pm 2.1 ; p=0,4$. Monozytenzahl kontralateral: TLR4-Ab vs. PBS: $10.9 \pm 1.6$ vs. $10.2 \pm 1.1 ; p=0,3$.

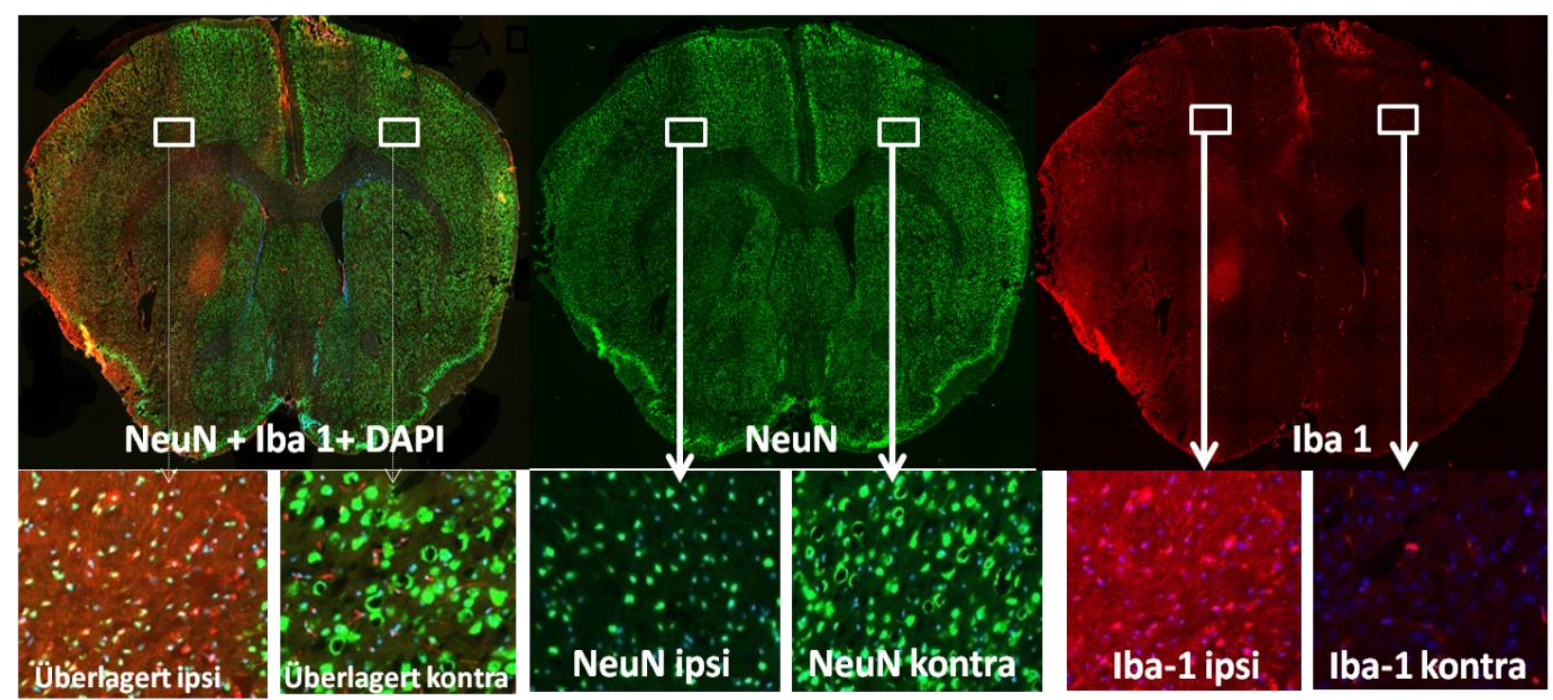

Abbildung 10: Immunfluoreszenzfärbungen von Neuronen und monozytären Zellen im Vergleich zwischen ipsilateralem und kontralateralem Infarktgebiet.

Zur Messung des neuronalen Überlebens und des Ausmaßes der Aktivierung von monozytären Zellen wurden die Gehirnpräparate immunfluoreszierend gefärbt und mikroskopiert. Dazu wurden Neurone mittels des Markerproteins NeuN und des Fluoreszenzfarbstoffes AlexaFluor488 markiert (in der Abbildung in grün). Makrophagen und aktivierte Mikroglia wurden mit dem Markerprotein Iba1 und dem Fluoreszenzfarbstoff Cy3 markiert (in der Abbildung rot). Die Farbkanäle wurden sowohl einzeln wie auch überlagert dargestellt. 

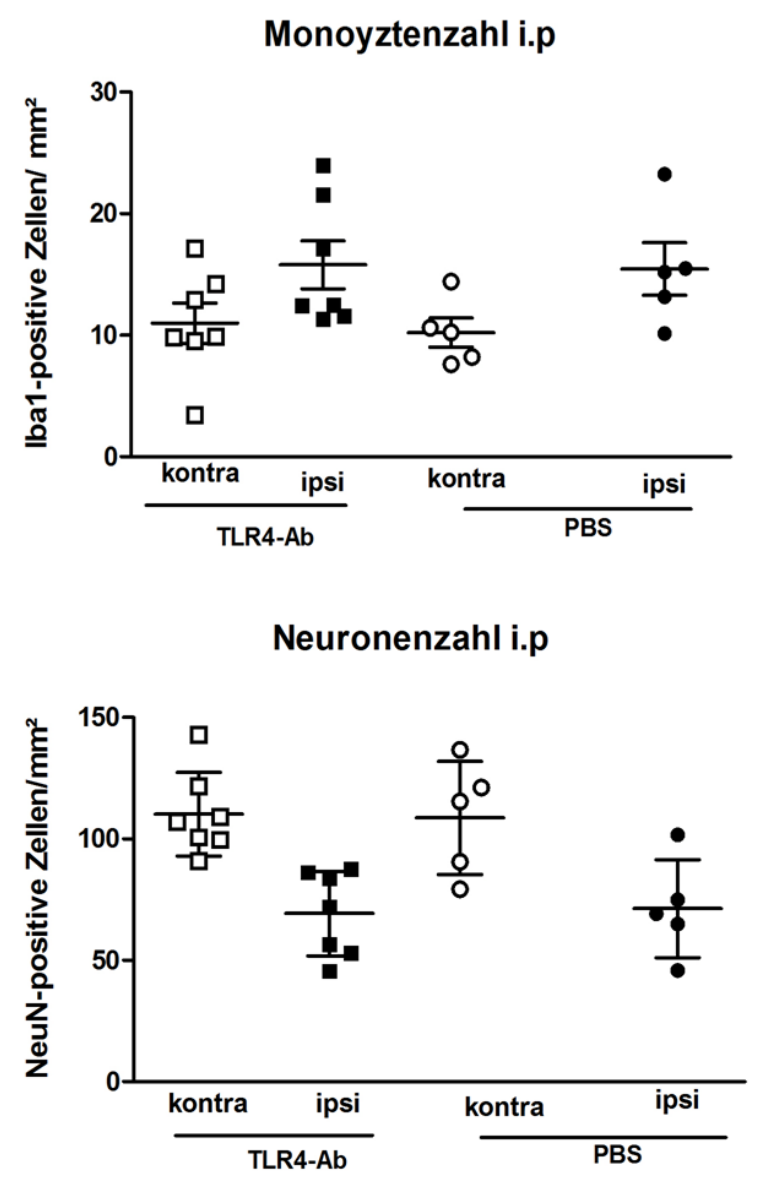

\section{Abbildung 11: Anzahl von Neuronen und Iba1-positiven Zellen 48 Stunden nach MCAO mit 45 Minuten Okklusionszeit nach i. p. Applikation.}

Die Zellzahl wurde in $\mathrm{mm}^{2}$ pro Gehirnhemisphäre in den mit PBS $(n=5)$ oder TLR4-Ab $(n=$ 7) behandelten Gruppen dargestellt. Die Behandlung erfolgte mit dem TLR4 Antikörper direkt nach der Reperfusion sowie 24 Stunden postoperativ. PBS wurde als Placebo appliziert. Es konnte kein signifikanter Unterschied in der Zellzahl der Neuronen oder der Iba1-positiven Zellen in der ipsilateralen oder der kontralateralen Seite zwischen den Gruppen festgestellt werden (einseitiger Mann-Whitney-U-Test). 
Zusammengefasst wurden Tiere mit dem MCAO-Modell mit 45 minutiger Okklusionszeit und 48 Stunden Reperfusionszeit behandelt. Hierbei erfolgte die i.p. Applikation eines TLR4-Antikörpers im Vergleich zu einem Isotyp und einer PBS Injektion. Das direkte und indirekte Infarktvolumen, das Hirnödem, die motorischen Defizite der Tiere sowie die Anzahl an überlebende Neuronen, wie auch die Anzahl an Iba-1 positive Zellen wurden zwischen den Gruppen verglichen. Es konnten mit dem verwendeten Modell, bis auf eine vorübergehende Signifikanz im 24 Stunden Bederson-Score, zwischen der Isotyp und der Placebo Gruppe, die allerdings nach 48 Stunden verschwunden war, keine signifikanten Unterschiede zwischen behandelten und unbehandelten Tiere festgestellt werden.

Daher wurde eine weitere MCAO Versuchsreihe durchgeführt. Bei dem zweiten Modell erfolgte die Applikation des TLR4 Antikörpers intravenös, in den retrookulären Venenplexus der Tiere. Die Injektion erfolgte direkt nach Ablauf der Reperfusionszeit sowie $24 \mathrm{~h}$ postoperativ. Die Okklusionszeit (45 min) und Reperfusionszeit (48 h) blieben bestehen. 


\subsection{Intravenöse TLR4-Antikörper Applikation im MCAO-Modell}

\subsubsection{Körpergewicht und Körpertemperatur}

Vor der MCAO-Induktion und postoperativ alle $24 \mathrm{~h}$ wurden Körpergewicht (Abbildung A) und -Temperatur (Abbildung B) der Tiere gemessen. Beobachtet wurden nach $24 \mathrm{~h}$ ein starker Gewichtsverlust der sich aber in den folgenden Stunden normalisierte und eine moderate Hypothermie der Tiere in allen Gruppen. Es konnten keine signifikanten Unterschiede zwischen den Antikörper-behandelten-Tieren (TLR4-Ab, $n=12$ ) und der Kontrollgruppe (PBS, $n=10$ ) festgestellt werden (Mann-Whitney-U-Test: Körpergewicht TLR4-Ab vs. PBS: $p=0,5$; Körpertemperatur TLR4-Ab vs. PBS: $p=0,2$ ). Dargestellt werden die Einzelwerte als Mittelwerte mit Standardabweichungen. Als Signifikanztest wurde stets der einseitige Mann-Whitney-U-Test verwendet.
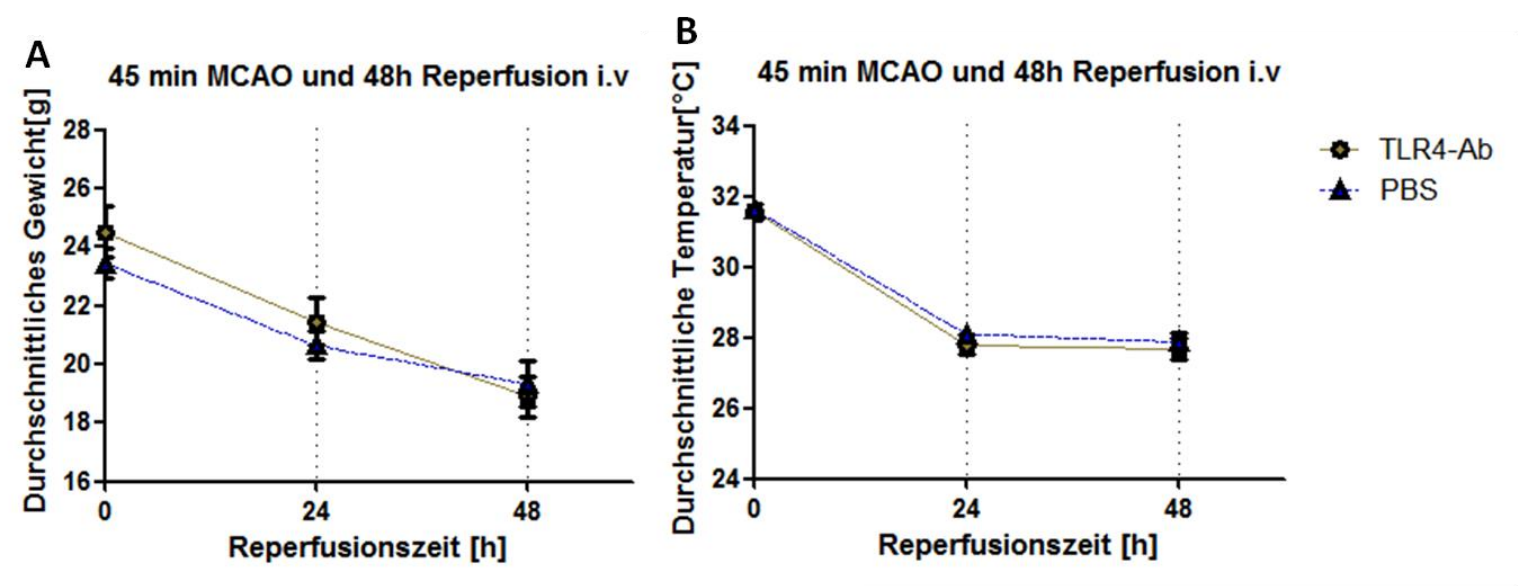

Abbildung 12: Gewichts- und Temperaturkontrollen der i.v. behandelten Mäuse.

(A) Entwicklung des mittleren Gewichts und (B) der mittleren Temperatur der Mäuse im 45-minOkklusions- und 48-h-Reperfusions-MCAO-Modell mit intravenöser Applikation über die Zeit $\left(n_{\mathrm{TLR} 4-\mathrm{Ab}}=12 ; n_{\mathrm{PBS}}=10\right)$.

\subsubsection{Infarktvolumetrie}

Die Infarktvolumetrie nach intravenöser Applikation des TLR4-Antikörpers (MTS 510) im Vergleich zur intravenösen Applikation von PBS als Placebo nach 45 Minuten MCAO und 48 Stunden Reperfusion zeigte signifikante Unterschiede. Es wurden insgesamt $2 \mu \mathrm{g}$ des MTS 510 Antikörpers, in $200 \mu$ PBS gelöst und pro Tier $(n=7)$ injiziert. Die halbe Dosis 
wurde direkt nach der Reperfusion und die andere Hälfte 24 h später appliziert. Die Placebo-Gruppe $(n=4)$ erhielt nur PBS.

Das direkte Infarktvolumen war in der mit dem Antikörper behandelten Gruppe deutlich geringer als in der Placebo-Gruppe (TLR4-Ab vs. PBS: $106,7 \pm 47,06 \mathrm{~mm}^{3}$ vs. $166,4 \pm$ $\left.21,18 \mathrm{~mm}^{3} \mathrm{PBS} ; p=0,0121\right)$. Das indirekte Infarktvolumen war nicht signifikant unterschiedlich (TLR4-Ab vs. PBS: $67,51 \pm 38,61 \mathrm{~mm}^{3}$ vs. $84,75 \pm 38,83 \mathrm{~mm}^{3} ; p=0,3242$ ). Im Unterschied dazu zeigte die Messung des Hirnödems signifikant geringere Ausprägungen in der mit dem Antikörper behandelten Gruppe (TLR4-Ab vs. PBS: 39,26 $\pm 14,3 \mathrm{~mm}^{3}$ vs. $\left.81,68 \pm 22,59 \mathrm{~mm}^{3} ; p=0,0121\right)$. Angewendet wurde der einseitige Mann-Whitney-U-Test.
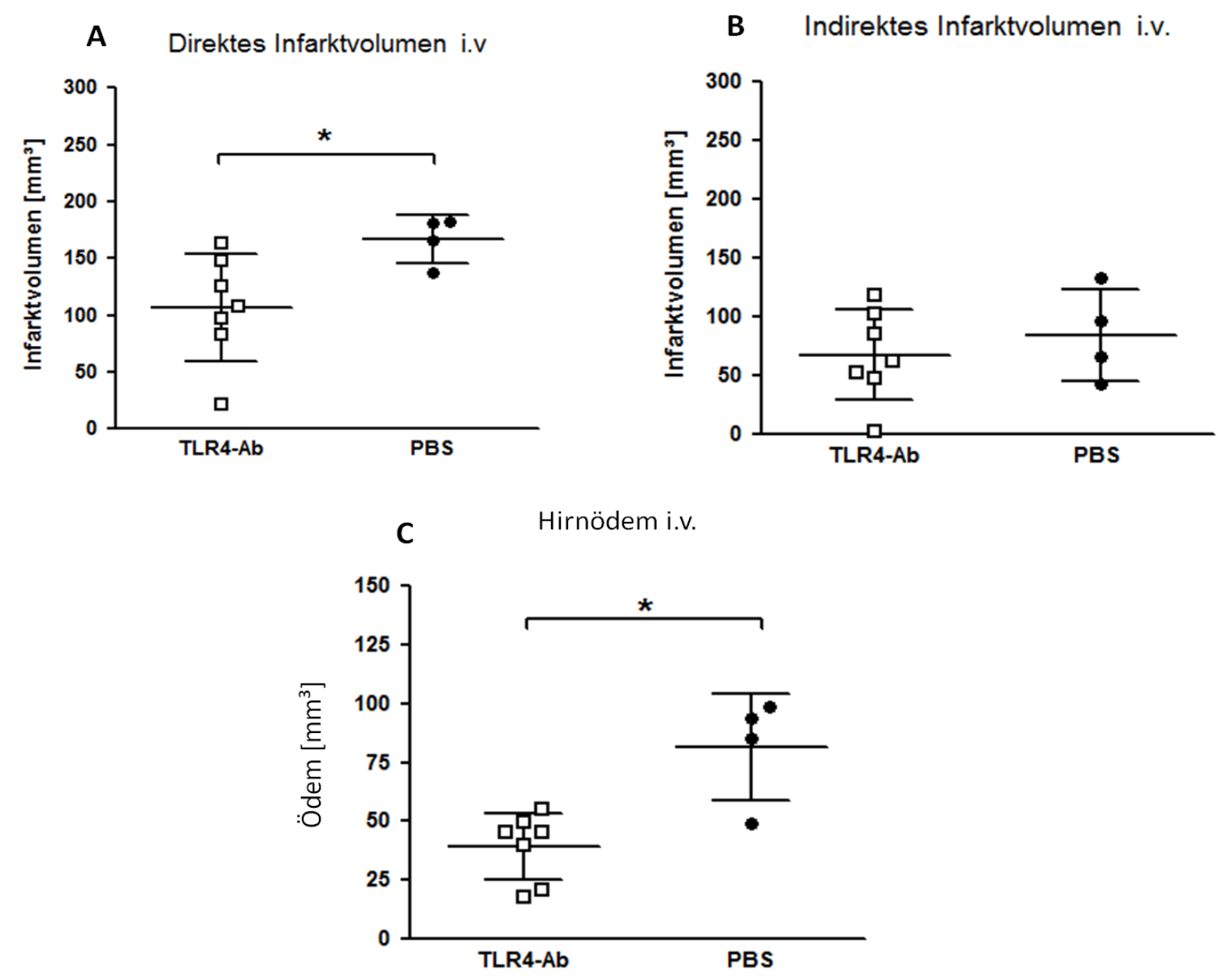

Abbildung 13: Direktes und indirektes Infarktvolumen und Hirnödem nach 45 Minuten MCAO und 48 Stunden Reperfusion bei intravenöser Applikation des TLR4-Antikörpers.

Behandelte Gruppe $\left(n_{\mathrm{TLR} 4}=7\right)$, Kontrollgruppe $\left(n_{\mathrm{PBS}}=4\right)$. Für die Auswertung wurde der einseitige Mann-Whitney-U-Test benutzt. In der Abbildung sind Mittelwerte \pm Standardabweichungen gezeigt. Signifikante Unterschiede waren beim direkten Infarktvolumen $(p=0,012)$ und dem Hirnödem $(p=0,012)$ darstellbar. $* p \leq 0,05$. 


\subsubsection{Neuroscore (Bederson-Score)}

Die Auswertung des neurologischen Defizites zeigte 24 Stunden und 48 Stunden postoperativ nach 45 Minuten MCAO kein signifikant besseres Ergebnis bei der mit dem TLR4-Antikörper behandelten Gruppe. Der Ausgangswert aller Tiere war der gleiche, sie zeigten präoperativ kein neurologisches Defizit, der Neuroscore lag somit bei 0 Punkten. Für die Auswertung wurden sowohl die Mäuse aus den Experimenten der Infarktvolumetrie, wie auch aus der Durchflusszytometrie eingeschlossen. Die Placebogruppe $\left(n_{\mathrm{PBS}}=13\right)$ und die Antikörpergruppe $\left(n_{\mathrm{TLR} 4-\mathrm{Ab}}=15\right)$ zeigten nach $24 \mathrm{~h}$ und $48 \mathrm{~h}$ keinen signifikanten Unterschied im neurologischen Score. Ergebnisse Bederson-Score nach 48 h: TLR4-Ab vs. PBS: $2 \pm 1,5$ vs. $1,92 \pm 1,45 ; p=0,4$ (Abbildung B). Ergebnisse Bederson-Score nach 24 h: TLR4-Ab vs. PBS: $2 \pm 1,13$ vs. $2,3 \pm 1,25 ; p=0,2$ (A).
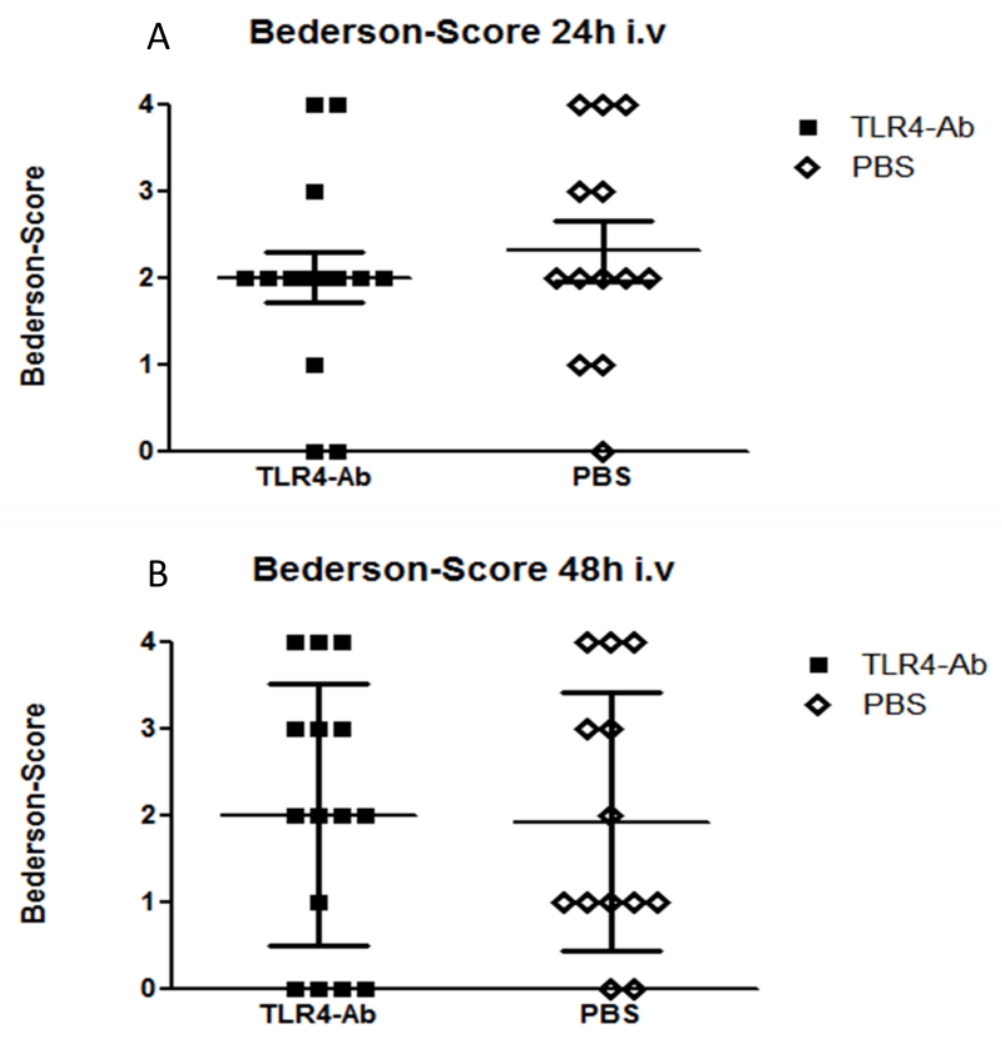

Abbildung 14: Bederson-Score 24 und 48 Stunden postoperativ nach 45 min MCAO und 48 h Reperfusion bei i.v. Applikation des TLR4-Antikörpers.

Der modifizierte Bederson Test wurde verwendet. Alle Tiere zeigten präoperativ einen Neuroscore von 0 (kein Defizit). (A) $24 \mathrm{~h}$ postoperativ, (B) $48 \mathrm{~h}$ postoperativ zwischen TLR4-Ab Gruppe $(n=15)$ und PBS Gruppe $(n=13)$. Für die Auswertung wurde der einseitige MannWhitney-U-Test angewendet. Angezeigt ist der Median und Standardabweichungen. 


\subsubsection{Durchflusszytometrie}

Mittels Durchflusszytometrie wurde die inflammatorische zelluläre Antwort des angeborenen und des adaptiven Immunsystems nach 45 Minuten MCAO und $48 \mathrm{~h}$ Reperfusion in den verschiedenen i.v. Interventionsgruppen an den Mäusen untersucht. Als "ipsi" wurde die ipsilaterale Hemisphäre mit dem Infarkt und als "kontra" die kontralaterale Hemisphäre bezeichnet, die beiden Hemisphären wurden getrennt analysiert. Verglichen wurde zwischen einer i.v. TLR4-Antikörper Gruppe $\left(n_{\mathrm{TLR} 4}=5\right)$ und einer i.v. PBS Gruppe $\left(n_{\mathrm{PBS}}=6\right)$. Die Applikation der Lösungen erfolgte immer am Zeitpunkt $24 \mathrm{~h}$ und $48 \mathrm{~h}$ postoperativ. Die Zellzahl wurde in absoluten Zahlen pro Gehirnhemisphäre bestimmt und auf $2 \times 10^{5}$ Zellen hochgerechnet. Hiernach wurden die Zellen im Durchflusszytometer mithilfe der Markierung von CD45.2 (Leukozyten) und deren Granulierung in bestimmte Populationen aufgetrennt. Diese wurden getrennt betrachtet und die CD11b positiven Zellen (aktivierte Makrophagen und Mikroglia und neutrophile Granulozyten) pro Gehirnhemisphäre bestimmt. Die Anzahl der CD45.2 positiven Zellen war in beiden Gruppen vergleichbar, sodass zwischen den ipsilateralen Seiten der beiden Gruppen kein signifikanter Unterschied gesehen werden konnte: TLR4-Ab vs. PBS: $6034 \pm 3767 / 2 \times 10^{5}$ Zellen vs. $5927 \pm 3099$ $12 \times 10^{5}$ Zellen; $p=0,5$. Die Zellzahl der CD11b+ Zellen (Makrophagen und Mikroglia) war ipsilateral, im Vergleich zwischen den beiden Gruppen, ebenso nicht signifikant unterschiedlich: TLR4-Ab vs. PBS: $1318 \pm 835,6$ vs. 453,7 \pm 528,6; $p=0,08$. Im Rahmen des dieses Versuches wurde auch die Reaktion des adaptiven Immunsystems im Schlaganfall unter Blockierung des TLR4-Rezeptors untersucht. Die T-Zellen wurden mit einem Antikörper gegen den CD3-Membranrezeptor und die B-Zellen mit einem Antikörper gegen den CD45.b220-Membranrezeptor markiert. Die Anzahl der CD3+ Zellen war in der TLR4-Ab Gruppe auf der ipsilateralen als auch auf der kontralateralen Seite im Vergleich zu der PBS-Gruppe signifikant höher: T-Zellen ipsilateral: TLR4-Ab vs. PBS: 94,55 \pm 132,3 vs. $5,473 \pm 12,61 ; p=0,0039$; T-Zellen kontralateral: TLR4-Ab vs. PBS: 25,29 \pm 27,8 vs. $0,4 \pm 0,46 ; p=0,0170$. Bezüglich der Reaktion der B-Zellen (CD45.b220 +) konnte im Vergleich zwischen den beiden Gruppen kein signifikanter Unterschied ermittelt werden. Trotz ähnlicher B-Zellzahl auf der ipsilateralen (betroffenen) Seite von beiden Gruppen, wurde auf der kontralateralen (gesunden) Seite der TLR4-Ab Gruppe ein größerer, aber nicht signifikanter Anstieg der B-Zellzahl beobachtet. B-Zellen kontralateral: TLR4-Ab vs. PBS: $22 \pm 27,45$ vs. 3,25 $\pm 3,3 ; p=0,062$. B-Zellen ipsilateral: TLR4-Ab vs. PBS: $20,2 \pm 18,12$ vs. $20,8 \pm 17 ; p=0,42$ ). 
A Mikroglia

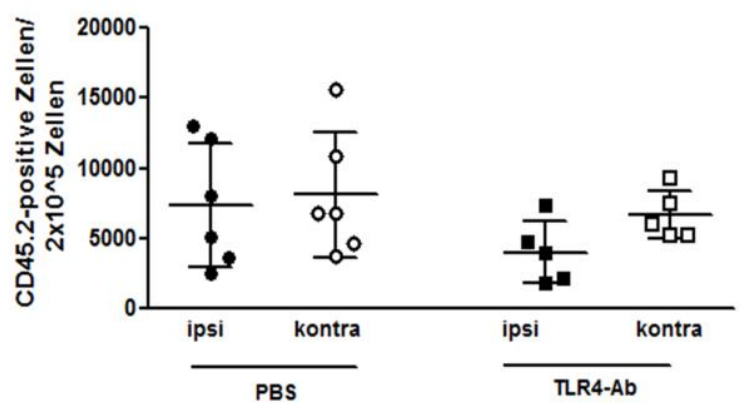

B aktivierte Makrophagen und Mikroglia

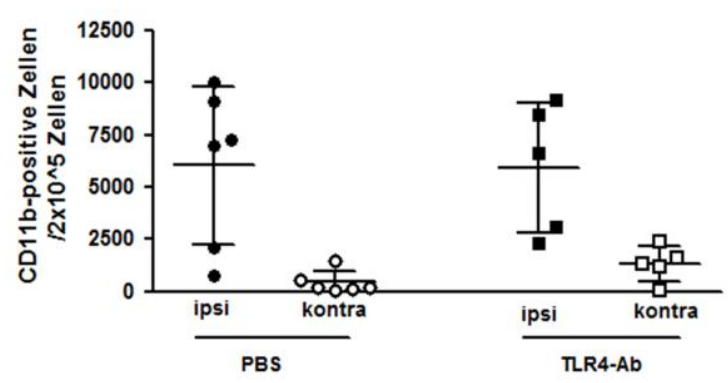

Abbildung 15: Zellzahl der inflammatorischen Zellen pro Hemisphäre nach i.v. Applikation des TLR4-Antikörpers nach 45 Minuten MCAO und 48 Stunden Reperfusion.

Es erfolgte die intravenöse Applikation des TLR4-Antikörpers in der behandelten Gruppe $\left(n_{\text {TLR4-Ab }}=5\right)$ und die Applikation von PBS in der Placebogruppe $\left(n_{\mathrm{PBS}}=6\right) . \mathrm{CD} 45 \cdot 2+$ Zellen (Leukozyten) sind alle pro Gehirnhemisphäre ipsilateral (ipsi) und kontralateral (kontra) in absoluten Zahlen angezeigt. Davon sind die CD11b+ Zellen die aktivierten Makrophagen und Mikroglia. Zu sehen ist Mittelwert \pm Standardabweichung. Angewendet wurde der Mann Whitney $U$-Test, ${ }^{*} p \leq 0,05$. 
T-Zellen

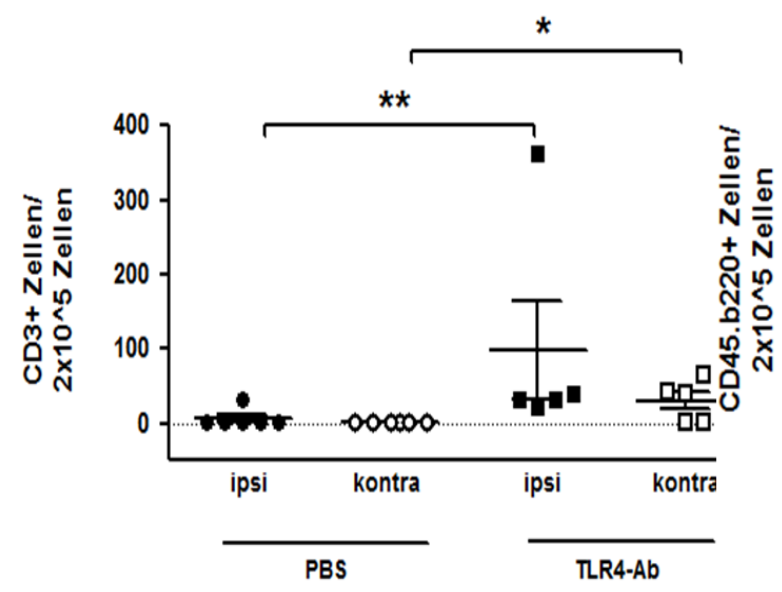

B-Zellen

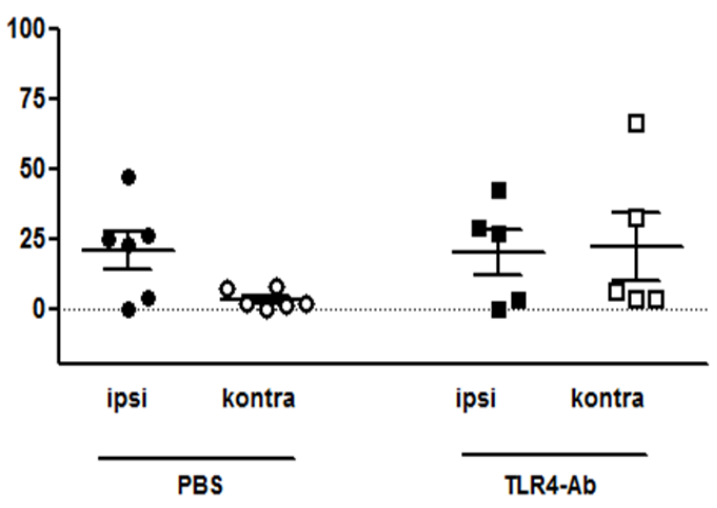

Abbildung 16: Analyse der zellulären Antwort des adaptiven Immunsystems nach 45 min MCAO und 48 h Reperfusion bei i.v. TLR4-Antikörper Applikation.

Beobachtet wurde ein signifikant höherer Anstieg der T-Zell Immunantwort bei denen mit dem TLR4-Antikörper behandelten Tieren sowohl auf der ischämischen (ipsi) als auch auf der gesunden (kontra) Seite im Vergleich zu denen mit PBS behandelten Tiere (A). Auf der kontralateralen Seite der TLR4-Ab Gruppe wurde im Vergleich zu der PBS Gruppe eine vermehrte B-Zell Reaktion beobachtet (B) die aber keine Signifikanz zeigte. Angezeigt werden Mittelwert \pm Standartdifferenz. Angewendet wurde der Mann-Whitney-U-Test. * $p \leq 0,05$. 


\subsection{Therapeutische Schlaganfallforschung und das Potential einer TLR4 Blockierung im Schlaganfallmodell.}

Der Schlaganfall ist und bleibt eine der häufigsten Todesursachen und der häufigste Grund für erworbene Behinderungen in der modernen Welt (Heuschmann et al. 2010). Die derzeitigen akuten Behandlungsmöglichkeiten sind auf eine Thrombolyse durch rtPA und die Rekanalisationstherapie mit mechanischer Thrombektomie begrenzt (Kolominsky-Rabas et al. 2006). Daneben steht ein großes Patientenkollektiv entweder aufgrund von Überschreitung des Thrombolyse-Therapiefensters von 4,5 Stunden oder wegen diversen Kontraindikationen (siehe Kapitel 1.1.2), bei denen diese Interventionen nicht möglich sind (Leitlinie ischämischer Schlaganfall 2012 und Ergänzung von 2015). Außerdem ist die weitere Behandlung, die auf zwei Säulen steht, nämlich die Sekundärprophylaxe und die Neurorehabilitation, sehr langwierig- und kostenintensiv und eine große sozioökonomische Belastung (Kolominsky-Rabas et al. 2006). Die zunehmende Lebenserwartung und die veränderte Lebensführung von heute hat als Konsequenz einen demographischen Wandel, der tendenziell zu einer Zunahme der älteren Population führt und trotz Verbesserung der Versorgung eine überproportionale Steigerung der Schlaganfallinzidenz zu erwarten lässt (Foerch et al. 2008). Aus den oben genannten Gründen wird die Forschung und Entwicklung von neuen Therapieansätzen zur Prophylaxe und Akutbehandlung des Schlaganfalls immer dringender.

Ein möglichst viel versprechender Therapieansatz für die zukünftige Akutbehandlung des Schlaganfalls scheint in der Schadensbegrenzung durch eine Hemmung der postischämischen Immunreaktion, die einem Schlaganfall folgt (Trendelenburg und Dirnagl 2005), zu sein. Noch in der subakuten Phase nach einem Schlaganfall kommt es zur Aktivierung von ortsständigen Immunzellen sowie zur Einwanderung von inflammatorischen Zellen ins Hirngewebe durch die beschädigte Blut-Hirn-Schranke. Dies führt wiederrum zu einer ausgeprägten Immunantwort, die eine Ödembildung und Freisetzung von proinflamatorischen Zytokinen und toxischen Sauerstoffradikalen hervorruft, die das Hirngewebe weiter schädigen und eine schlechtere Prognose mit sich bringen (Dirnagl et al. 1999). Ein potentieller Weg eine Hemmung der Immunantwort zu erreichen, ist die Inaktivierung des TLR4 Rezeptors und seiner Transduktionskaskaden. Diverse Forschungsgruppen haben sich mit diesem Thema beschäftigt: Schon 2007 wurde, im Modell der permanenten zerebralen Ischämie mittels MCAO, an TLR4 defizienten Mäusen eine protektive Wirkung in Bezug auf Infarktvolumen und neurologisches Outcome nach 2 und 7 Tagen postischämisch ge- 
zeigt (Caso et al. 2007). 2008 bewies die gleiche Gruppe, ebenso mit Hilfe des permanenten MCAO-Modells und nach vorheriger Durchführung eines Immobilisationsstresses (die Tiere wurden jeweils für eine Stunde über sieben Tage im wachen Zustand immobilisiert, was zu Ausschüttung von Stresshormonen führte), dass TLR4 defiziente Mäuse eine mildere Immunreaktion mit geringerer Ausschüttung von Cyclooxygenase-2 (COX-2) und NO, sowie kleinere Infarkte im Vergleich zu Wild-Typ-Mäusen zeigten (Caso et al. 2008). Darüber hinaus wurden 2010, TLR3, TLR4 und TLR9 defiziente Mäuse in einem MCAO Modell mit 2 Stunden Okklusion und 24 Stunden Reperfusion mit Wild-Typ Mäuse verglichen. Sowohl das Infarktvolumen als auch das Infarktareal waren bei den TLR4-KnockOut Mäusen signifikant kleiner, bei den TLR3 und 9 aber nicht. Die Motorik war ebenso bei den TLR4-Knock-Out Mäusen besser, sie hatten weniger aktivierte Mikroglia im Infarktareal und eine geringere Ausschüttung von NFkB. Somit wurde nachgewiesen, dass die Ausschaltung des TLR4 Rezeptors, aber nicht die des TLR3 oder TLR9 Rezeptors, eine besondere Rolle im Infarktgeschehen spielt (Hyakkoku et al. 2010).

Nachdem es mehrere Hinweise dafür gab, dass der TLR4 und seine Beteiligung im Schlaganfallgeschehen ausschlaggebend für die weitere Prognose sind, wurden Versuche unternommen diesen Rezeptor pharmakologisch zu blockieren, um die Auswirkungen zu evaluieren. Mittels Resatorvid (TAK 242), einem TLR4 Signalinhibitor, wurde im MCAO Modell mit 2 Stunden Okklusion und 22 h Reperfusion an Wild-Typ Mäusen der TLR4 Rezeptor blockiert. Die Applikation erfolgte intrazerebroventrikulär, direkt nach Ablauf der Reperfusionszeit. Gezeigt werden konnte, dass sich die TLR4 Inhibition protektiv auf die Infarktgröße auswirkt, das neurologische Outcome bessert und vor oxidativem Stress schützt (Suzuki et al. 2012). Auch vorausgehende interne Versuche aus unserer Arbeitsgruppe durch die Doktorandin Sarah Grünewald zeigten, dass sich im MCAO Modell mit 45 min Okklusion und 48 Stunden Reperfusion die TLR4/MD2 Komplex Blockierung mit dem MTS 510 Antikörper protektiv auf Infarktvolumen und Neuroscore auswirkt bei intraarterieller Applikation direkt vor der Okklusion (Andresen et al. 2016). Im aktuellen Versuch zeigte die intraperitoneale Applikation des MTS 510 Antikörpers nach 45 min MCAO und 48h Reperfusion keine signifikanten Unterschiede in Bezug auf Infarktgröße, neurologischen Score oder das Überleben von Neuronen zwischen den beiden Gruppen. Mit der intravenösen Applikation unter identischen Bedingungen konnten allerdings das direkte Infarktvolumen und das Hirnödem signifikant reduziert werden. Diese Ergebnisse deuten auf eine bessere Wirkung des Antikörpers je früher, direkter und näher er an der 
Infarktregion appliziert wird und lassen eine schnelle Verstoffwechselung durch die Leber und eine schlechte Gewebsdurchgängichkeit vermuten.

In einem ähnlichen Modell der zerebralen Ischämie bei Mäusen mittels MCAO mit 45 min Okklusion und 24 Stunden Reperfusion ergab der Versuch eine neuroprotektive Wirkung durch Blockierung des TLR2 Rezeptors mit einer intraarteriellen Applikation des antiTLR2-Antikörpers T2.5 bei Wild-Typ Mäusen im Vergleich zu TLR2 defizienten Mäusen (Ziegler et al. 2011). Allerdings wiesen Langzeitversuche nach transientem MCAO und 7 Tage Reperfusion bei TLR2-Knockout Mäusen auf eine verspätete Immunreaktion mit schlechterem Outcome als bei Wild-Typ Tieren hin (Bohacek et al. 2012). Eine negative Auswirkung der Langzeitblockierung des TLR4-Rezeptors konnte intern in unserer Arbeitsgruppe von der Doktorandin Lena Andresen, bei 15 min MCAO sowie 7 und 14 Tage Reperfusion nach i.a. Applikation des MTS 510 Antikörpers nicht festgestellt werden (Andresen et al. 2016). Somit ist die TLR4-Blockierung ein besser geeigneter Therapieeinsatz sowohl kurz als auch langfristig nach einem ischämischen Schlaganfall.

Wichtig zu erwähnen ist, dass die Aktivierung und Beteiligung des TLR4 Rezeptors als relevant für die Prognose nach einem Schlaganfall, auch bei Menschen, im Rahmen einer Studie nachgewiesen werden konnte (Brea et al. 2011). 110 Schlaganfallpatienten vergleichbaren Alters und mit ähnlichen Komorbiditäten wurden in dieser Studie mit einbezogen. Als Kontrollgruppen wurden 60 gesunde Patienten verwendet. Das neurologische Outcome der Patienten wurde mit dem Modified Rankin Scale (mRS-Score) beurteilt. Dieser Score hat 7 Stufen und es können maximal 6 Punkte erreicht werden; von 0 für kein neurologisches Defizit bis 6 was den Tod durch den Apoplex bedeutet (Cheng et al. 2014). Als gutes Outcome wurde ein mRS-Score $\leq 2$ ( 2 = leichte Beeinträchtigung, kann sich ohne Hilfe versorgen, ist aber im Alltag eingeschränkt) nach 3 Monate betrachtet, höhere Werte als schlechtes Outcome. Verglichen wurden der mRS-Score mit der Expression des TLR4 in Monozyten im Blut der Patienten an verschiedenen Zeitpunkten (bei Aufnahme, nach 24 h, 48 h, 72 h und 7 Tagen) nach einem Schlaganfall. Das Infarktvolumen der Patienten wurde mit Hilfe von der Computertomographie (CT) bestimmt. Gezeigt wurde, dass Patienten mit einem schlechteren mRS-Score, eine erhöhte Expression von TLR4 im Blut hatten. Außerdem hatten Patienten mit größerem Infarktvolumen und hohe Konzentrationen an IL-6, IL-1ß, TNF- $\alpha$ und VCAM1 auch eine höhere Expressionen des TLR4. Dies deutet daraufhin, dass sich die TLR4 Blockierung auch als ein potentieller Therapieansatz bei Menschen gut anbietet. 


\subsection{Methoden und Ergebnisdiskussion}

Die durchgeführte tierexperimentelle Studie wurde auf der Basis von früheren Arbeitsgruppen- und Team -internen Arbeiten am Schlaganfallmodel konzipiert, um einen Vergleich zwischen den erzielten Ergebnissen zu ermöglichen. Als am besten geeignet wurde ein mittelschweres Kurzzeit-MCAO-Modell mit 45 Minuten Okklusion und 48 Stunden Reperfusion ausgewählt. Zur Blockierung des TLR4 wurde der TLR4/MD2 RezeptorAntikörper-Klon MTS 510 aus der Ratte verwendet. Vor Anwendung wurde die Wirksamkeit des Antikörpers durch unsere Gruppe in einem in vitro Versuch mit Anwendung einer Zellreihe von murinen Makrophagen und Inkubation mit dem Antikörper, einer Aktivierung durch LPS und Bestimmung des Endproduktes (TNF- $\alpha$ ) überprüft (Andresen et al. 2016).

\subsubsection{Induktion eines ischämischen Schlaganfalls und Auswertung der Infarktgröße}

Für die Durchführung dieses Versuches benötigten wir ein Modell der zerebralen Ischämie, was bei Tieren ohne größere Risiken angewendet werden kann, der Entstehung eines ischämischen Schlaganfalls, vom Menschen ähnel, und gut reproduzierbar ist. Mäuse und Ratten haben eine dem Menschen sehr ähnliche arterielle Gefäßversorgung des Gehirns, sodass sie sich am besten für Schlaganfallmodelle eignen (Rami et al. 2008). Es gibt verschiedene Modelle der zerebralen Ischämie: Die intraluminale Naht, die Photothrombosis, das embolische Modell, direkte Ischämien nach Kraniotomie und das MCAO-Modell (Fluri et al. 2015). Das MCAO-Modell hat sich allerdings, aufgrund seiner hohen Reproduzierbarkeit, der guten Kontrolle über die Okklusions- und Reperfusionszeit, wegen der Entstehung einer Penumbra Region (wie beim Menschen) und wegen des geringeren invasiven Risikos für das Tie, gegenüber den anderen Modellen durchgesetzt. Anderseits weist das Modell verschiedene Nachteile, wie ein erhöhtes Blutungsrisiko, eine hohe Abhängigkeit von der Erfahrung des Operateurs und der Infarktgröße von der Beschaffenheit des Filaments auf (Fluri et al. 2015). Um diese Nachteile so weit wie möglich zu minimieren wurden die Tiere in diesem Versuch stets durch dieselbe Person operiert und es wurden für diese Arbeit ausschließlich kommerziell erworbene Silikon-überzogene Filamente eingesetzt.

Für die Bestimmung des Infarktvolumens stehen verschiedene invasive und nicht invasive Methoden zu Verfügung. Zu den nicht invasiven Methoden gehören z. B. die Computer- 
tomographie (CT) oder die Magnetresonanztomographie (MTR), die allerdings aufwendig und kostspielig sind und keine Aussage über das Geschehen auf zellulärer Ebene erlauben (Zille et al. 2012). Diesen gegenüber stehen die invasiven Methoden, die das Hirngewebe erst postmortal nach Extraktion untersuchen und eine Aussage über das Endergebnis erlauben. $\mathrm{Zu}$ Verfügung stehen histologische Methoden wie z. B. die Färbung des Gewebes mittels Hämatoxylin-Eosin-Färbung (HE) (Eidizadeh et al. 2015) oder die Färbung mittels 2,3,5-Triphenyltetrazoliumchlorid (TTC), wie in dieser Arbeit. Vorteil der TTC Methode ist die einfache Durchführung und die Möglichkeit das gesamte Infarktvolumen zu bestimmen (Zille et al. 2012).

Initial wurde ein Versuch mit drei verschiedenen Gruppen (siehe Kapitel 2.2.2) durchgeführt. Die Okklusionszeit betrug 45 Minuten, die Reperfusionszeit 48 Stunden. Die Behandlung der Tiere erfolgte intraperitoneal (i.p) mit dem Anti-TLR4/MD2 Antikörper direkt nach der Reperfusion und 24 Stunden danach (siehe Kapitel 2.2.3). Nach Ablauf der Reperfusionszeit wurden die Tiere euthanasiert und die Gehirne wurden entnommen. Mit Hilfe der TTC-Färbung wurden das direkte und das indirekte Infarktvolumen sowie das Hirnödem bestimmt. Nach Auswertung der Ergebnisse zeigte die intraperitoneale Applikation von insgesamt $2 \mu \mathrm{g}$ des Antikörpers keine positive Auswirkung auf Infarktgröße oder Hirnödem. Allerdings zeigten zum gleichen Zeitpunkt von der Doktorandin S. Grünewald, in unserem Labor, laufende Versuche mit intraarterieller Applikation des gleichen Antikörpers, noch vor der Okklusion der A. cerebri media, hoch signifikante Ergebnisse. Somit stellten sich gleichzeitig zwei Fragen: Einerseits warum es so einen großen Unterschied zwischen den beiden Versuchsreihen gab und anderseits, ob es einen Applikationsweg gibt, der sowohl die gewünschte Wirkung zeigt als auch klinisch relevant ist und erst nach dem ischämischen Schlaganfall seine Anwendung erlaubt.

Verschiedene Hypothesen können zur Beantwortung der ersten Fragestellung betrachtet werden: Eine nicht ausreichende Konzentration des Antikörpers bei der intraperitonealen Applikation wäre eine mögliche Ursache. Um das zu überprüfen müssten mehrere Versuchsreihen mit verschiedenen Antikörperkonzentrationen durchgeführt werden, um die richtige Menge zu eruieren. Dies wäre aber mit sehr hohen Kosten und einem unsicheren Ergebnis verbunden. Ein weiterer Faktor bei dem intraperitonealen Versuch könnte die zu schnelle Metabolisierung des Antikörpers durch die Leber darstellen. Eine komplette Ausscheidung des Antikörpers über die Niere wäre eine andere mögliche Ursache. Um dies auszuschließen, wäre eine Messung der Antikörperkonzentration im Gehirn und im Urin 
nach Ablauf des Versuchs sinnvoll. Da aber eine intraperitoneale oder intraarterielle Applikation für die klinische Anwendung nicht praktikabel sind, wendeten wir uns der zweiten Fragestellung zu und überlegten, wie wir die Antikörperapplikation klinisch relevanter durchführen könnten mit der Hoffnung das Ergebnis aus dem intraarteriellen Versuch reproduzieren zu können. Die intravenöse Injektion des Antikörpers schien eine gute Alternative zu bieten. Auf diesem Weg könnte die potentielle neuroprotektive Wirkung der TLR4-Inaktivierung nach einem Schlaganfall in einem klinisch relevanteren Modell untersucht werden und parallel einige der Hypothesen aus der ersten Fragestellung möglicherweise geklärt werden.

Das zweite Experiment erfolgte unter identischen Bedingungen wie der intraperitoneale Versuch. Allerdings wurden nur zwei Gruppen miteinander verglichen. Auf eine IsotypKontrollgruppe konnte verzichtet werden, da schon im vorangegangenen Versuch gezeigt wurde, dass alleine die Applikation eines strukturähnlichen Antikörpers, der aber nicht für die Inaktivierung des TLR4-Rezeptors geeignet ist, nicht ausreicht um Veränderungen bei den gemessenen Parametern hervorzurufen. Die intraveenöse Applikation wurde, wie schon im Detail beschrieben, im retrobulbären Venenplexus der Maus direkt nach der Reperfusion sowie $24 \mathrm{~h}$ später durchgeführt. Es wurden pro Tier entweder insgesamt $2 \mu \mathrm{g}$ MTS510-Antikörper in PBS oder nur PBS als Placebo gespritzt.

Die Infarktvolumetrie erfolgte ebenso mit der TTC Färbung. Dieses Mal zeigte sich eine neuroprotektive Wirkung des Antikörpers in Bezug auf das direkte Infarktvolumen und das Hirnödem. Dieses Ergebnis konnte zwar den Effekt aus dem i.a. Versuch nicht erreichen, bestätigte aber die Hypothese, die sich aus dem i.a. Versuch ergab, dass die Blockierung des TLR4 Antikörpers neuroprotektiv ist und kleinere Infarkte sowie weniger Hirnödem mit sich bringt. Die intravenöse Applikation erfolgte im retrobulbären Venenplexus, also viel näher am Ort des Geschehens, als bei der intraperitonealen Applikation, aber trotzdem nicht unmittelbar im Versorgungsgebiet der A. cerebri media, wie bei dem intraarteriellen Versuch. Durch die kürzere Strecke, die der Antikörper überwinden musste und der Tatsache, dass er sich schon im Gefäßsystem befand und nicht erst peritoneal resorbiert werden musste und durch die schon gestörte Blut-Hirn Schranke, konnte vermutlich eine höhere Dosis des Antikörpers in die Infarktregion gelangen. Eine noch höhere Antikörperdosis und somit eine breitere Blockierung des Rezeptors hätte möglicherweise die gleichen Ergebnisse erzielt. In weiteren Versuchen könnte daher die Bestimmung des besten DosisWirkungsverhältnisses durch eine Konzentrationsreihe des Antikörpers sinnvoll sein. 


\subsubsection{Beurteilung des neurologischen Defizites}

Schlaganfallpatienten sind oft in der Lage selbst Auskunft über ihre motorischen Einschränkungen zu geben. Ein Vergleich zwischen vor und nach dem Schlaganfall ist somit möglich und leichter zu erheben. Im Unterschied dazu können Tiere kein Feedback über deren neurologische Veränderungen angeben, deswegen sind wir auf präzise Beobachtungen und Tests angewiesen, um einen validen Neuroscore zu erheben.

Das neurologische Defizit wurde in diesem Versuch mit dem Bederson-Score bestimmt. In diesem Score wird besonders auf die Motorik der Tiere nach der Ischämie geachtet und typische Verhaltensmuster werden beurteilt und verglichen (Bederson et al. 1986). Da das Testergebnis potentiell vom Untersucher abhängig ist, ist es sehr wichtig dass er immer von der gleichen Person durchgeführt wird. Die untersuchende Person soll im Bezug auf die Art der Behandlung, die die Tiere erhalten haben, stets verblindet sein. So wurde es auch in diesem Versuch gemacht. Im intraperitonealen Versuch zeigte sich kein Unterschied zwischen Antikörper-behandelten und -unbehandelten Tiere. Allerdings zeigten die Tiere, die mit dem Isotyp behandelt worden waren, nach 24 Stunden einen schlechteren Neuroscore als die mit Placebo behandelte Gruppe. Dieser Unterschied verschwand aber nach 48 Stunden und konnte nicht mehr beobachtet werden. Dies lag daran, dass die Tiere aus der Isotyp-Gruppe rascher, schon in der ersten $24 \mathrm{~h}$, eine Verschlechterung ihrer Motorik zeigten aber deren Zustand im weiteren Verlauf weitgehend stabil blieb. Im Unterschied dazu zeigten die Tiere aus der PBS-Gruppe erst später, nach 48 h, eine Zunahme des motorischen Defizites, sodass am Ende der Experimentzeit, keiner signifikanter Unterschied zwischen den beiden Gruppen zu sehen war. Diese Beobachtung ist nicht einfach zu interpretieren. Die kleine Tieranzahl pro Gruppe könnte eine Rolle spielen indem eine gröBere Abweichung bei ein oder zwei Tieren einer Gruppe, eine Signifikanz hervorrufen könnte, die bei einer höheren Tierzahl nicht zu beobachten wäre. Anderseits könnte es aber auch an einem schädlichen Effekt des Isotyp-AKs liegen, der eine schnellere Verschlechterung der Motorik, durch stärkere Aktivierung des Immunsystems verursacht, als das Placebo, wie auch im TLR-2 Blocking Versuch von G. Ziegler beobachtet werden konnte (Ziegler et al. 2011) .Bei diesem Versuch verschwand aber die Tendenz im Laufe des weiteren Versuchs und die Tiere aus der Isotyp-Kontrollgruppe hatten nach Ablauf der Untersuchungszeit wieder einen schlechteren Neuroscore noch größere Infarkte in der Infarktvolumetrie im Vergleich zu der Placebo Gruppe sodass es davon auszugehen war, dass das Isotyp keinen relevanten Einfluss auf die Ergebnisse haben könnte. 
Trotz der kleineren Infarkte und des kleineren Hirnödems der mit dem Antikörper behandelten Gruppe, konnte auch im Rahmen des intravenösen Versuchs kein Unterschied, im Neuroscore, zwischen den beiden Gruppen beobachtet werden. Dies widerspricht sich mit dem Ergebnis aus dem intraarteriellen Versuch und den Versuchen, die an TLR4 defizienten Tieren durchgeführt wurden (Cao et al. 2007; Caso et al. 2007). Möglicherweise zeigt dieses Ergebnis, dass Unterschiede in Infarktgröße und Ödem nicht unbedingt eine unmittelbare Auswirkung auf die Motorik haben müssen oder, dass der verwendete Neuroscore eventuell zu grob ist um feine motorische Defizite zu erfassen. Weiterhin könnten der Zeitpunkt der Applikation des Antikörpers (erst nach der Induktion des Schlaganfalls) oder eine unzureichende Konzentration des Antikörpers, mögliche Gründe für dieses wiedersprechende Ergebnis sein. Bekannterweise ist der Score nach Bederson nur eine grobe Skala zu Erhebung des neurologischen Defizits nach einem Schlaganfall. Ein feingliedrigeres Bewertungssystem mit weiteren Einschlusskriterien oder andere motorische Tests könnten eventuell die Unterschiede in den Gruppen besser darstellen.

\subsubsection{Veränderungen auf zellulärer Ebene}

\subsubsection{Aktivierte Makrophagen und Mikroglia}

Um potentielle Unterschiede zwischen den untersuchten Gruppen auf zellulärer Ebene nachweisen zu können, wurden für den intraperitonealen Versuch immunhistologische Färbungen von Gehirnpräparate angefertigt. Gefärbt wurden die Iba-1 positiven Zellen. Iba-1 ist ein spezifischer Marker für aktivierte Makrophagen und Mikroglia. Die Zellzahl wurde dann mit Hilfe von Bildabschnitten, die digital angefertigt wurden, bestimmt und pro $\mathrm{mm}^{2}$ ausgerechnet (siehe Kapitel 2.2.8).

In den intravenösen Versuchen wurde wiederum die Anzahl der aktivierten Mikroglia und Makrophagen mit Hilfe der Durchflusszytometrie bestimmt. Diese Methode erlaubte uns, im Vergleich zu der Immunfluoreszenz, die gesamte Anzahl einer Zellreihe pro Hemisphäre zu bestimmen. Somit wollten wir ausschließen, dass eine Ansammlung von aktivierte Makrophagen und Mikroglia z.B. in einer Gehirnregion, die nicht in den vorgefertigte Bildabschnitten miteingeschlossen war, übersehen wurde.

Der TLR4, vor allem an Immunzellen zu lokalisieren, führt zu einer Aktivierung von Mikroglia und Makrophagen (Jin et al. 2013). Daraus lässt sich umgekehrt durch die Blockierung des TLR4 eine reduzierte Anzahl an aktivierten Mikroglia und Makrophagen vermuten. Die Anzahl der aktivierten Makrophagen und Mikroglia auf der ipsilateralen 
und der kontralateralen Seite unserer Versuchstiere wurden verglichen. Es konnte allerdings kein Unterschied zwischen den Gruppen nachgewiesen werden. Weder in der Immunfluoreszenz bei den intraperitoneal behandelten Tieren noch durchflusszytometrisch bei den intravenös behandelten Tieren zeigte sich im Vergleich zu der Placebo Gruppe eine reduzierte Anzahl an aktivierten Makrophagen und Mikroglia 48 Stunden postoperativ. Dies widerspricht den Ergebnissen des Versuches von (Hyakkoku et al. 2010) die immunhistochemisch zeigten, dass es bei TLR $4^{-/-}$Mäusen, im Vergleich zu Wild-Typ Tieren nach MCAO, eine geringere Anzahl von aktivierten Makrophagen und Mikroglia gibt. Diese Beobachtung stimmt aber mit dem gruppeninternen Versuch von S. Grünewald im intraarteriellen Modell überein. Auch im Versuch von (Ziegler et al. 2011) konnte mittels Blockierung des TLR2 Rezeptors nach 45 min MCAO und 48 Stunden Reperfusion keine signifikant geringere Anzahl an aktivierten Mikroglia und Makrophagen nach MCAO beobachtet werden, obwohl bei TLR2 defizienten Mäusen eine geringere Anzahl dieser Zellen beobachtet wurde (Ziegler et al. 2011). In der Studie (Sansing et al. 2011) an TLR4 ${ }^{-/-}$Mäusen konnten im Vergleich zu Wild-Typ Tieren nach einem Modell des hämorrhagischen Insults folgende Erkenntnisse gewonnen werden: Einerseits wurden drei Tage nach intrazerebraler Hämorrhagie (ICH) die CD11b+ Zellen ipsilateral immunhistochemisch markiert und die Anzahl davon an fünf verschiedenen Stellen um das Infarktareal bestimmt. Es konnte kein Unterschied zwischen der Anzahl der CD11b+ Zellen zwischen den beiden Genotypen in der Periinfarktregion gemessen werden, aber die Wild-Typ Tiere zeigten eine signifikant höhere Anzahl an großvakuoligen CD11b+ Zellen im Vergleich zu den TLR4 $^{-/-}$Tieren. Dies könnte ein Hinweis darauf sein, das der TLR4 außerhalb der Infarktregion keinen Einfluss auf die Anzahl der Makrophagen und Mikroglia hat, sondern nur auf deren Funktion/Aktivierungsgrad (Sansing et al. 2011). Angenommen, dass die pharmakologische Blockierung des TLR4 in unserem Versuch ebenso keinen direkten Einfluss auf die Anzahl der Mikroglia und Makrophagen hat, sondern nur auf deren Funktion, könnte dies die kleineren Infarktvolumina und das reduzierte Ödem, trotz gleiche Anzahl an Immunzellen erklären. Um das zu beweisen, könnten ebenso nach Blockierung des TLR4 immunhistochemisch die Anzahl der groß- und kleinvakuoligen CD11b+ Zellen und deren Produkte wie proinflammatorische Zytokine (z.B. IL1- $\beta$ oder TNF- $\alpha$ ) bestimmt werden. In der gleichen Studie (Sansing et al. 2011) zeigte sich im Rahmen der Durchflusszytometrie drei Tage nach ICH, aber nicht ein Tag nach ICH, eine signifikant höhere Anzahl an CD11b+ Zellen bei den Wild-Typ Tieren als bei den TLR4 ${ }^{-/-}$Tieren. In diesem Versuch wurde die Durchflusszytometrie aber schon 48 Stunden nach MCAO durchgeführt. Wie 
aber in der Studie von (Sansing et al. 2011) zu sehen ist, konnte kein Unterschied in der Anzahl der Makrophagen und Mikroglia nach 24 Stunden, sondern erst 72 Stunden nach der ICH beobachtet werden, es könnte möglicherweise so sein, dass nach 48 Stunden der maximale Peak an Monozyten gar nicht erreicht wurde und wir deswegen keinen Unterschied zwischen den beiden Gruppen sehen konnten. Interessant wäre die Anzahl der Zellen an verschiedenen Zeitpunkten zu messen, um einen doch bestehenden Unterschied an einem anderen Zeitpunkt nicht zu übersehen.

\subsubsection{Neuronenzahl}

In Bezug auf die Anzahl der überlebenden Neuronen wurden die Präparate mit der NeuNFärbung immunfluoreszierend gefärbt. Es wurden Bildabschnitte angefertigt, die stets eine Breite von $1 \mathrm{~mm}$ und die Länge der gesamten Hemisphäre hatten. Die Fläche des Areals wurde bestimmt und die Zellen wurden ausgezählt. Dann wurde die Anzahl der Zellen pro $\mathrm{mm}^{2}$ ausgerechnet. Diese Methode erlaubte einen zuverlässigen Vergleich zwischen den beiden Versuchsgruppen, bei dem absolute Zahlen miteinander verglichen wurden. Allerdings konnte bei dem intraperitonealen Versuch kein Unterschied zwischen den beiden Gruppen ermittelt werden. Ursachen dafür könnte an der verwendeten Methode liegen: Es wurde nur eine kleine Schnittebene mit einer Breite von $1 \mathrm{~mm}$ gemessen. Zwar liegt dieser Abschnitt im Bereich der größten Infarktausprägung, aber eventuell wären eine Beachtung von mehreren Ebenen und die Bestimmung des Mittelwertes aussagekräftiger. Ein weiterer Aspekt könnten Artefakte gewesen sein, entweder bedingt durch die Präparation oder durch das Hirnödem in den fluoreszenzmarkierten Arealen. Allerdings sind die Daten kongruent zu den Messungen aus der Infarktvolumetrie, in denen auch kein Unterschied zwischen den Gruppen festgestellt werden konnte.

Bei dem intravenösen Versuch wurde auf eine Bestimmung der Neuronenzahl verzichtet. Dies geschah aus folgenden Gründen: Die Ergebnisse der Neuronenauszählung aus dem intraarteriellen Versuch von S. Grünewald, der sonst sehr signifikante Unterschiede in der Infarktvolumetrie und im Neuroscore zeigte, lies in diesem Punkt keinen Unterschied zwischen den beiden Gruppen nachweisen und ein Unterschied in der Neuronenanzahl hätte im Rahmen des i.v. Versuches keine große Relevanz gehabt, da der Neuroscore auch keine Signifikanz zwischen den beiden Gruppen ergab, aber dafür eine große Anzahl an Versuchstieren zusätzlich hätte verwendet werden müssen.

\subsubsection{Die Anzahl der Lymphozyten, ein kontroverses Ergebnis}


Obwohl es mehrere Studien über den Zusammenhang zwischen der Aktivierung des TLR4 auf das Verhalten und die Funktion von Makrophagen und Mikroglia gibt, ist nur wenig über die Wechselwirkung zwischen TLR4 Aktivierung/Blockierung und die Immunantwort von Lymphozyten im ZNS bekannt. Vor allem T-Zellen wird eine wichtige Rolle im inflammatorischen Prozess durch die Freisetzung von IL-17, INF- $\gamma$ oder IL-4 nach einem ischämischen Schlaganfall zugeschrieben, der zu einer erhöhten Morbidität und Mortalität durch Immunsuppression und sekundäre Infektionen führt (Gu et al. 2015). Versuche an Tund B-Zell defizienten Mäusen zeigten kleinere Infarkte und geringere Entzündungsparameter nach 90 Minuten MCAO und 22 Stunden Reperfusion (Hurn et al. 2007). Der TLR4 wird bekanntermaßen auch an Lymphozyten wie T und B Zellen exprimiert, somit lässt seine Blockierung eine geringere Anzahl von Lymphozyten bei den behandelten Tieren vermuten. Im Rahmen der intravenösen Blockierung des TLR4 Rezeptors mit dem antiTLR4/MD2 Antikörper wurden die T-Zellen (CD3 positiv) und die B-Zellen (CD45.b220 positiv) (Brait et al. 2010) markiert und eine Durchflusszytometrie wurde durchgeführt, um die Anzahl an Lymphozyten pro Gehirnhemisphäre zu bestimmen. Die o.g. Hypothese ließ sich allerdings nicht bestätigen. Interessanterweise zeigten sogar die Versuchstiere aus der mit dem Antikörper behandelten Gruppe eine höhere Anzahl an T-Zellen sowohl ipsilateral als auch kontralateral im Vergleich zu der Kontrollgruppe. Die Anzahl an B-Zellen war in der behandelten Gruppe auch tendenziell erhöht aber nicht signifikant. Wie ist dieser Effekt der TLR4 Blockierung auf die Lymphozyten zu erklären?

Derkow et al. zeigten 2015, dass aktivierte Mikroglia über die TLR 2, 4 und 9, durch die Freisetzung von proinflammatorischen Zytokinen, zu einer Polarisierung von $\gamma \delta$-T-Zellen zu neurotoxischen $\mathrm{IL}-17^{+}-\gamma \delta$-T-Zellen führen und somit zur Verschlechterung der Prognose nach einem Schlaganfall beitragen können (Derkow et al. 2015). Wenn also die Aktivierung der T-Zellen von der Zytokinfreisetzung durch die aktivierten Mikroglia abhängt und die Blockierung des TLR4, wie in diesem Versuch gezeigt wurde, keinen Einfluss auf die Anzahl der aktivierten Mikroglia hat, ist eine reduzierte Anzahl an T-Zellen auch nicht zu erwarten. Aber was könnte zu der erhöhten Anzahl an T-Zellen beitragen und welcher pathophysiologische Mechanismus hat letztendlich zu den kleineren Infarkten und dem reduzierten Hirnödem geführt? Eine Hypothese wäre, dass T-Zellen wie CD4 ${ }^{+}$-Th2 Zellen oder Treg Zellen die bekanntermaßen in Reparaturmechanismen mitbeteiligt sind und neuroprotektive Wirkungen haben, eine Rolle spielen (Xin et al. 2012; Jones et al. 2015). Die genaue Differenzierung der T-Zellen in weiteren Versuchen könnte mehr Klarheit darüber 
bringen, welche Rolle sie im Schlaganfall haben und wie sie durch den TLR4 beeinflusst werden.

\subsection{Die klinische Translation der experimentellen Therapieansätze an Menschen schlägt häufig fehl, was steckt dahinter?}

Bis zum Jahr 2012 konnten nur insgesamt drei Phase III klinische, randomisierte Studien im Bereich des ischämischen Schlaganfalls komplettiert werden (NINDS; PROACT II; ECASS III) (Furlan 2012). Alle drei beschäftigten sich mit der Reperfusionstherapie nach einem Apoplex und dabei ergab sich die heute einzig zugelassene medikamentöse Akutbehandlung mit rtPA die zeigte, dass eine Lysetherapie möglich ist und somit die Schlaganfallbehandlung revolutionierte (Furlan 2012). Allerdings ist diese Therapiemöglichkeit mit einem sehr engen Therapiefenster und vielen Ausschlusskriterien verbunden und daher nicht für alle Patienten geeignet (Heuschmann et al. 2010). Im Jahr 2015 wurden 5 voneinander unabhängige, randomisierte klinische Studien publiziert, die sich mit der mechanischen Thrombektomie beschäftigeten (ESCAPE, EXTEND-IA, MR CLEAN, REVASCAT und SWIFT-PRIME)(Goyal Mayank et al. 2016). Diese Studien zeigten, dass die mechanische Rekanalisation von großen Hirngefäße wie z.B die A. carotis interna als Ergänzung zu der Lysetherapie mit rTPA ein verbessertes klinisches Outcome verspricht (Goyal Mayank et al. 2016). Die endovaskuläre Therapie bietet also eine Erweiterung der Therapie des akuten Schlaganfalls ersetzt aber die bisher gut erprobte Lysetherapie nicht.

Obwohl bis heute diverse tierexperimentelle Modelle zu Schlaganfallbehandlung vielversprechende Ergebnisse geliefert haben, konnte bislang keine randomisierte klinische Studie, die die Phase III erreichte, einen neuroprotektiven Effekt zeigen (Furlan 2012). Die Übertragung von Ergebnisse aus Tiermodellen auf den Menschen stellt sich als sehr schwierig und weitgehend erfolglos dar (O'Collins et al. 2006). Aber woran das liegt, ist nicht ganz klar. Mögliche Hypothesen, die dieses Phänomen erklären könnten, sind folgende: Die Verfügbarkeit der rtPA Therapie macht es besonders aus ethischer Seite schwierig alternative bzw. Placebobasierte klinische Studien durchzuführen. Insofern macht diese Situation vor allem Studien möglich, die die Wirkung von neuen Medikamente als Zusatztherapie testen (Zivin 1997). Weitere Ursachen könnten ein zu großes Zeitfenster zwischen Geschehen und Therapieeinleitung sein (Wahlgren und Ahmed 2004) oder die Tatsache, dass typische Schlaganfallpatienten in der Regel viel älter sind und mehr Komorbiditäten haben im Vergleich zu den jungen, gesunden Tieren die in Tiermo- 
dellen verwendet werden (Wahlgren und Ahmed 2004). Das verwendete Tiermodell, die Auswertungsmethode, oder die falsche bzw. ungenügende Konzentration des Medikaments was beim Patienten appliziert wurde, konnten weitere Gründe für das Fehlschlagen der Studien sein (Cheng et al. 2004). Risiken und Wechselwirkungen der Medikamente, wie z.B. das Auslösen von psychotische Reaktionen im Rahmen der $N$-methyl- $D$-aspartat Antagonisten (NMDA-Antagonisten) Studie (Zivin 1997), die während der Experimente im Tiermodel nicht aufgefallen waren, sind nicht zu unterschätzen. Statistische Fehlanalysen und zu kurze experimentelle Zeitfenster könnten auch für die negativen Ergebnisse verantwortlich sein (Cheng et al. 2004).

Offensichtlich sind positive Ergebnisse im Tiermodell keine Garantie für die erfolgreiche Umsetzung in klinischen Studien, aber leider sind derzeit nur wenige Alternativen gegeben. Für die Entwicklung und Durchführung einer klinischen Studie werden positive Ergebnisse im Tiermodell vorausgesetzt (Wahlgren und Ahmed 2004).

Allerdings könnte ein standardisiertes Schlaganfall-Tiermodell für die präklinische Medikamentenentwicklung mit Verwendung von älteren Tieren, die ähnliche Komorbiditäten wie Risikopatienten haben, mehr Klarheit und bessere Übertragbarkeit schaffen (Wahlgren und Ahmed 2004). Außerdem könnte die Suche nach multimodalen Therapieansätzen mit einer Kombination von Thrombolyse, Neuroprotektion und Hemmung der Entzündungsreaktion in der akuten Phase eine erfolgreiche therapeutische Strategie ergeben.

Durch das Stroke Therapy Academic Industry Roundtable (STAIR) wurden sogar folgende Empfehlungen zu einer Erhöhung der Effektivität von klinischen Studien ausgesprochen (Furlan 2012): 1. Es sollen adäquate Dosis-Reaktions-Kurven der Agentien definiert werden. 2. Es sollen Daten darüber verfügbar sein, dass das Medikament seinen Zielort, das Gehirn, wirklich erreichen kann. 3. Genaue Definitionen des therapeutischen Fensters, wie im Tiermodel, sollen vorliegen. 4. Alle Tierexperimente sollen verblindet und randomisiert durchgeführt werden mit Einbezug auch psychischer Veränderungen mit prädefinierten Ausschlusskriterien und mit adäquaten Gruppengrößen. 5. Sowohl Infarktvolumen als auch das neurologische Outcome sollen kurz und langfristig beobachtet werden. 6. Die Effizienz einer Therapie soll an jungen Tieren auch im Modell der permanenten Ischämie überprüft werden. 7. Initialstudien sollen an Nagetiere gemacht werden bevor Studien an Arten mit höherer Gyrierung vorgenommen werden. 8. Agentien mit positiven Ergebnissen sollen auch an weiblichen Tieren, alten Tieren und Tieren mit Komorbiditäten wie Hypertension, 
Diabetes Mellitus und Hypercholesterinämie durchgeführt werden. 9. Relevante Endpunkte und Biomarker wie Diffusions-/Perfusions-MRT oder serologische Marker sollten mitbeurteilt werden. 10. Die Interaktion zwischen bestehenden und neuen Therapien sollte in Studien mitbeurteilt werden. Somit könnten die Qualität und Reproduzierbarkeit der Studien verbessert werden.

\subsection{Blockierung des TLR4 und seine klinische Anwendung beim is- chämischen Schlaganfall? Ein Ausblick.}

Mehrere Studien an Mäusen konnten einen bedeuteten Einfluss des TLR4 in Bezug auf Inflammation und ein negatives Outcome im Rahmen eines Schlaganfalls beweisen (Cao et al. 2007; Caso et al. 2008; Derkow et al. 2015, S. 4). Knockout Tiere oder Tiere bei denen ein Medikament, was den TLR4 blockiert, vor Induktion der Ischämie appliziert wurde, zeigten stets signifikant geringere Infarktgrößen, besseres neurologisches Defizit und geringere Entzündungsparameter (Suzuki et al. 2012; Andresen et al. 2016). In dieser Arbeit konnte erstmalig gezeigt werden, dass die TLR4 Deaktivierung durch eine intravenöse Verabreichung eines monoklonalen Antikörpers neuroprotektiv wirkt und auch dann protektiv ist, wenn sie erst mit dem Beginn der Reperfusionszeit (Rekanalisation) und nicht prophylaktisch, vor der Ischämie, erfolgt. Dies ist ein wichtiges Ergebnis für die weitere Forschung an den TLR4, da eine genetische Blockierung des Rezeptors beim Menschen ethisch zum derzeitigen Zeitpunkt problematisch und sehr aufwendig wäre. Allerdings kann nun durch die neu gewonnenen Erkenntnisse davon ausgegangen werden, dass auch im klinischen Alltag eine postischämische Blockierung des TLR4 z.B. in Kombination mit der Rekanalisationstherapie (rtPA oder Thrombektomie) einen neuroprotektiven Effekt mit einer gebesserten Prognose für den Patienten haben könnte.

Außerdem konnte hier erstmalig ein Einfluss des TLR4 auf die Aktivierung und Migration von Lymphozyten, primär T-Zellen, im Hirngewebe nach einem ischämischen Schlaganfall beobachtet werden. Laut unseren Ergebnissen kommt es durch die Blockierung des TLR4 zwar zu kleineren Infarkte und gemindertem Hirnödem, aber einer höheren Aktivierung/Einwanderung von Lymphozyten in die Infarktregion. Welcher Mechanismus dahinter steckt und welche Art von T-Zellen durch diese Blockierung vermehrt aktiviert wird, bzw ob es sich um neurotoxische oder neuroprotektive Zelltypen handelt, bleibt noch zu entdecken. 
Erwähnenswert sind Erkenntnisse aus anderen Schlaganfallversuchen die zeigten, dass auch weitere TLR im postischämischen Geschehen beteiligt sind. Die Blockierung des TLR2 in einem kurzen MCAO Modell zeigte ebenso kleinere Infarktvolumina und ein erhöhtes neuronales Überleben (Ziegler et al. 2011). Allerdings kam es in einem Langzeitmodell der TLR2 Defizienz zu einem umgekehrten Ergebnis was durch eine verspätete Immunreaktion erklärt wurde (Bohacek et al. 2012). Die Stimulierung des TLR8 im Rahmen des ischämischen Schlaganfalls zeigte ebenso eine schädliche Auswirkungen auf die Mäuse nach MCAO mit erhöhter Mortalität, ausgeprägten neurologischen Defiziten und erhöhter Einwanderung von T-Zellen (Tang et al. 2013).

Letztendlich zeichnet sich aus den verschiedenen Studien heraus, dass die Immunantwort nach einem Schlaganfall und die daraus zu erwartende Prognose nicht von einem TLR abhängt, sondern ein Wechselspiel zwischen den verschiedenen TLRs und deren Liganden ist. Die Blockierung der TLRs kann sowohl protektive, als auch schädliche Auswirkungen haben und eine gezielte Therapie sollte nicht allein gegen einen davon gerichtet sein. Vielmehr könnte die Lösung der ultimativen Therapie des Schlaganfalls in einem multimodalen Therapieverfahren stecken, welches sowohl die Rekanalisation, als auch die Immunregulation in Anbetracht auf die verschiedenen Wirkungen der TLRs, mit einbezieht. Um dies zu erreichen, ist ein besseres Verständnis über die Mechanismen der TLRs, deren Signalkaskaden und deren Interaktionen nötig. Nur so können wir zukünftig ein gezieltes und wirksames Therapieverfahren entwickeln. 


\section{Zusammenfassung}

Einer der häufigsten Volkskrankheiten unserer Zeit ist der ischämische Schlaganfall. Unser Lebensstil führt dazu, dass kardiovaskuläre Erkrankungen und darunter die Anzahl der Schlaganfälle stetig zunehmen. Dies hat diverse negative Folgen für Betroffene und die Gesellschaft. Es ist also dringend notwendig bessere Bewältigungsstrategien für dieses Krankheitsbild auszuarbeiten, um die negativen Auswirkungen zu lindern. Die Hemmung der Immunantwort des Körpers auf einen Schlaganfall und die dadurch resultierende Abbremsung der Entzündungsausbreitung und des Zelluntergangs werden schon länger als Therapieansatz untersucht, ein effektives Vorgehen konnte aber bislang nicht etabliert werden.

Die Blockierung des TLR4-Rezeptors könnte in diesem Zusammenhang eine potentielle Therapieoption bieten. Die Toll-like-Rezeptoren (TLR) sind Transmembranproteine deren Aktivierung im Körper diverse Immunreaktionen auslöst. Bislang sind 9 dieser Rezeptoren bekannt und die Signalkaskaden werden jeweils durch unterschiedliche Liganden in Gang gesetzt. Der TLR4 wird auf Zellen im ZNS exprimiert, wird sowohl durch bakterielle Lipoproteine (LPS) als auch durch endogene Liganden wie HSP 60 und 70 aktiviert und trägt wesentlich bei der Entstehung einer Entzündungsreaktion bei.

Im Rahmen dieser Arbeit wurde mit Hilfe des MTS-510-Antikörpers der TLR4 Rezeptor blockiert und die Auswirkung dieser Blockierung im Tiermodell untersucht. Dafür wurden Mäuse nach dem Middle Cerebral Artery Occlusion (MCAO) Modell, einem Standardmodell in der Schlaganfallforschung, mit einer transienten Okklusion der Arteria. cerebri media, operiert und entsprechend mit dem MTS-510-Antikörper oder mit PBS behandelt. Es wurden zwei verschiedene Applikationswege verwendet, intraperitoneal (i.p) und intravenös (i. v). Die Okklusionszeit betrug 45 Minuten und die Reperfusionszeit 48 Stunden. Es wurden die Parameter Infarktgröße, Hirnödem, neurologischer Defizit, Neuronenzahl und Anzahl von Immunzellen untersucht. Dabei konnte in der intraperitonealen Gruppe kein neuroprotektiver Effekt im Vergleich zur Kontrollgruppe festgestellt werden. In der intravenösen Gruppe konnte allerdings ein schützender Effekt der TLR4-Blockierung in Bezug auf Infarktvolumen und Hirnödem gemessen werden. Weiterhin wurde eine Durchflusszytometrie zur Untersuchung von inflammatorischen Zellen des ZNS, wie Mikroglia und Makrophagen, und von Zellen des adaptiven Immunsystems, wie $\mathrm{T}$ - und B-Zellen, durchgeführt. Obwohl die Anzahl der 
inflammatorischen Zellen keinen signifikanten Unterschied zwischen den Gruppen zeigte, wurde eine erhöhte Anzahl von T-Zellen bei der mit dem Antikörper behandelten Gruppe festgestellt. Ein Ergebnis dessen Verständnis weitere Forschung verlangt.

Zusammenfassend wird ein protektiver Effekt durch die Blockierung des TLR4 im ischämischen Schlaganfall deutlich. Es sind allerdings weitere Untersuchungen notwendig um die genaue Funktion und die Auswirkungen dieser Rezeptoren im ZNS zu verstehen, bevor eine klinische Anwendung möglich ist. 


\section{Literatur}

Ahmad A, Crupi R, Campolo M, Genovese T, Esposito E, Cuzzocrea S (2013): Absence of TLR4 Reduces Neurovascular Unit and Secondary Inflammatory Process after Traumatic Brain Injury in Mice. PLoS ONE $\underline{8}$

Amantea D, Nappi G, Bernardi G, Bagetta G, Corasaniti MT (2009): Post-ischemic brain damage: pathophysiology and role of inflammatory mediators. FEBS J 276, 13-26

Andresen L, Theodorou K, Grünewald S, Czech-Zechmeister B, Könnecke B, Lühder F, Trendelenburg G (2016): Evaluation of the therapeutic potential of anti-TLR4-antibody MTS510 in experimental stroke and significance of different routes of application. PLoS ONE $\underline{11}, \mathrm{e} 0148428$

Anrather J, Iadecola C (2016): Inflammation and Stroke: An Overview. Neurotherapeutics $\underline{13}$, $661-670$

Ansari S, Azari H, McConnell DJ, Afzal A, Mocco J (2011): Intraluminal middle cerebral artery occlusion (MCAO) model for ischemic stroke with laser doppler flowmetry guidance in mice. J Vis Exp JoVE

Bederson JB, Pitts LH, Tsuji M, Nishimura MC, Davis RL, Bartkowski H (1986): Rat middle cerebral artery occlusion: evaluation of the model and development of a neurologic examination. Stroke $\underline{17}, 472-476$

Benjamin EJ, Virani SS, Callaway CW, Chamberlain AM, Chang AR, Cheng S, Chiuve S, Cushman M, Delling FN, Deo R,et al. (2018): Heart Disease and Stroke Statistics 2018 Update: A Report From the American Heart Association. Circulation 137, e67-e492

Bohacek I, Cordeau P, Lalancette-Hébert M, Gorup D, Weng YC, Gajovic S, Kriz J (2012): Tolllike receptor 2 deficiency leads to delayed exacerbation of ischemic injury. $\mathrm{J}$ Neuroinflammation $\underline{9}, 191$

Brait VH, Jackman KA, Walduck AK, Selemidis S, Diep H, Mast AE, Guida E, Broughton BR, Drummond GR, Sobey CG (2010): Mechanisms contributing to cerebral infarct size after stroke: gender, reperfusion, T lymphocytes, and Nox2-derived superoxide. J Cereb Blood Flow Metab Off J Int Soc Cereb Blood Flow Metab 30, 1306 
Brea D, Blanco M, Ramos-Cabrer P, Moldes O, Arias S, Pérez-Mato M, Leira R, Sobrino T, Castillo J (2011): Toll-like receptors 2 and 4 in ischemic stroke: outcome and therapeutic values. J Cereb Blood Flow Metab Off J Int Soc Cereb Blood Flow Metab 31, 1424-1431

Cao CX, Yang QW, Lv FL, Cui J, Fu HB, Wang J-Z (2007): Reduced cerebral ischemiareperfusion injury in Toll-like receptor 4 deficient mice. Biochem Biophys Res Commun $\underline{353}, 509-514$

Caso JR, Pradillo JM, Hurtado O, Lorenzo P, Moro MA, Lizasoain I (2007): Toll-Like Receptor 4 is involved in brain damage and inflammation after experimental stroke. Circulation 115(12):1599-608

Caso JR, Pradillo JM, Hurtado O, Leza JC, Moro MA, Lizasoain I (2008): Toll-like receptor 4 is involved in subacute stress-induced neuroinflammation and in the worsening of experimental stroke. Stroke $\underline{39}, 1314-1320$

Cheng B, Forkert ND, Zavaglia M, Hilgetag CC, Golsari A, Siemonsen S, Fiehler J, Pedraza S, Puig J, Cho T-H, et al. (2014): Influence of Stroke Infarct Location on Functional Outcome Measured by the Modified Rankin Scale. Stroke 45(6):1695-702

Cheng YD, Al-Khoury L, Zivin JA (2004): Neuroprotection for Ischemic Stroke: Two Decades of Success and Failure. NeuroRx $\underline{1}, 36$

Coupland AP, Thapar A, Qureshi MI, Jenkins H, Davies AH (2017): The definition of stroke. J R Soc Med $\underline{110}, 9-12$

Daubeuf B, Mathison J, Spiller S, Hugues S, Herren S, Ferlin W, Kosco-Vilbois M, Wagner H, Kirschning CJ, Ulevitch R, Elson G (2007): TLR4/MD-2 Monoclonal Antibody Therapy Affords Protection in Experimental Models of Septic Shock. J Immunol 179, 6107-6114

Derkow K, Krüger C, Dembny P, Lehnardt S (2015): Microglia Induce Neurotoxic IL-17+ $\gamma \delta$ T Cells Dependent on TLR2, TLR4, and TLR9 Activation. PLOS ONE 10, e0135898

DGN (2012) Akuttherapie des ischämischen Schlaganfalls (Leitlinie für Diagnistik und Therapie in der Neurologie).S1 Leitlinie der Deutschen Gesellschaft für Neurologie. http://www.dgn.org/leitlinien/2310-II-22-2012-akuttherapie-des-ischämischen-schlaganfalls; abgerufen am 17.04.2019

DGN (2015) Akuttherapie des ischämischen Schlaganfalls-Rekanalisierende Therapie (Ergänzug 2015 (Leitlinie für Diagnistik und Therapie in der Neurologie). S2k Leitlinie der Deutschen Gesell- 
schaft für Neurologie. http://www.dgn.org/leitlinien/3198-030-140-rekanalisierende therapieergaenzug-akuttherapie-schlaganfall; abgerufen am 17.04.2019

DGN (2015) Sekundärprophylaxe ischämischer Schlaganfall und transitorische ischämische Atta-

cke (Teil 1).S3 Leitlinie der Deutschen Gesellschaft für Neurologie. http://www.dgn.org/leitlinien/3024-II-23-II-sekundaerprophylaxe-ischaemischer-schlaganfall-und transitorische-ischaemische-attacke; abgerufen 17.04.2019

DGNR(2015) Rehabilitation der Mobilität nach Schlaganfall. S2e Leitlinie der Deutschen Gesellschaft für Neurorehabilitation http:// www.dgnr.de/images/pdf/leitlinien/S2e_Leitlinie_Rehabilitation_der_Mobilitaet_nach Schlaganfall; abgerufen 17.04.2019

Dirnagl U, Iadecola C, Moskowitz MA (1999): Pathobiology of ischaemic stroke: an integrated view. Trends Neurosci 22, 391-397

Dirnagl U, Klehmet J, Braun JS, Harms H, Meisel C, Ziemssen T, Prass K, Meisel A (2007): Stroke-Induced Immunodepression. Stroke 2007 Feb;38(2 Suppl):770-3

Eidizadeh A, Khajehalichalehshtari M, Freyer D, Trendelenburg G (2015): Assessment of the Therapeutic Potential of Metallothionein-II Application in Focal Cerebral Ischemia In Vitro and In Vivo. PloS One 10, e0144035

Fernández G, Moraga A, Cuartero MI, García-Culebras A, Peña-Martínez C, Pradillo JM, Hernández-Jiménez M, Sacristán S, Ayuso MI, Gonzalo-Gobernado R,et al. (2018): TLR4Binding DNA Aptamers Show a Protective Effect against Acute Stroke in Animal Models. Mol Ther J Am Soc Gene Ther 26, 2047-2059

Ferronato S, Lira MG, Olivato S, Scuro A, Veraldi GF, Romanelli MG, Patuzzo C, Malerba G, Pignatti PF, Mazzucco S (2011): Upregulated expression of Toll-like receptor 4 in peripheral blood of ischaemic stroke patients correlates with cyclooxygenase 2 expression. Eur J Vasc Endovasc Surg Off J Eur Soc Vasc Surg 41, 358-363

Fluri F, Schuhmann MK, Kleinschnitz C (2015): Animal models of ischemic stroke and their application in clinical research. Drug Des Devel Ther $\underline{9}, 3445$

Foerch C, Misselwitz B, Sitzer M, Steinmetz H, Neumann-Haefelin T (2008): The Projected Burden of Stroke in the German Federal State of Hesse up to the Year 2050. Dtsch Aerzteblatt Online 105(26): 467-473 
Furlan AJ (2012): Challenges in Acute Ischemic Stroke Clinical Trials. Curr Cardiol Rep 14, 761766

Geiseler SJ, Morland C (2018): The Janus Face of VEGF in Stroke. Int J Mol Sci 19,1362-1367

Gesuete R, Kohama SG, Stenzel-Poore M (2014): Toll-Like Receptors and Ischemic Brain Injury. J Neuropathol Exp Neurol $\underline{73}, 378$

Goyal Mayank, Yu Amy Y.X., Menon Bijoy K., Dippel Diederik W.J., Hacke Werner, Davis Stephen M., Fisher Marc, Yavagal Dileep R., Turjman Francis, Ross Jeffrey, et al. (2016): Endovascular Therapy in Acute Ischemic Stroke. Stroke 47, 548-553

Grau AJ, Weimar C, Buggle F, Heinrich A, Goertler M, Neumaier S, Glahn J, Brandt T, Hacke W, Diener H-C, Collaborators on behalf of the GSDB (2001): Risk Factors, Outcome, and Treatment in Subtypes of Ischemic Stroke: The German Stroke Data Bank. Stroke $\underline{32}$, 2559-2566

Gu J, Su S, Guo J, Zhu Y, Zhao M, Duan J-A (2018): Anti-inflammatory and anti-apoptotic effects of the combination of Ligusticum chuanxiong and Radix Paeoniae against focal cerebral ischaemia via TLR4/MyD88/MAPK/NF- $\mathrm{kB}$ signalling pathway in MCAO rats. J Pharm Pharmacol 무, 268-277

Gu L, Jian Z, Stary C, Xiong X (2015): T Cells and Cerebral Ischemic Stroke. Neurochem Res 40, 1786-1791

Hanisch U-K, Johnson TV, Kipnis J (2008): Toll-like receptors: roles in neuroprotection? Trends Neurosci $31,176-182$

Hara H, Huang PL, Panahian N, Fishman MC, Moskowitz MA (1996): Reduced brain edema and infarction volume in mice lacking the neuronal isoform of nitric oxide synthase after transient MCA occlusion. J Cereb Blood Flow Metab Off J Int Soc Cereb Blood Flow Metab $\underline{16}, 605-611$

Heuschmann P, Busse O, Wagner M, Endres M, Villringer A, Röther J, Kolominsky-Rabas P, Berger K (2010): Schlaganfallhäufigkeit und Versorgung von Schlaganfallpatienten in Deutschland. Aktuelle Neurol 37, 333-340

Hua F, Tang H, Wang J, Prunty MC, Hua X, Sayeed I, Stein DG (2015): TAK-242, an Antagonist for Toll-like Receptor 4, Protects against Acute Cerebral Ischemia/Reperfusion Injury in Mice. J Cereb Blood Flow Metab 35, 536-542 
Huang H, Huang Q, Wang F, Milner R, Li L (2016): Cerebral ischemia-induced angiogenesis is dependent on tumor necrosis factor receptor 1-mediated upregulation of $\alpha 5 \beta 1$ and $\alpha \mathrm{V} \beta 3$ integrins. J Neuroinflammation $\underline{13,227}$

Huang L, Wu Z-B, ZhuGe Q, Zheng W, Shao B, Wang B, Sun F, Jin K (2014): Glial Scar Formation Occurs in the Human Brain after Ischemic Stroke. Int J Med Sci 11, 344

Hurn PD, Subramanian S, Parker SM, Afentoulis ME, Kaler LJ, Vandenbark AA, Offner H (2007): T- and B-cell-deficient mice with experimental stroke have reduced lesion size and inflammation. J Cereb Blood Flow Metab Off J Int Soc Cereb Blood Flow Metab 27, 1798

Hyakkoku K, Hamanaka J, Tsuruma K, Shimazawa M, Tanaka H, Uematsu S, Akira S, Inagaki N, Nagai H, Hara H (2010): Toll-like receptor 4 (TLR4), but not TLR3 or TLR9, knock-out mice have neuroprotective effects against focal cerebral ischemia. Neuroscience $\underline{171}, 258-$ 267

Iadecola C, Anrather J (2011): The immunology of stroke: from mechanisms to translation. Nat Med 17, 796

Jackman K, Iadecola C (2015): Neurovascular Regulation in the Ischemic Brain. Antioxid Redox Signal $\underline{22}, 149$

Jin R, Liu L, Zhang S, Nanda A, Li G (2013): Role of inflammation and its mediators in acute ischemic stroke. J Cardiovasc Transl Res $\underline{6}$

Jones KJ, Lovett-Racke AE, Walker CL, Sanders VM (2015): CD4+T Cells and Neuroprotection: Relevance to Motoneuron Injury and Disease. J Neuroimmune Pharmacol Off J Soc NeuroImmune Pharmacol 10, 587

Kolominsky-Rabas PL, Heuschmann PU, Marschall D, Emmert M, Baltzer N, Neundörfer B, Schöffski O, Krobot KJ (2006): Lifetime cost of ischemic stroke in Germany: results and national projections from a population-based stroke registry: the Erlangen Stroke Project. Stroke $\underline{37}, 1179-1183$

Leifer D, Kowall NW (1993): Immunohistochemical patterns of selective cellular vulnerability in human cerebral ischemia. J Neurol Sci 119, 217-228

Leitlinie Ergänzung zur Akuttherapie des ischämischen Schlaganfalls 2015 siehe DGN-Leitlinie 2015

Leitlinie Sekundärprophylaxe ischämischer Schlaganfall und TIA 2015 siehe DGN-Leitlinie 2015 
Lindvall O, Kokaia Z (2015): Neurogenesis following Stroke Affecting the Adult Brain. Cold Spring Harb Perspect Biol $\underline{7}$

Liu J, Chen Q, Jian Z, Xiong X, Shao L, Jin T, Zhu X, Wang L (2016): Daphnetin Protects against Cerebral Ischemia/Reperfusion Injury in Mice via Inhibition of TLR4/NF-kB Signaling Pathway. BioMed Res Int 2016, 2816056

Liu X, Zhang X, Wang F, Liang X, Zeng Z, Zhao J, Zheng H, Jiang X, Zhang Y (2017): Improvement in cerebral ischemia-reperfusion injury through the TLR4/NF-kB pathway after Kudiezi injection in rats. Life Sci $\underline{191}, 132-140$

Marks MP, Heit JJ, Lansberg MG, Kemp S, Christensen S, Derdeyn CP, Rasmussen PA, Zaidat OO, Broderick JP, Yeatts SD, et al. (2018): endovascular treatment in the DEFUSE-3 study. Stroke $\underline{49}, 2000-2003$

Marsh BJ, Williams-Karnesky RL, Stenzel-Poore MP (2009): Toll-Like Receptor Signaling in Endogenous Neuroprotection and Stroke. Neuroscience 158, 1007

Medzhitov R, Janeway CA (1997): Innate immunity: impact on the adaptive immune response. Curr Opin Immunol 9, 4-9

Nogueira RG, Jadhav AP, Haussen DC, Bonafe A, Budzik RF, Bhuva P, Yavagal DR, Ribo M, Cognard C, Hanel RA, et al. (2018): Thrombectomy 6 to 24 Hours after Stroke with a Mismatch between Deficit and Infarct. N Engl J Med $\underline{378}, 11-21$

O’Collins VE, Macleod MR, Donnan GA, Horky LL, van der Worp BH, Howells DW (2006): 1,026 Experimental treatments in acute stroke. Ann Neurol 59, 467-477

O’Neill LAJ, Golenbock D, Bowie AG (2013): The history of Toll-like receptors — redefining innate immunity. Nat Rev Immunol 13, 453-460

Pfeilschifter W, Czech-Zechmeister B, Sujak M, Foerch C, Wichelhaus TA, Pfeilschifter J (2011): Treatment with the immunomodulator FTY720 does not promote spontaneous bacterial infections after experimental stroke in mice. Exp Transl Stroke Med $\underline{3}, 2$

Pohar J, Pirher N, Benčina M, Manček-Keber M, Jerala R (2014): The Ectodomain of TLR3 Receptor Is Required for Its Plasma Membrane Translocation. PLoS ONE 9 e92391.

Predominant phagocytic activity of resident microglia over hematogenous macrophages following transient focal cerebral ischemia: An investigation using green fluorescent protein transgenic bone marrow chimeric mice (2005) Exp Neurol 196, 290-297 
Pushkov D, Nicholson JD, Michowiz S, Novitzky I, Weiss S, Ben Hemou M, Hochhauser E, Goldenberg-Cohen N (2016): Relative neuroprotective effects hyperbaric oxygen treatment and TLR4 knockout in a mouse model of temporary middle cerebral artery occlusion. Int $\mathbf{J}$ Neurosci 126, 174-181

Rami A, Langhagen A, Steiger S (2008): Focal cerebral ischemia induces upregulation of Beclin 1 and autophagy-like cell death. Neurobiol Dis $\underline{29}, 132-141$

Rezaie AR (2014): Protease-activated Receptor Signaling by Coagulation Proteases in Endothelial Cells. Thromb Haemost $\underline{112}, 876$

Rolls A, Shechter R, Schwartz M (2009): The bright side of the glial scar in CNS repair. Nat Rev Neurosci 10, 235

S2 Leitlinie Rehabilitation der Mobilität nach Schlaganfall 2017

Sansing LH, Harris TH, Welsh FA, Kasner SE, Hunter CA, Kariko K (2011): Toll-like Receptor 4 Contributes to Poor Outcome after Intracerebral Hemorrhage. Ann Neurol 70, 646

Schilling M, Besselmann M, Müller M, Strecker JK, Ringelstein EB, Kiefer R (2005): Predominant phagocytic activity of resident microglia over hematogenous macrophages following transient focal cerebral ischemia: An investigation using green fluorescent protein transgenic bone marrow chimeric mice. Exp Neurol 196, 290-297

Spalding KL, Bergmann O, Alkass K, Bernard S, Salehpour M, Huttner HB, Boström E, Westerlund I, Vial C, Buchholz BA, et al. (2013): Dynamics of hippocampal neurogenesis in adult humans. Cell $\underline{153}, 1219$

Sun M, Deng B, Zhao X, Gao C, Yang L, Zhao H, Yu D, Zhang F, Xu L, Chen L, Sun X (2015): Isoflurane preconditioning provides neuroprotection against stroke by regulating the expression of the TLR4 signalling pathway to alleviate microglial activation. Sci Rep $\underline{5}$, 11445

Suzuki Y, Hattori K, Hamanaka J, Murase T, Egashira Y, Mishiro K, Ishiguro M, Tsuruma K, Hirose Y, Tanaka H, et al. (2012): Pharmacological Inhibition of Tlr4-Nox4 Signal Protects Against Neuronal Death in Transient Focal Ischemia. Sci U S A 104, 1379813803

Tang S-C, Yeh S-J, Li Y-I, Wang Y-C, Baik S-H, Santro T, Widiapradja A, Manzanero S, Sobey CG, Jo D-G, et al. (2013): Evidence for a detrimental role of TLR8 in ischemic stroke. Exp Neurol 250, 341-347 
Tobin MK, Bonds JA, Minshall RD, Pelligrino DA, Testai FD, Lazarov O (2014): Neurogenesis and inflammation after ischemic stroke: what is known and where we go from here. $\mathbf{J}$ Cereb Blood Flow Metab $\underline{34}, 1573$

Trendelenburg G, Dirnagl U (2005): Neuroprotective role of astrocytes in cerebral ischemia: Focus on ischemic preconditioning. Glia $\underline{50}, 307-320$

Türeyen K, Vemuganti R, Sailor KA, Dempsey RJ (2004): Infarct volume quantification in mouse focal cerebral ischemia: a comparison of triphenyltetrazolium chloride and cresyl violet staining techniques. J Neurosci Methods $\underline{139}$, 203-207

Wahlgren NG, Ahmed N (2004): Neuroprotection in Cerebral Ischaemia: Facts and Fancies - The Need for New Approaches. Cerebrovasc Dis 17, 153-166

Xin J, Mesnard NA, Beahrs T, Wainwright DA, Serpe CJ, Alexander TD, Sanders VM, Jones KJ (2012): CD4+ T cell-mediated neuroprotection is independent of T cell-derived BDNF in a mouse facial nerve axotomy model. Brain Behav Immun 26, 886

Ziegler G, Freyer D, Harhausen D, Khojasteh U, Nietfeld W, Trendelenburg G (2011): Blocking TLR2 in vivo protects against accumulation of inflammatory cells and neuronal injury in experimental stroke. J Cereb Blood Flow Metab $\underline{31}, 757$

Zille M, Farr TD, Przesdzing I, Müller J, Sommer C, Dirnagl U, Wunder A (2012): Visualizing cell death in experimental focal cerebral ischemia: promises, problems, and perspectives. J Cereb Blood Flow Metab $\underline{\text { 32, }} 213$

Zivin JA (1997): Neuroprotective Therapies In Stroke. Drugs 54, 83-89

\section{Internetquellen}

High Resolution Mouse Brain Atlas:

Sidman, R.L., Kosaras, B., Misra, B.M. and Senft, S.L.: High Resolution Mouse Brain Atlas. 1999 http://www.hms.harvard.edu/research/brain. Zugriff am 03.09.2018

Toll-like-Rezeptor:

http://www.chemie.de/lexikon/Toll-like_Receptor.html\#Entdeckung_der_TLRs; Zugriff am 03.09 .2018 


\section{Danksagung}

Ein großen Dank an die Klinik für Neurologie der Universitätsmedizin Göttingen und den Chefarzt Prof. Dr. med. M. Bähr, für diese einmalige Chance, die mir gegeben wurde, meine experimentelle Doktorarbeit dort durchzuführen.

Besonders danken möchte ich auch meinem Doktorvater, George Trendelenburg, für das Vertrauen, die Unterstüzung, die Geduld und die Zuverlässigkeit, die er stets während der Erarbeitung meiner Dissertation zeigte. Für eine ausserordenlich gute Mitbetreuung und Hilfe bei allen Fragestellungen und Problemlösungen danke ich meinen Mitarbeiterinnen im Labor, Irina Graf, Birte Könnecke, Regine Kruse und Bozena Zechmeister. Danken möchte ich außerdem meinen Mitstudenten und Mitdoktoranten Abass Eidizadeh und Sarah Grünewald, die mich im Rahmen des Studiums immer begleitet und moralisch unterstützt haben.

Zusätzlich möchte ich Fred Lühder vom Institut für Multiple Sklerose Forschung (IMSF) und Neuroimmunologie für die gute Zusammenarbeit bei der Durchführung der Flusszytometrischen Analysen danken. 


\section{Lebenslauf}

Ich, Konstantina Theodorou, bin am 02.04.1990 in Lovec, Bulgarien, geboren und bin ab dem 3. Lebensjahr in Paphos, Zypern, aufgewachsen, wo ich die Grundschule, das Gymnasium und das Lyceum besuchte und 2008 meinen Schulabschluss machte.

Im August 2008 bin ich nach Deutschland gezogen und besuchte von August 2008 bis Februar 2009 im Zentrum für interkulturelle Kommunikation in Göttingen Sprachkurse im Rahmen dessen ich die deutsche Sprache erlernte.

Im Sommersemester 2009 begann ich mein Humanmedizinstudium an der Georg Augusr Universität Göttingen. Im Frühjahr 2011 schloss ich das erste Staatsexamen erfolgreich ab. Im Herbst 2014 folgte der erfolgreiche Abschluss des zweiten Staatsexamens. Vom Herbst 2014 bis zum Herbst 2015 absolvierte ich das Praktische Jahr. Das erste.und zweite. Tertial erfolgten in den Abteilungen Innere Medizin und Allgemein- und Unfallchirurgie am Stadtkrankenhaus Korbach und das dritte. Tertial in der Gynäkologie und Geburtshilfe am Kantonspital Thurgau Münsterlingen (Schweiz). Im November 2015 schloss ich mit dem dritten Staatsexamen das Humanmedizinstudium ab und erhielt im Januar 2016 die Approbation als Ärztin.

Vom März 2016 bis zum März 2017 war ich als Assistenzärztin für Innere Medizin in der Onkologisch/Hämatologischen Klinik im DRK Klinikum Kassel tätig.

Vom März 2017 bis zum Dezember 2019 war ich als Assistenzärztin der Gynäkologie und Geburtshilfe im Agaplesion Diakonie Krankenhaus in Kassel beschäftigt.

Seit Januar 2020 bin ich als Assistenzärztin für Gynäkologie und Geburtsthilfe im Asklepios Schwalm-Eder Klinikum Schwalmstadt tätig.

Parallel zum Studium begann ich meine Promotionsarbeit zum Thema „Auswirkung der TLR4-Inhibition bei verschiedenen Applikationswegen im Modell des ischämischen Schlaganfalls, in der Klinik für Neurologie in der Arbeitsgruppe „Experimentelle Schlaganfallforschung“ bei Prof. Dr. med. George Trendelenburg. 